\title{
Measurements of mantle wave velocities and inversion for lateral heterogeneity and anisotropy - III. Analysis by the single-station method
}

\author{
Ichiro Nakanishi ${ }^{\star}$ and Don L. Anderson Seismological \\ Laboratory, California Institute of Technology, Pasadena, California 91125, USA
}

Received 1984 January 20 ; in original form 1983 July 31

\begin{abstract}
Summary. Phase and group velocities of $G_{2}, G_{3}, R_{2}$ and $R_{3}(100-330 \mathrm{~s})$ are measured by the single-station method and are inverted to give a spherical harmonic representation of the velocity lateral variation. Approximately 200 paths have been studied. The results are presented for degrees and orders up to 6 . The even harmonics of the phase velocity representation are consistent with those obtained from great circle phase velocities (Paper I). The odd harmonics are less constrained and generally have larger standard deviations than the even harmonics. To suppress the poorly determined harmonics in the velocity contour maps we construct a filter which is derived from an inverse problem formulation. The filter reduces the amplitudes of regional variations, but does not change the overall pattern. The patterns of the regional variations are generally consistent with those obtained by regionalized inversion of great circle data (Paper I). The velocity maps show significant differences within oceans and continents. An analysis is made of correlations of surface wave velocities with heat flow and the non-hydrostatic geoid. The slownesses correlate well with heat flow for $l=1-6$. The correlation peaks at $l=2$ and 5 . The geoid has an anticorrelation with the slownesses at $l=2$ and 3 , and a positive correlation from $l=4$ to 6 .
\end{abstract}

\section{Introduction}

We use the single-station method (Brune, Nafe \& Oliver 1960) to analyse long-period Love $(G)$ and Rayleigh $(R)$ waves recorded on digital seismic networks to study the lateral heterogeneity of surface wave velocities. The method has been applied for the last two decades to short-period minor are surface waves to study regional scale structure (see a review by Knopoff 1972).

The most accurate determinations of surface wave velocity use the phase difference of two multiple phases (great circle phase velocity) (Satô 1958), or equivalently, the eigenfrequencies of the Earth (see recent studies by Silver \& Jordan 1981; Masters et al. 1982).

Present address: Research Center for Earthquake Prediction, Faculty of Science, Hokkaido University, Sapporo 060, Japan. 
Nakanishi \& Anderson (1983, henceforth Paper I) have applied Satô's method to multiple Love and Rayleigh waves.

Backus (1964) and Zharkov \& Lyubimov (1970), however, pointed out that great circle phase velocities and eigenfrequencies are insensitive to odd harmonics of the aspherical heterogeneity of the Earth. To obtain a complete description of the Earth's asphericity, we need to consider both minor $\left(G_{1}, R_{1}\right)$ and major $\left(G_{2}, R_{2}\right)$ arcs. Nakanishi \& Anderson (1982) analysed Rayleigh wave group velocities along this line. In the present paper we apply a similar method to the determination of phase and group velocities of long-period Love and Rayleigh waves ovar many minor and major arcs.

Information about the earthquake source, such as origin time, source location, source mechanism, and source finiteness, is required when measuring velocities by the single-station method. Our data are long-period seismograms of fundamental-mode Love and Rayleigh waves from 17 large earthquakes that occurred during 1980. It is often difficult to determine the $M_{y z}$ and $M_{x z}$ components of the moment tensor of shallow earthquakes (Kanamori \& Given 1981). These components affect the initial phase of the surface wave which is used to calculate the phase velocity in the single-station method. To constrain $M_{y z}$ and $M_{x z}$, Nakanishi \& Kanamori (1984) added $P$-wave first motions to the surface wave data and redetermined the source mechanisms of the earthquakes analysed by Kanamori \& Given (1982). In the present paper we use these results to calculate the initial phases.

We must also consider the finite duration of the source process. Nakanishi \& Kanamori (1984) measured source durations with a method proposed by Furumoto \& Nakanishi (1983). Using this method we can calculate the source process time as accurately as we can measure the great circle phase velocity. All previous single-station measurements of group velocity of long-period surface waves have ignored the source duration. Some great earthquakes (e.g. the 1960 Chilean and 1964 Alaskan earthquakes) have source durations of about $400 \mathrm{~s}$ (Furumoto \& Nakanishi 1983). This introduces significant errors in group velocity determinations.

Correcting for these source effects we determine phase and group velocities of $G_{2}$, $G_{3}, R_{2}$ and $R_{3}$, and interpret the observations in terms of lateral variations by adopting a spherical harmonic representation. We pay special attention to errors in the odd harmonics determined by the inversions. We will show that our approach gives a realistic view of the lateral heterogeneity of the upper mantle. Finally, we will correlate the surface wave results with other geophysical observations.

\section{Data set}

We analysed digital seismograms from 17 large $\left(M_{\mathrm{s}} \gtrsim 6.5\right)$ earthquakes recorded by IDA (International Deployment of Accelerographs: Agnew et al. 1976) and GDSN (Global Digital Seismographic Network: Engdahl, Peterson \& Orsini 1982) networks. The latter network consists of SRO, ASRO and DWWSSN stations. We used NEIS (National Earthquake Information Service) epicentre locations and origin times in this study. These are listed in Table 1 .

We use the double-couple point-source solutions and source process times determined by Nakanishi \& Kanamori (1984). We selected 13 earthquakes for phase velocity measurement using the following criteria. First, at least one of the two nodal planes is well constrained by $P$-wave first motions. Second, to minimize the effect of the source finiteness, a small event is chosen from a group of earthquakes occurring in the same region, such as event 16 (Santa Cruz Islands earthquake sequence) and event 21 (Loyalty Islands earthquake sequence). Table 2 lists the source process times $(\tau)$, source depths $(d)$, seismic moments 
Table 1. List of earthquakes (in 1980) used.

\begin{tabular}{|c|c|c|c|c|c|c|c|c|c|c|}
\hline \multirow{2}{*}{ No. } & \multicolumn{2}{|c|}{ Date } & \multicolumn{3}{|c|}{ Titae } & \multirow{2}{*}{$\begin{array}{l}\text { Lat. } \\
\text { deg }\end{array}$} & \multirow{2}{*}{$\begin{array}{l}\text { Long. } \\
\text { deg }\end{array}$} & \multirow{2}{*}{$\begin{array}{c}\text { Depth } \\
\mathrm{km}\end{array}$} & \multirow[t]{2}{*}{$\mathrm{M}_{\mathrm{S}}$} & \multirow[t]{2}{*}{ Region } \\
\hline & III & d & $\mathrm{h}$ & m & $s$ & & & & & \\
\hline 1 & 1 & 1 & 16 & 42 & 40.0 & $38.815 \mathrm{~N}$ & $27.780 \mathrm{~W}$ & 10 & 6.7 & Azores \\
\hline 3 & 2 & 7 & 10 & 49 & 16.0 & $54.158 \mathrm{~S}$ & $158.890 \mathrm{E}$ & 10 & 6.5 & Macquarie is. \\
\hline 4 & 2 & 23 & 5 & 51 & 3.2 & $43.530 \mathrm{~N}$ & $146.753 \mathrm{E}$ & 44 & 7.0 & Kurile Is. \\
\hline 7 & 3 & 24 & 3 & 59 & 51.3 & $52.969 \mathrm{~N}$ & $167.670 \mathrm{~W}$ & 33 & 6.9 & Fox Is. \\
\hline 8 & 6 & 9 & 3 & 28 & 18.9 & $32.220 \mathrm{~N}$ & $114.985 \%$ & 5 & 6.4 & Cal-Mex Border \\
\hline 10 & 6 & 18 & 17 & 14 & 54.5 & $9.475 \mathrm{~N}$ & $126.657 \mathrm{E}$ & 54 & 6.8 & Mindanao \\
\hline 14 & 7 & 14 & 16 & 15 & 1.7 & $29.273 \mathrm{~S}$ & $177.154 \mathrm{~W}$ & 49 & 6.6 & Kermadec \\
\hline 16 & 7 & 29 & 3 & 11 & 56.3 & 13.1015 & $166.338 \mathrm{E}$ & 48 & 6.7 & Vanuatu Is. \\
\hline 17 & 7 & 29 & 14 & 58 & 40.8 & $29.598 \mathrm{~N}$ & $81.092 \mathrm{E}$ & 18 & 6.5 & Nepal \\
\hline 18 & 9 & 26 & 15 & 20 & 37.1 & $3.225 \mathrm{~S}$ & $142.237 \mathrm{E}$ & 33 & 6.5 & Papua \\
\hline 19 & 10 & 20 & 12 & 25 & 23.5 & $36.195 \mathrm{~N}$ & $1.354 \mathrm{E}$ & 10 & 7.3 & Algerta \\
\hline 21 & 10 & 25 & 7 & 0 & 7.9 & $21.982 \mathrm{~S}$ & $170.025 E$ & 33 & 6.7 & Loyalty Is. \\
\hline 24 & 11 & 8 & 10 & 27 & 34.0 & $41.117 \mathrm{~N}$ & $124.253 \mathrm{~W}$ & 19 & 7.2 & N. Calif \\
\hline 25 & 11 & II & 10 & 36 & 58.2 & 51.4225 & $28.796 \mathrm{E}$ & 10 & 6.7 & S. Africa \\
\hline 26 & 11 & 23 & 18 & 34 & 53.8 & $40.914 \mathrm{~N}$ & $15.366 \mathrm{E}$ & 10 & 6.9 & Italy \\
\hline 27 & 12 & 17 & 16 & 21 & 58.8 & $49.479 \mathrm{~N}$ & $129.496 \mathrm{~W}$ & 10 & 6.8 & Vancouver Is. \\
\hline 28 & 12 & 31 & 10 & 32 & 11.0 & $46.060 \mathrm{~N}$ & $151.453 \mathrm{E}$ & 33 & 6. & Kurile Is. \\
\hline
\end{tabular}

$\left(M_{0}\right)$, and source mechanisms (dip $\delta$, slip angle $\lambda$, and strike $\left.\phi\right)$ of the 13 earthquakes. Focal mechanism diagrams of the earthquakes are shown in Fig. 1. Nakanishi \& Kanamori have obtained these solutions using radiation patterns of Rayleigh waves recorded at IDA and GDSN stations and the $P$-wave first motions read from WWSSN and GDSN records. We do not believe that adding the Love wave information to the Rayleigh wave and the

Table 2. Parameters for source mechanisms and source processes.

\begin{tabular}{|c|c|c|c|c|c|c|}
\hline $\begin{array}{c}\text { Event } \\
\text { No. }\end{array}$ & $\begin{array}{c}\tau \\
\sec \end{array}$ & $\begin{array}{c}\mathrm{d} \\
\mathrm{km}\end{array}$ & $\mathrm{x} 10^{27} \frac{\mathrm{M}_{\mathrm{o}}}{\mathrm{dyne} \cdot \mathrm{cm}}$ & $\begin{array}{c}\delta \\
\operatorname{deg}\end{array}$ & $\begin{array}{c}\lambda \\
\text { deg }\end{array}$ & $\begin{array}{c}\$ \\
\text { deg }\end{array}$ \\
\hline 1 & 17.2 & 9.75 & 0.238 & 86.2 & 3.0 & $-3 I .0$ \\
\hline 3 & 29.7 & 9.75 & 0.202 & 90.0 & 180.0 & 30.0 \\
\hline 4 & 19.3 & 43.0 & 0.631 & 70.0 & 89.2 & 27.0 \\
\hline 7 & 30.1 & 33.0 & 0.295 & 60.0 & 88.1 & 53.3 \\
\hline 8 & 15.4 & 9.75 & 0.0465 & 90.0 & 180.0 & 140.1 \\
\hline 14 & 18.0 & 43.0 & 0.138 & 70.0 & 82.9 & 10.0 \\
\hline 16 & 19.1 & 43.0 & 0.157 & 54.0 & 93.5 & 160.0 \\
\hline 19 & 30.2 & 9.75 & 0.489 & 54.0 & 81.8 & 225.0 \\
\hline 21 & 38.7 & 33.0 & 0.930 & 74.0 & 93.2 & 143.0 \\
\hline 24 & 31.7 & 16.0 & 1.03 & 90.0 & 0.0 & 49.8 \\
\hline 26 & 44.7 & 9.75 & 0.284 & 63.0 & 275.8 & -43.0 \\
\hline 27 & 26.2 & 9.75 & 0.154 & 90.0 & 180.0 & -37.1 \\
\hline 28 & 27.8 & 33.0 & 0.290 & 68.0 & 89.6 & 28.3 \\
\hline 10 & 26.3 & & & & & \\
\hline 17 & 1.5 .1 & & & & & \\
\hline 18 & 14.4 & & & & & \\
\hline 25 & 27.6 & & & & & \\
\hline
\end{tabular}




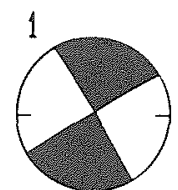

8

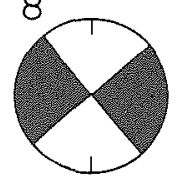

21

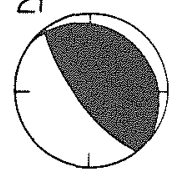

28

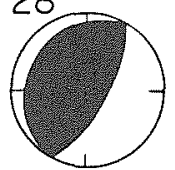

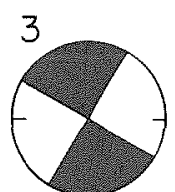

14

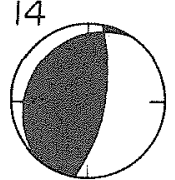

24
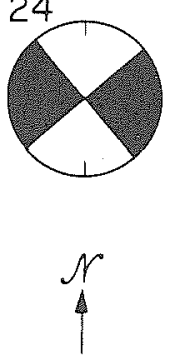

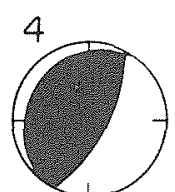

16

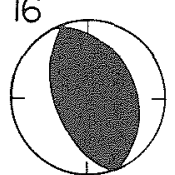

26
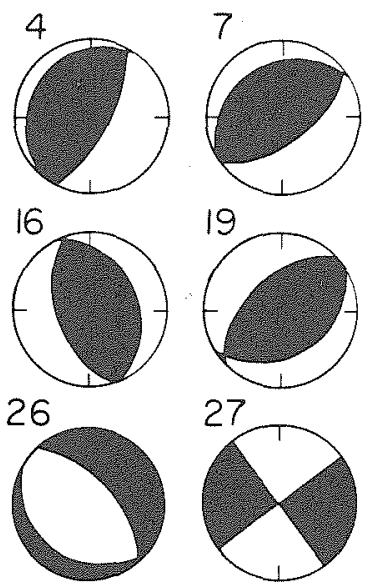

19

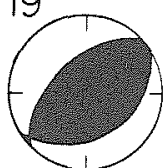

27

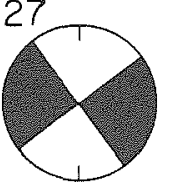

Figure 1. Fault plane solutions of 13 earthquakes. Equal area projections of the lower focal hemisphere are shown. Dark areas are compressional quadrants.

$P$-wave first motion data would further help to constrain the source mechanisms. As the results of Paper I and this paper show, Love waves suffer more from the lateral heterogeneity of the upper mantle than do Rayleigh waves in the period range concerned. Our viewpoint here is to determine source mechanisms from seismic data which are least sensitive to lateral

Table 3. Number of waves analysed.

\begin{tabular}{|c|c|c|c|c|c|c|}
\hline $\begin{array}{c}\text { Event } \\
\text { No. }\end{array}$ & $\begin{array}{c}\mathrm{CG} \\
(\mathrm{GDSN})\end{array}$ & $\begin{array}{c}\mathrm{CR} \\
(\mathrm{CDSN})\end{array}$ & $\begin{array}{c}\mathrm{CR} \\
\text { (IDA) }\end{array}$ & $\begin{array}{c}\text { UG } \\
(\operatorname{GDSN})\end{array}$ & $\begin{array}{c}\mathrm{UR} \\
\text { (GDSN) }\end{array}$ & $\begin{array}{l}\text { UR } \\
\text { (IDA) }\end{array}$ \\
\hline 1 & 18 & 18 & 8 & 22 & 14 & 7 \\
\hline 3 & 24 & 15 & 8 & 28 & 13 & 11 \\
\hline 4 & 23 & 15 & 13 & 25 & 15 & 13 \\
\hline 7 & 18 & 23 & 10 & 22 & 20 & 11 \\
\hline 8 & 22 & 18 & 14 & 22 & 13 & 13 \\
\hline 10 & & & & 28 & & \\
\hline .14 & 19 & 23 & 10 & 20 & 22 & 10 \\
\hline 16 & 24 & 21 & 15 & 22 & 19 & 14 \\
\hline 17 & & & & 25 & & \\
\hline 18 & & & & 29 & & \\
\hline 19 & 22 & 13 & 9 & 26 & 13 & 9 \\
\hline 21 & 26 & 18 & 18 & 23 & 22 & 18. \\
\hline 24 & 27 & 26 & 17 & 26 & 23 & 19 \\
\hline 25 & & & & 25 & & \\
\hline 26 & 15 & 19 & 17 & 16 & 19 & 1.7 \\
\hline 27 & 29 & 27 & 14 & 28 & 30 & II \\
\hline 28 & 22 & 14 & 11 & 21 & 15 & 8 \\
\hline Sutil & 289 & 250 & 164 & 408 & 238 & 161 \\
\hline
\end{tabular}

$C=$ phase velocity $\mathrm{U}=$ group velocity $; \mathrm{G}=$ Love wave $; \mathrm{R}=$ Rayleigh wave. 

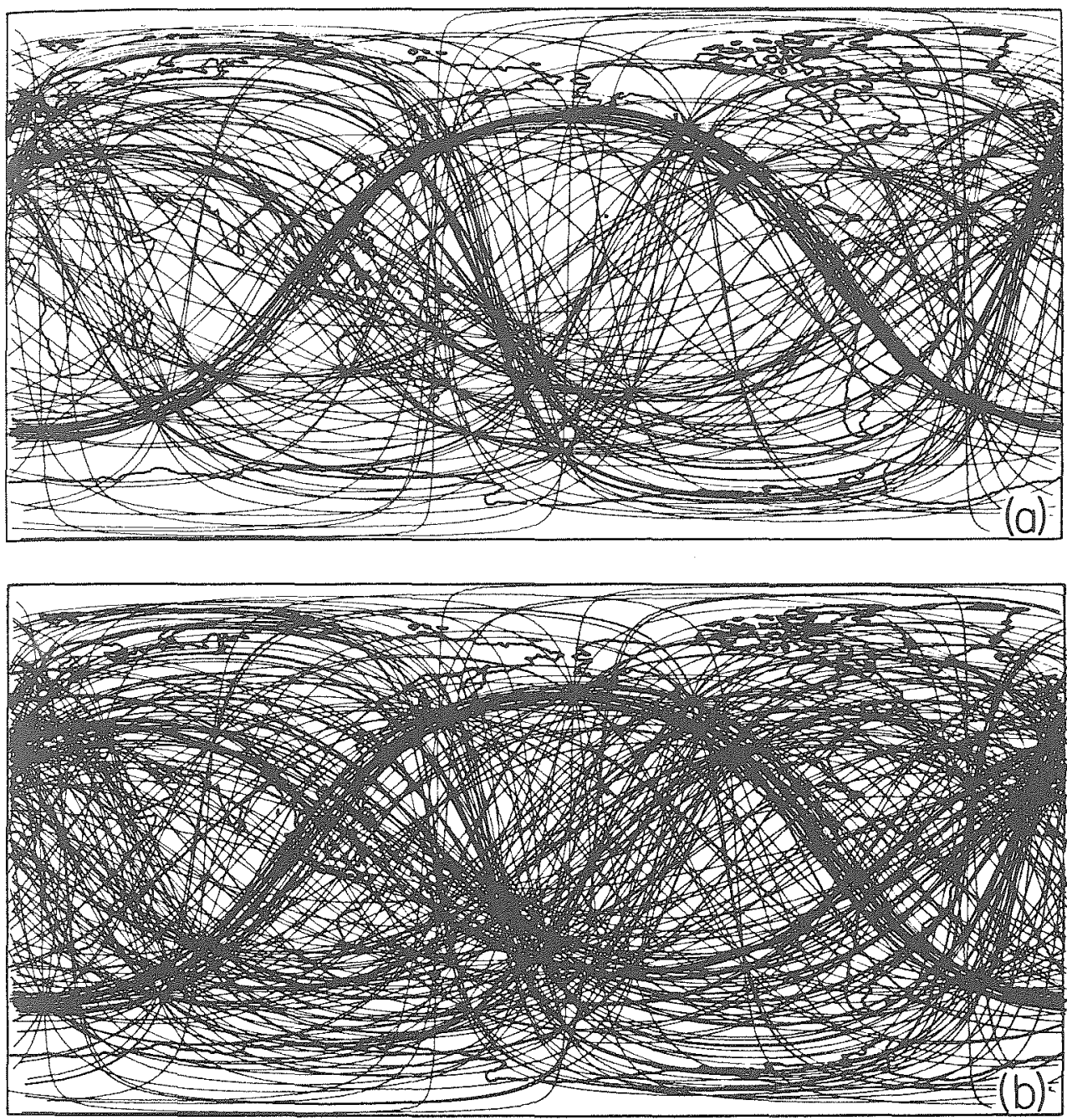

Figure 2. Surface wave paths for phase velocities. (a) Love waves. (b) Rayleigh waves.

heterogeneity. The source mechanisms listed in Table 2 were obtained by using laterally homogeneous phase and group velocities and $Q$.

We add four earthquakes (events 10,17, 18 and 25) to the 13 earthquakes when measuring Love wave group velocities in order to increase the size of the data set. The source process times of the four earthquakes are listed in Table 2. As will be shown later, the Love wave group velocities are very insensitive to source mechanism in the period range of concern.

We used the same transverse component and vertical component seismograms as those used for the great circle phase velocity measurement of Paper I. We applied group velocity windows $4.5-4.2$ and $4.0-3.35 \mathrm{~km} \mathrm{~s}^{-1}$ to Love and Rayleigh waves, respectively. We measured phase and group velocities of $G_{2}, G_{3}, R_{2}, R_{3}$ and a few $R_{4}$. The numbers of waves analysed for each earthquake are summarized in Table 3 . Fig. 2 presents surface wave paths for phase velocity measurements. A similar path coverage is obtained for group velocity. Using data from both IDA and GDSN stations we have a very dense path coverage over the Earth's surface. 


\section{Single-station method}

\subsection{PHASE VELOCITY}

Observed phase $\phi_{i}$ is written, for the transverse component Love wave $G_{i}$ from a point source, as

$\phi_{i}^{\mathrm{L}}=\omega t_{0}-\pi / 4+\phi_{\mathrm{s}}^{\mathrm{L}}-\omega l_{i} / C_{i}^{\mathrm{L}}+(i-1) \pi / 2-\phi_{\mathrm{f}}^{\mathrm{L}}-\phi_{\mathrm{r}}^{\mathrm{L}}+2 N \pi+(i-1) \pi$,

and for the vertical component Rayleigh wave $R_{i}$, as

$\phi_{i}^{\mathrm{R}}=\omega t_{0}+\pi / 4+\phi_{\mathrm{s}}^{\mathrm{R}}-\omega l_{i} / C_{i}^{\mathrm{R}}+(i-1) \pi / 2-\phi_{\mathrm{f}}^{\mathrm{R}}-\phi_{\mathrm{r}}^{\mathrm{R}}+2 N \pi$,

where $\omega$ is the angular frequency, $t_{0}$ is the starting time of the group velocity window, $\left(-\pi / 4+\phi_{\mathrm{s}}^{\mathrm{L}}\right)$ and $\left(\pi / 4+\phi_{\mathrm{s}}^{\mathrm{R}}\right)$ are the initial phases at the source, $l_{i}$ is the length of surface wave path, $C_{i}$ is the apparent phase velocity along the entire surface wave path, the term $(i-1) \pi / 2$ comes from the polar phase shifts (Brune, Nafe \& Alsop 1961) at the pole and antipole, $\phi_{\mathrm{f}}$ is the phase delay due to finite source process, $\phi_{\mathrm{r}}$ is the instrumental phase delay, $2 N \pi$ is an ambiguity of phase arising from the multivalued nature of Fourier phase, and the term $(i-1) \pi$ in (1) comes from the definition of Love wave source phase $\left(-\pi / 4+\phi_{\mathrm{s}}^{\mathrm{L}}\right)$, which is defined to be positive for counter-clockwise motion at the epicentre. From (1) and (2), we have apparent phase velocity along the entire surface wave path, for $G_{i}$

$C_{i}^{\mathrm{L}}=\omega l_{i} /\left[-\phi_{i}^{\mathrm{L}}+\omega t_{0}-\pi / 4+\phi_{\mathrm{s}}^{\mathrm{L}}+3(i-1) \pi / 2-\phi_{\mathrm{f}}^{\mathrm{L}}-\phi_{\mathrm{r}}^{\mathrm{L}}+2 N \pi\right]$,

and for $R_{i}$

$C_{i}^{\mathrm{R}}=\omega l_{i} /\left[-\phi_{i}^{\mathrm{R}}+\omega t_{0}+\pi / 4+\phi_{\mathrm{s}}^{\mathrm{R}}+(i-1) \pi / 2-\phi_{\mathrm{f}}^{\mathrm{R}}-\phi_{\mathrm{r}}^{\mathrm{R}}+2 N \pi\right]$.

We use (3) and (4) to measure the apparent phase velocities of $G_{i}$ and $R_{i}$. The integer $N$ in (3) and (4) is determined so as to connect smoothly with the phase velocities expected from eigenperiods of the Earth's oscillations. The length of the surface wave path $l_{i}$ is calculated from Rucioe's formula (Bomford 1962; Maruyama 1967) on the geoellipsoid of revolution by using a geometric flattening $f_{\mathrm{g}}=1 / 297.001$ and a mean radius $R_{0}=6371.211 \mathrm{~km}$. Frequency dependence of the ellipticity advocated by Dahlen (1975) (Dahlen 1976; Dziewonski \& Sailor 1976) is not considered in this paper. This affects $l=2$ spherical harmonics, but does not change the conclusions of this study. The instrumental phase delay for IDA stations is calculated from the transfer functions and the constants provided by the IDA project team at the Institute of Geophysics and Planetary Physics, University of California at San Diego. The instrumental correction for GDSN stations is made by using the transfer functions and the constants stored in the network day tapes of the GDSN data.

The correction for source mechanism $\left(\phi_{\mathrm{S}}^{\mathrm{L}}\right.$ or $\left.\phi_{\mathrm{S}}^{\mathrm{R}}\right)$ is made by assuming a double-couple point source and by using the NEIS epicentre locations and source information listed in Table 2. The azimuthal part $\phi_{\mathrm{S}}$ of initial phase for a double-couple source is written (Kanamori \& Stewart 1976)

$\phi_{\mathrm{S}}=\tan ^{-1}[\operatorname{Im}\{S(\omega)\} / \operatorname{Re}\{S(\omega)\}]$,

where: for the transverse component of Love waves

$S(\omega)=M_{0}\left(p_{L} P_{L}^{(1)}+i q_{L} Q_{L}^{(1)}\right)$ 
and for the vertical component of Rayleigh waves

$S(\omega)=M_{0}\left(s_{R} S_{R}^{(1)}+p_{R} p_{R}^{(1)}+i q_{R} Q_{R}^{(1)}\right)$

where $M_{0}$ is the scalar seismic moment, $P_{L}^{(1)}, Q_{L}^{(1)}, S_{R}^{(1)}, P_{R}^{(1)}$ and $Q_{R}^{(1)}$ are the excitation functions given by Kanamori \& Stewart (1976), and the coefficients $p_{L}, q_{L}, s_{R}, p_{R}$ and $q_{R}$ are determined from the fault parameters $(\delta, \lambda$ and $\phi)$ and the azimuth of the station. We use earth model 5.08M (Kanamori 1970) to calculate the excitation functions. Dependence of the measured phase velocities upon the assumed earth model will be discussed later.

For a horizontal unilateral fault (Ben-Menahem 1961) with a delay of the main faulting from the initial break, the phase delay $\phi_{\mathrm{f}}$ due to the finite source process is approximated by

$\phi_{\mathrm{f}}=\frac{\omega L}{2 V}\left(1-\frac{V}{C} \cos \theta\right)+\omega \tau_{\mathrm{D}}$,

where $\omega$ is the angular frequency, $L$ is the fault length, $V$ is the rupture velocity, $C$ is the phase velocity of Love or Rayleigh waves at frequency $\omega, \theta$ is the azimuth of the station measured from the rupture direction, and $\tau_{D}$ is the delay of the main faulting from the initial break. We define the source process time $\tau$ by

$\tau=\frac{L}{V}+2 \tau_{\mathrm{D}}$

and rewrite (8) as

$\phi_{\mathrm{f}}=\frac{\omega \tau}{2}-\frac{\omega L}{2 C} \cos \theta$.

Since an origin time error is absorbed in $\tau_{\mathrm{D}}$, the origin time errors of several to several tens of seconds do not affect the velocity measurement except for the shift of group velocity window if we correct for $\tau$. Nakanishi \& Kanamori (1984) measured $\tau$ for all of the earthquakes used in this paper. The measured $\tau$ are listed in Table 2.

For a symmetric bilateral fault (Aki 1966), the phase delay $\phi_{\mathrm{f}}$ is

$\phi_{\mathrm{f}}=\phi_{\mathrm{f}}^{\mathrm{O}}+\omega \tau_{\mathrm{D}}$,

where

$\phi_{\mathrm{f}}^{\mathrm{O}}=\tan ^{-1}\left\{\frac{\sin ^{2} X / X+\sin ^{2} Y / Y}{\sin X \cos X / X+\sin Y \cos Y / Y}\right\}$,

$X=\frac{\omega L}{4}\left(\frac{1}{V}-\frac{\cos \theta}{C}\right)$

and

$Y=\frac{\omega L}{4}\left(\frac{1}{V}+\frac{\cos \theta}{C}\right)$

Here $L$ is the total fault length. For the symmetric bilateral fault, the observed source process times (Table 2 ) are azimuthal averages of

$\tau(\theta)=2 \phi_{\mathrm{f}}^{\mathrm{O}} / \omega+2 \tau_{\mathrm{D}}$. 
Thus for the bilateral fault, the phase delay is

$$
\begin{aligned}
\phi_{\mathrm{f}} & =\omega \tau(\theta) \\
& =\omega \bar{\tau}+\Delta \phi_{\mathrm{f}}(\theta),
\end{aligned}
$$

where $\bar{\tau}$ is the non-directional part of the source process times and $\Delta \phi_{\mathrm{f}}(\theta)$ is the directional part of the phase delay. The symmetry in the bilateral fault reduces the directivity of the phase delay considerably. $\phi_{\mathrm{f}}^{\mathrm{O}}(\theta)$ has a maximum at $\theta=90^{\circ}$ and $270^{\circ}$ and a minimum at $0^{\circ}$ and $180^{\circ}$. For $L=100 \mathrm{~km}, T=200 \mathrm{~s}, C=4.9 \mathrm{~km} \mathrm{~s}^{-1}$ and $V=3 \mathrm{~km} \mathrm{~s}^{-1}$, the maximum and the minimum are 0.26180 and $0.25952 \mathrm{rad}$, respectively. The difference, $0.00228 \mathrm{rad}$, is equivalent to a directivity of the source duration of $0.14 \mathrm{~s}$ (see 15). Therefore, if an earthquake is bilateral we can correct for the finite source process very accurately by using the observed source process time $\bar{\tau}$.

If we know that an earthquake has a horizontal unilateral fault, and know $L$ and $\theta$, we can correct for $\phi_{\mathbf{f}}$. If we know that an earthquake is a symmetric bilateral fault, we need correct only for $\bar{\tau}$. The earthquakes used in this study, however, occurred recently (during 1980). Thus, it was generally difficult to obtain information about aftershock distributions determined by local networks or finite source models inferred from body wave waveform modelling. In this study we corrected only for the non-directional part of the source finiteness. The effect of this simplification upon the measured phase velocities will be discussed later when making an error analysis.

\subsection{GROUP VELOCITY}

The group velocity $U_{i}$ of Love wave $G_{i}$ or Rayleigh wave $R_{i}$ is calculated by using the formula:

$U_{i}=l_{i} /\left(t_{\mathrm{g}}+d \phi_{\mathrm{s}} / d \omega-d \phi_{\mathrm{f}} / d \omega-d \phi_{\mathrm{r}} / d \omega\right)$,

where $l_{i}$ is the length of surface wave path, $t_{\mathrm{g}}$ is the arrival time of the wave group at centre angular frequency $\omega$ on the seismogram, $\phi_{\mathrm{S}}$ is the directional part of the initial phase at the source, $\phi_{\mathrm{f}}$ is the phase delay due to finite source process, and $\phi_{\mathrm{r}}$ is the instrumental phase delay. The path length $l_{i}$ is calculated in the same way as for the phase velocity measurement.

Group arrival time $t_{\mathrm{g}}$ is measured by making a moving window analysis (Landisman, Dziewonski \& Satô 1969). An important parameter in the moving window analysis is the width of the moving window. An appropriate value of the width was determined by numerical experiments on seismograms synthesized by normal mode summation. We used a width of four times the wave period and 12 times the wave period for Love and Rayleigh waves, respectively.

The effect of source orientation $d \phi_{\mathrm{S}} / d \omega$ is corrected for by numerical differentiation of $\phi_{\mathrm{s}}$. This effect was ignored in all previous group velocity measurements in the period range of this study. The derivative $d \phi_{\mathbf{s}} / d \omega$ vanishes for a vertical strike-slip fault and $45^{\circ}$ pure dip-slip fault (Ben-Menahem, Rosenman \& Harkrider 1970), and for the source at the surface (Ben-Menahem \& Harkrider 1964). Knopoff \& Schwab (1968) made an estimate of the source orientation effect upon the Rayleigh wave group velocity. In the Appendix we show results of the numerical differentiation of $\phi_{\mathrm{S}}$ for events 4,21 and 26 . The same initial phase $\phi_{\mathrm{s}}$ as for the phase velocity measurement is used there. The results in the Appendix and for the other earthquakes show that for Love waves this source effect may be negligible, within the accuracy of the moving window analysis, except for nodal directions. Thus, we added four earthquakes whose source mechanisms are not necessarily very well determined 
to increase the number of Love wave paths, ignoring the small effect of source mechanism. For Rayleigh waves, however, the effect may be significant except for shallow earthquakes (events 19 and 26), and we corrected for the source mechanisms.

The source group delay due to finite source process is obtained from $(10)$ for a horizontal unilateral fault:

$\frac{d \phi_{\mathrm{f}}}{d \omega}=\frac{\tau}{2}-\frac{L}{2 U} \cos \theta$.

As in the phase velocity measurement, we ignored the directional term of (18) and corrected only for $\tau / 2$. The source process times in Table 2 are used as $\tau$.

The instrumental group delay $d \phi_{\mathbf{r}} / d \omega$ is calculated by numerical differentiation of the same $\phi_{\mathrm{r}}$ as used in the phase velocity measurement.

\section{Error analy sis for velocity measurements}

In the following we estimate errors due to the uncertainty in origin time, epicentral location, source depth, source mechanism and source finiteness; errors in the assumed earth model; errors in instrumental response, including clock errors; and higher mode contamination of fundamental mode Love waves. The estimation is expressed as a delay time.

\subsection{INSTRUMENTAL CALIBRATION}

Prior to the present analysis for surface wave velocities, the same data were used to determine source mechanisms and source process times of the earthquakes listed in Table 1 (Nakanishi \& Kanamori 1984). During the source study we found some seismograms which we suspected of having errors in instrumental response. In some of the GDSN data three channels (Z, NS, EW) were interchanged in the network day tapes. Examining the polarities of rotated Love and Rayleigh waves, we corrected these malfunctions and used the corrected data in the velocity measurements. When we had possible polarity reversal, found by the examination of initial phases or noted in the GDSN day tapes, the seismograms were processed for group velocity but not for phase velocity. IDA data sometimes showed spurious phase advances or delays in the initial phases of Rayleigh waves when they were equalized back to the epicentre. Although it is possible to use these data in the velocity measurement, after correcting the phase shift by using the apparent source process time as suggested by Nakanishi \& Kanamori (1982), we abandoned all such data in the measurements of both phase and group velocities. We assume errors due to the instrumental response to be negligible.

\subsection{ORIGIN TIME AND EPICENTRAL LOCATION}

The values listed in Table 1 also have errors. Theoretically we could correct the error in origin time by measuring the apparent source process time as mentioned before. An examination of the differences between the spherical average phase velocities obtained from the great circle method (Paper I) and the single-station method of this paper suggests that the errors are about $3 \mathrm{~s}$. Although this value is estimated from an analysis of phase velocities, the same value may be applied to group velocities.

Mislocations of explosions give us an estimate for the uncertainty in epicentral locations of natural earthquakes. Longshot nuclear explosion (1965) on Amchitka Island in the 
central Aleutians was located $23 \mathrm{~km}$ to the north of the detonation point by the worldwide seismic network (Herrin \& Taggart 1968). Gnome explosion (1961) in New Mexico was determined $16 \mathrm{~km}$ to the east of the test point (Herrin \& Taggart 1962). Based on experience in locating explosions, a value of $4 \mathrm{~s}$ is an estimate of the timing error associated with mislocations in the epicentre determined by the world-wide seismic network.

\subsection{SOURCE FINITENESS}

The non-directional part of the source finiteness is considered above in connection with origin time. Here we analyse the effect of the directional part of the source finiteness. As already shown, this effect is largest for a horizontal unilateral fault. From (10) and (18) the directional parts of the phase and group delays due to a unilateral fault are

$\frac{\phi_{\mathrm{f}}}{\omega}=-\frac{L}{2 C} \cos \theta$

and

$\frac{d \phi_{\mathrm{f}}}{d \omega}=-\frac{L}{2 U} \cos \theta$

As shown by Furumoto \& Nakanishi (1983), the statistical relation between seismic moment $M_{0}$ (dyne $\mathrm{cm}$ ) and source process time $\tau(\mathrm{s})$ can be expressed by

$M_{0}=2.5 \times 10^{22} \tau^{3}$

Although this empirical relation is derived from low-angle thrust events along deep sea trenches, we adopt it in the following error estimate. The source process time consists of the duration of rupture propagation $(L / V)$ and the delay time of the rupture from the initiation of the earthquake $\left(\tau_{D}\right)$, as (9) shows. According to Furumoto \& Nakanishi, $\tau_{\mathrm{D}}$ is statistically estimated to be about $0.2 \tau$. To estimate an averaged effect of the finiteness, we compute a mean of the seismic moments of the earthquakes used for the phase velocity measurements. $\bar{M}_{0}=0.37 \times 10^{27}$ dyne $\mathrm{cm}$. From (21), we have $\bar{\tau}=24 \mathrm{~s}$. Thus the averaged error due to a unilateral fault is estimated to be $\bar{L} / 2 C=0.3 \bar{\tau} V / C=4.4 \mathrm{~s}$, when we assume $V=3 \mathrm{~km} \mathrm{~s}^{-1}$ and $C=4.9 \mathrm{~km} \mathrm{~s}^{-1}$. If we use the averaged value of the source process times listed in Table $1(\bar{\tau}=25 \mathrm{~s})$, we have $\bar{L} / 2 C=4.6 \mathrm{~s}$. The phase velocity corresponds to that of Love waves at about $200 \mathrm{~s}$ or Rayleigh waves at about $250 \mathrm{~s}$ (see Tables 4 and 5). Since we assumed unilateral faulting in the above error estimation, an expected maximum error due to the finiteness is estimated to be $4.5 \mathrm{~s}$. As shown already, if the earthquake is a symmetric bilateral fault, the error due to directivity is estimated to be only about $0.1 \mathrm{~s}$.

\subsection{SOURCE DEPTH AND SOURCE MECHANISM}

Errors caused by uncertainty in the source depths and source mechanisms are largest at stations in the azimuths of nodes in the amplitude radiation pattern. To minimize this source of error, we eliminated data from stations within about $5^{\circ}$ of the nodal azimuths. The surface waves at these stations, of course, have small amplitudes. Thus they are usually removed by visual selection of data. We should note that there is a large difference between Love and Rayleigh waves (in the period range 100-300 s) in the errors due to the inaccuracy of the depth and the mechanism. The initial phases and group delays of Love waves are 
much more insensitive to the errors than are the Rayleigh waves. This might be one of the reasons that the effect of incompleteness in source information on single-station velocity measurements has been studied only for Rayleigh waves (Knopoff \& Schwab 1968; Frez \& Schwab 1976).

The other thing to be addressed about source mechanism is a possible effect of a frequency-dependent source mechanism. It is assumed that the $P$-wave $(\sim 10 \mathrm{~s}$ period $)$ first motion and the long-period Rayleigh waves (256s in the study of Nakanishi \& Kanamori 1984) have an identical source mechanism. As far as we know, this assumption has been adopted in all previous studies. Considering the general consistency between body wave, long-period surface wave, and free oscillation studies, we believe that this assumption does not cause serious errors in the single-station velocity measurement.

For measuring phase velocity, we select earthquakes with well-determined mechanisms. The $P$-wave first motions and the radiation patterns of Rayleigh waves give generally consistent results. The uncertainty in the node directions is unlikely to exceed $5^{\circ}$. We avoided data within this azimuthal range. To estimate the error outside this range, we examined the initial phase plots at $256 \mathrm{~s}$ of all the earthquakes. Including the uncertainty in the source depths, we assign the average error in the initial phases for $256 \mathrm{~s}$ Rayleigh waves to be $0.06 \mathrm{rad}$. This value is equivalent to an error of 1.0 and $2.4 \mathrm{~s}$ in phase delay for periods of 100 and $250 \mathrm{~s}$, respectively. We adopt this error estimate for both Love and Rayleigh wave phase velocities. For Love waves the value must be overestimated, because of the insensitivity of the Love wave excitation function to the error in the assumed source depth.

Love wave group velocities were not corrected for source mechanisms. In addition we used four earthquakes whose source mechanisms are not necessarily very well constrained. However, the associated errors are unlikely to exceed $1 \mathrm{~s}$ except near the nodal directions. We discarded data within this range where $d \phi_{\mathrm{s}} / d \omega$ shows a rapid azimuthal variation. Even for the four additional earthquakes, we constrain the nodal directions well $\left(\sim 10^{\circ}\right)$ from Rayleigh wave amplitude radiation patterns. We estimate the error in Love wave group delays due to source mechanism and depth to be $0.5 \mathrm{~s}$.

Rayleigh wave group velocities are corrected for source mechanism by using the parameters listed in Table 2. As shown in the Appendix, the calculated $d \phi_{\mathrm{s}} / d \omega$ show a strong dependence on source depth. A comparison of $d \phi_{\mathrm{s}} / d \omega$ for $d=43 \mathrm{~km}$ and that for $d=33 \mathrm{~km}$ suggests that a change in source depth from 33 to $43 \mathrm{~km}$ can cause a change in the group delay of about $10 \mathrm{~s}$. Events 4 and 21 have steep dip angles, $70^{\circ}$ and $74^{\circ}$, respectively. Event 14 also has a steeply dipping $\left(\delta=70^{\circ}\right)$ fault plane and is located at a depth of $33 \mathrm{~km}$. For strike-slip earthquakes (events 1, 3, 8, 24 and 27) and shallow intraplate earthquakes (events 19 and 26), the errors may be at most $1 \mathrm{~s}$. Considering the differences in expected errors among different types of earthquakes, an averaged error of $3 \mathrm{~s}$ is assigned to the group velocity measurement of Rayleigh waves in the whole period range of this study.

\subsection{EARTH MODEL}

Excitation functions were computed for an oceanic earth model (5.08M). The earthquakes that we analysed occurred in tectonically active regions, e.g. islands arcs and ridges. However, the use of oceanic structure may be more appropriate in studying the global lateral heterogeneity than a tectonic model, because we use excitation functions which are appropriate in the far field. Frez \& Schwab (1976) studied the dependence of Rayleigh wave initial phase on the earth structure. For strike-slip earthquakes the effect may be considered to be negligible. Even for dip-slip earthquakes the effect may be negligible if the 
dip angle is close to $45^{\circ}$. If the earthquake has a steeply dipping fault (e.g. $70^{\circ}$ ) and is located at the bottom of the crust $(33 \mathrm{~km})$, the expected errors reach about $2 \mathrm{~s}$ for the period range of concern. Those earthquakes are events $4,14,21$ and 28 . If we assign an error of $2 \mathrm{~s}$ to these earthquakes and assume the other earthquakes to be free from error, we have an averaged error of about $1 \mathrm{~s}$. Weidner (1974) also examined the structural dependence of Rayleigh waves for the specific earthquakes in the Atlantic Ocean and reported that the effect on the initial phase may be negligible for shallow crustal earthquakes. Errors in Love wave phase velocities, and Love and Rayleigh wave group velocities due to the uncertainty in the earth model, are assumed to be of the same order as those for Rayleigh wave phase velocities. We assign an average error of $1 \mathrm{~s}$ as the uncertainty due to an erroneous earth structure for all of the four data sets.

\subsection{HIGHER MODE CONTAMINATION}

For Love waves there is a possible problem with higher mode interference at periods around $100 \mathrm{~s}$. The situation depends on the earth structure. For an oceanic structure the group velocities of the fundamental and first higher mode overlap at periods around $100 \mathrm{~s}$.

Thatcher \& Brune (1969) and Boore (1969) studied the effects of higher mode contamination on the measurement of phase velocity of the fundamental modes. Their analysis methods are similar, but their conclusions are different. Thatcher \& Brune suggested that higher mode contamination causes anomalously high apparent phase velocities. Boore suggested that the contamination produces large scatter, but no uniform bias in measured phase velocities from a number of earthquake-station pairs. James (1971) measured the phase velocities from the phase difference of waves observed at two stations located on the same great circle path by using $G_{1}$ and $G_{3}$ waves. He reported anomalously high Love wave phase velocities from $G_{1}$, but normal values from $G_{3}$. Schlue (1975) adopted the method of Thatcher \& Brune to estimate the effects of the higher mode contamination in a wide period range from 20 to $260 \mathrm{~s}$ by assuming the two modes to exist in the identical group velocity window. For periods longer than $150 \mathrm{~s}$ the group arrivals of the first higher mode are far ahead of the group velocity window $\left(4.5-4.2 \mathrm{~km} \mathrm{~s}^{-1}\right)$ of our study. His results suggest that effects of the contamination are smaller than $0.01 \mathrm{~km} \mathrm{~s}^{-1}$ for long distances, such as those of $G_{2}$ and $G_{3}$, and that the expected errors show fluctuations, but not any systematic high or low velocity among different periods. In Paper I we made a similar numerical experiment for the great circle phase velocity measurement $(l \sim 40000 \mathrm{~km})$. The results show that the higher mode contamination does not seem to cause systematic biases in the great circle phase velocity measurement.

We estimate the amplitude of the fluctuations due to the higher mode to be at most $0.005 \mathrm{~km} \mathrm{~s}^{-1}$. However, generally we did not observe these large-amplitude fluctuations in experimental phase velocities. In many cases the phase velocities show very smooth residual dispersion curve (= observed-calculated) in the period range of the measurement. In some cases the phase velocities exhibit strong fluctuations from period to period. Although we do not know whether the fluctuations were caused by higher mode contamination, we eliminated those data from further consideration. The estimated error of $0.005 \mathrm{~km} \mathrm{~s}^{-1}$ in phase velocity is equivalent to an error of $7.0 \mathrm{~s}$ in phase delay if we consider a $100 \mathrm{~s} G_{2}$ wave observed at an epicentral distance of $90^{\circ}$.

The interference by higher modes can also cause error in group velocity measurements. The interference causes a ringing in the time domain and disturbs the group velocity measurement by the moving window method. Multipathing, due to possible strong lateral heterogeneity, can also cause the interference pattern on the seismograms. In our moving 
window analysis we examined contours of arriving energy as a function of period and group velocity when determining the ridge of the contours. In some cases the contours showed complicated patterns at shorter periods. In these cases we discarded the observations, at least those parts showing a possible interference effect, from the following inversion analysis.

\subsection{TOTAL ERROR}

In the above error estimation we assume independence of the various errors. This assumption is questionable for some of the error sources, particularly those associated with source parameters. Epicentral and directional (finiteness) errors appear to have a similar effect on the velocity measurements. We use NEIS parameters for origin time, epicentral location and source depth. These are determined simultaneously and are not internally independent. For shallow dip-slip events, focal mechanisms can be strongly depth-dependent. The dependence is weak for strike-slip events. Considering these facts our error estimate should be taken as somewhat optimistic.

If we assume the errors estimated above are independent and are normally distributed, the total rms error can be estimated by the usual formula

$E=\sqrt{\sum_{i=1}^{N} e_{i}^{2},}$

where $e_{i}$ is the rms error due to each factor considered above and $N$ is the number of the factors. For each of the four data sets we have

$E=\left(3^{2}+4^{2}+4.5^{2}+1^{2}+1^{2}+7^{2}\right)^{1 / 2}=9.8 \mathrm{~s}$

for short-period (100s) Love wave phase velocity;

$E=\left(3^{2}+4^{2}+4.5^{2}+2.4^{2}+1^{2}+0^{2}\right)^{1 / 2}=7.2 \mathrm{~s}$

for long-period (250s) Love wave phase velocity;

$E=\left(3^{2}+4^{2}+4.5^{2}+1^{2}+1^{2}+0^{2}\right)^{1 / 2}=6.9 \mathrm{~s}$

for short-period $(100 \mathrm{~s})$ Rayleigh wave phase velocity;

$E=\left(3^{2}+4^{2}+4.5^{2}+0.5^{2}+1^{2}+0^{2}\right)^{1 / 2}=6.8 \mathrm{~s}$

for Love wave group velocity;

$E=\left(3^{2}+4^{2}+4.5^{2}+3^{2}+1^{2}+0^{2}\right)^{1 / 2}=7.4 \mathrm{~s}$

for Rayleigh wave group velocity.

The estimated total errors will be considered when we interpret the observed variations of phase and group velocities in terms of lateral velocity heterogeneity.

\section{Estimation of geographical distribution of surface wave velocities}

We adopt a spherical harmonic representation to interpret the observed phase and group velocities. We point out two advantages of this approach. One is that the method does not need any a priori assumption about lateral heterogeneity except the truncation level of the expansion. It is straightforward to increase the maximum order and degree as the data set size increases. The other advantage is that the use makes it easy to compare the seismic 
data with other geophysical data, such as heat flow and geoid, which have been presented in terms of spherical harmonics. However, we should note disadvantages in this approach. As will be shown later, there exists the problem of oscillatory side lobes (ringing) in the averaging function. If the truncation level is low, the amplitude of the side lobe is significant. This makes the choice of the truncation level the most severe problem in spherical harmonic analysis. From independent seismological data we know that there are sharp lateral discontinuities in mantle structure. To represent these features a gridding technique might be superior to the spherical harmonic method.

\subsection{DETERMINATION OF SPHERICAL HARMONIC COEFFICIENTS}

Phase or group slowness $1 / v(\theta, \phi)$ is expanded in terms of spherical harmonics

$1 / v(\Omega)=\sum_{l=0}^{\infty} \sum_{m=-l}^{m=l} s_{l m} Y_{l m}(\Omega)$

where $\Omega$ represents polar angles $(\theta, \phi), Y_{l m}(\Omega)$ is fully-normalized spherical harmonics, and a convention

$$
\sum_{m=0}^{l}\left(A_{l m} \cos m \phi+B_{l m} \sin m \phi\right) P_{l m}(\cos \theta)=\sum_{m=-l}^{m=l} s_{l m} Y_{l m}(\Omega)
$$

is used. With the representation (23), we write phase or group delay along a surface wave path as

$\int_{\Gamma_{i}} \frac{d s}{v(\Omega)}=\sum_{l=0}^{\infty} \sum_{m=-l}^{m=l} s_{l m} \int_{\Gamma_{i}} Y_{l m}(\Omega) d s, \quad i=1, \ldots, N$

where $\Gamma_{i}$ is the surface wave path, and $N$ is the number of observations. The left side of this equation is the observed phase or group delay due to the propagation between earthquake and station. The integral of $Y_{l m}$ along $\Gamma_{i}$ is evaluated numerically. If we truncate the expansion (23) at $l=L$, the number of the coefficients $s_{l m}$ is equal to

$$
M=1+3+5 \ldots+(2 L+1)=(L+1)^{2} \text {. }
$$

Throughout this paper $L$ means the maximum $l$ in the expansion. If $N \gg M$ and the path $\Gamma_{i}$ are well distributed on the Earth's surface, we can determine all coefficients $s_{l m}$ up to degree and order $L$ from a least-squares solution of the observation equations (25). Using this solution we can synthesize the distribution of the surface wave velocity $v(\Omega)$ on the Earth's surface from (23).

In this study we measured the apparent velocities of $G_{2}, G_{3}, R_{2}, R_{\mathbf{3}}$ and $R_{\mathbf{4}}$. To calculate the integral of $Y_{l m}$ of (25) for these waves, we used Backus' (1964) solution of the great circle integral of spherical harmonics and numerical evaluation of the integral for $G_{1}$ or $R_{1}$. For $G_{n}$ or $R_{n}$, we can write the integral as

$$
\int_{n=n} Y_{l m}(\Omega) d s=\left[\frac{n}{2}\right]\left(2 \pi R_{0}\right) P_{l}(0) Y_{l m}(\Theta, \Phi)+(-1)^{n-1} \int_{n=1} Y_{l m}(\Omega) d s, \quad \text { for } l=\text { even }
$$

or

$$
\int_{n=n} Y_{l m}(\Omega) d s=0+(-1)^{n-1} \int_{n=1} Y_{l m}(\Omega) d s, \quad \text { for } l=\text { odd }
$$


where [ ] represents the largest integer equal to or less than the argument, $(\Theta, \Phi)$ is the position of the positive pole of great circle path, $R_{0}$ is the radius of the spherical earth, and $P_{l}(0)$ is the Legendre function. Thus we need to make the numerical evaluation for only the minor arc integral of $Y_{l m}(\Omega)$.

We have the velocity measurements for $G_{2}(n=2)$ and $G_{3}(n=3)$ for many earthquakestation pairs. For $G_{2}$ and $G_{3}$, using (25) and (26) we have

$\int_{n=2} \frac{d s}{v}=\sum_{l=\text { even }} \sum_{m=-l}^{m=l} s_{l m}\left(C_{l m}-D_{l m}\right)+\sum_{l=\text { odd }} \sum_{m=-l}^{m=l} s_{l m}\left(-D_{l m}\right)$,

$\int_{n=3} \frac{d s}{v}=\sum_{l=\text { even }} \sum_{m=-l}^{m=l} s_{l m}\left(C_{l m}+D_{l m}\right)+\sum_{l=\text { odd }} \sum_{m=-l}^{m=l} s_{l m}\left(D_{l m}\right)$,

where:

$C_{l m}=2 \pi R_{0} P_{l}(0) Y_{l m}(\Theta, \Phi)$

and

$D_{l m}=\int_{n=1} Y_{l m}(\Omega) d s$.

From (27) and (28), we obtain

$\int_{n=2} \frac{d s}{v}+\int_{n=3} \frac{d s}{v}=2 \sum_{l=\text { even }} \sum_{m=-l}^{m=l} s_{l m} C_{l m}$

and

$\int_{n=2} \frac{d s}{v}-\int_{n=3} \frac{d s}{v}=-2 \sum_{l=\text { evenandodd }} \sum_{m=-l}^{m=l} s_{l m} D_{l m}$.

Equations (29) and (30) correspond to great circle velocity and minor arc velocity, respectively. The latter equation is expected to have errors due to asymmetry of source properties, such as source mechanism, source finiteness and epicentral mislocation. In the former equation, these errors cancel out. Odd harmonics of lateral heterogeneity are constrained through (30). Even harmonics are constrained by (29) and (30). Therefore we expect larger uncertainties in the least-squares solutions for odd harmonics than for even harmonics.

\subsection{SYNTHESIS OF VELOCITY DISTRIBUTION}

We can synthesize velocity distributions from the spherical harmonic coefficients determined from a least-squares solution of (25) by adopting the usual sum rule (23). However, two problems arise. A straight truncation of the spherical harmonic series at a finite $l$, say $L$, is undesirable because of the well-known ringing phenomenon. The other problem involves errors in the spherical harmonic coefficients, especially the odd harmonics. To overcome these problems we follow the linear inverse approach taken by Whaler \& Gubbins (1981) in their analysis of the geomagnetic field. They used Schmidt quasi-normalized spherical harmonics. Here we use fully-normalized spherical harmonics. 
Following Whaler \& Gubbins, we write the estimate $\bar{s}$ of the slowness perturbation $s\left(=1 / v-1 / v_{00}\right)$ at $\Omega_{0}$ as a linear combination of $s_{l m}$

$$
\begin{aligned}
\bar{s}\left(\Omega_{0}\right) & =\sum_{l=1}^{L} \sum_{m=-l}^{m=l} q_{l m}\left(\Omega_{0}\right) s_{l m} \\
& =\oint A\left(\Omega ; \Omega_{0}\right) s(\Omega) d \Omega,
\end{aligned}
$$

where

$A\left(\Omega ; \Omega_{0}\right)=\frac{1}{4 \pi} \sum_{l=1}^{L} \sum_{m=-l}^{m=l} q_{l m}\left(\Omega_{0}\right) Y_{l m}(\Omega)$.

$A\left(\Omega ; \Omega_{0}\right)$ is an averaging function or filter. Whaler \& Gubbins choose $q_{l m}$ so as to make the averaging function $A\left(\Omega ; \Omega_{0}\right)$ peak near the point $\Omega_{0}$ and be small elsewhere. They adopted the so-called First Dirichlet Condition for defining the criterion of spread of $A\left(\Omega ; \Omega_{0}\right)$. They showed that this criterion leads to the usual sum rule (23), namely $q_{l m}\left(\Omega_{0}\right)=Y_{l m}\left(\Omega_{0}\right)$. The averaging function is found to be

$A\left(\Omega ; \Omega_{0}\right)=\frac{1}{4 \pi} \sum_{l=1}^{L} \sqrt{2 l+1} P_{l}(\cos \gamma)$

where $\gamma$ is the angle between the points $\Omega(\theta, \phi)$ and $\Omega_{0}\left(\theta_{0}, \phi_{0}\right)$. As they show, a straight truncation causes ringing in the estimate $\bar{s}\left(\Omega_{0}\right)$.

Next we construct a filter to damp the effects of the poorly determined spherical harmonics. Following Whaler \& Gubbins, we use the trade-off curve

$T(\lambda)=\alpha \cos \lambda+\epsilon^{2} \sin \lambda, \quad 0 \leqslant \lambda \leqslant \frac{\pi}{2}$,

where $\alpha$ is the spread of $A\left(\Omega ; \Omega_{0}\right)$ defined by the First Dirichlet Condition

$\alpha=\oint\left[A-\delta\left(\Omega-\Omega_{0}\right)\right]^{2} d \Omega$,

and $\epsilon^{2}$ is the variance of the estimate $\bar{s}\left(\Omega_{0}\right)$

$\epsilon^{2}=\sum_{i, j=1}^{K} a_{i} a_{j} V_{i j}$,

$\left\{a_{i}\right\}$ are the set of multipliers $\left\{q_{l m}\right\}$ of $(31)$, ordered with a single subscript, $V_{i j}$ is the covariance matrix of the data $\left\{s_{l m}\right\}$, and $K=L(L+2)$. To construct the filter we minimize (35). Assuming that the data $\left(=\left\{s_{l m}\right\}\right)$ are uncorrelated $\left(V_{i j}=\sigma_{i}^{2} \delta_{i j}\right)$, we have

$q_{l m}=\frac{Y_{l m}\left(\Omega_{0}\right)}{1+(4 \pi \tan \lambda) \sigma_{l m}^{2}}$,

where $\sigma_{l m}$ are the standard deviations of $s_{l m}$. If $\lambda=0$ or $\sigma_{l m}=0$, the combination of (31) and (38) is the usual sum formula. For $\lambda \neq 0$ and $\sigma_{l m} \neq 0$, the contribution of poorly determined (large $\sigma_{l m}$ ) coefficients to the estimate $\bar{s}$ is damped compared with that of well-determined (small $\sigma_{l m}$ ) coefficients. From (37) and (38), the variance of the estimate is found to be

$\epsilon^{2}=\sum_{l=1}^{L} \sum_{m=-l}^{m=l}\left(q_{l m}^{2} \sigma_{l m}^{2}\right)$. 
If $\sigma_{l m}^{2}=\sigma_{l}^{2}$ for all $m$,

$\sigma_{l}^{2}=\frac{1}{2 l+1} \sum_{m=-l}^{m=l} \sigma_{l m}^{2}$,

using the addition theorem, we have

$\epsilon^{2}=\sum_{l=1}^{L}\left\{\left[\frac{\sigma_{l}}{1+(4 \pi \tan \lambda) \sigma_{l}^{2}}\right]^{2}(2 l+1)\right\}$.

Substituting (38) and (40) into (33), we have the averaging function

$A\left(\Omega ; \Omega_{0}\right)=\frac{1}{4 \pi} \sum_{l=1}^{L} \frac{\sqrt{2 l+1}}{1+(4 \pi \tan \lambda) \sigma_{l}^{2}} P_{l}(\cos \gamma)$.

If $\lambda=0$ or $\sigma_{l}=0,(42)$ reduces to (34). In our analysis of surface wave velocities, we use (31), (33), (38), (40), (41) and (42). Appropriate values of $\lambda$ will be found by considering the variance of the estimate.

\section{Results of inversions}

In this section we describe the results of spherical harmonic inversion of the surface wave velocities. Equation (25) is solved by a least-squares method for phase and group velocities of Love and Rayleigh waves. In the next section the geographical distribution of surface wave velocities will be synthesized by using the coefficients obtained in the inversions.

Let us examine variations of the observed phase and group velocities before discussing the inversion results. In Tables $4-7$ the variances of the velocities are presented in terms of delay times $\left(\sigma_{b}\right)$ for each of the four data sets. From the tables we see that the observed variances are at least three times as large as the errors estimated in the previous sections as associated with our single-station velocity measurements. Therefore, we can expect that our inversion results are expansions of velocity variations, not expansions of the errors.

Figs 3-6 show variance reductions attained by the inversions of four data sets. The variance reduction $V R$ is defined as $V R=\left(\sigma_{b}^{2}-\sigma_{a}^{2}\right) / \sigma_{b}^{2}$, where $\sigma_{b}^{2}$ and $\sigma_{a}^{2}$ are the variances before and after the inversions. $\sigma_{b}$ are listed in Tables $4-7$. We notice several features of

Table 4. Spherically symmetric average Love wave phase velocity.

\begin{tabular}{|c|c|c|c|c|}
\hline $\begin{array}{l}\text { Period } \\
\text { (sec) }\end{array}$ & $\begin{array}{c}\mathrm{C}_{00} \\
(\mathrm{~km} / \mathrm{sec})\end{array}$ & $\begin{array}{l}\mathrm{C}_{00^{-}} \mathrm{C}_{\text {PREM }} \\
(\mathrm{km} / \mathrm{sec})\end{array}$ & $\begin{array}{c}\sigma\left(\mathrm{c}_{\mathrm{OO}}\right) \\
(\mathrm{km} / \mathrm{sec})\end{array}$ & $\begin{array}{c}\sigma_{b}^{*} \\
(\mathrm{sec})\end{array}$ \\
\hline 333.33 & 5.3360 & 0.0002 & 0.0021 & 46.528 \\
\hline 285.71 & 5.1826 & -0.0008 & 0.0014 & 36.122 \\
\hline 250.00 & 5.0713 & 0.0005 & 0.0012 & 34.008 \\
\hline 222.22 & 4.9867 & 0.0011 & 0.0012 & 36.534 \\
\hline 200.00 & 4.9195 & 0.0004 & 0.0011 & 35.758 \\
\hline 181.82 & 4.8656 & -0.0007 & 0.0010 & 36.883 \\
\hline 166.67 & 4.8214 & -0.0017 & 0.0011 & 38.971 \\
\hline 153.85 & 4.7851 & -0.0022 & 0.0011 & 40.525 \\
\hline 142.86. & 4.7545 & -0.0025 & 0.0011 & 41.712 \\
\hline 133.33 & 4.7285 & -0.0027 & 0.0011 & 42.857 \\
\hline 125.00 & 4.7061 & -0.0026 & 0.0012 & 44.636 \\
\hline 117.65 & 4.6867 & -0.0026 & 0.0012 & 46.136 \\
\hline 111.11 & 4.6693 & -0.0022 & $0.0013^{\circ}$ & 47.906 \\
\hline 105.26 & 4.6542 & -0.0017 & 0.0013 & 50.511 \\
\hline 100.00 & 4.6405 & -0.0015 & 0.0014 & 51.675 \\
\hline
\end{tabular}


Table 5. Spherically symmetric average Rayleigh wave phase velocity.

\begin{tabular}{|c|c|c|c|c|}
\hline $\begin{array}{l}\text { Period } \\
\text { (sec) }\end{array}$ & $\begin{array}{c}\mathrm{C}_{00} \\
(\mathrm{~km} / \mathrm{sec})\end{array}$ & $\begin{array}{c}\mathrm{C}_{00^{-}} \mathrm{C}_{\text {PREM }} \\
(\mathrm{km} / \mathrm{sec})\end{array}$ & $\begin{array}{c}\sigma\left(c_{00}\right) \\
(\mathrm{km} / \mathrm{sec})\end{array}$ & ${ }^{\sigma_{b}}{ }^{\star}$ \\
\hline $\begin{array}{l}333.33 \\
285.71 \\
250.00 \\
222.22 \\
200.00 \\
181.82 \\
166.67 \\
152.85 \\
142.86 \\
133.33 \\
125.00 \\
117.65 \\
111.11 \\
165.26 \\
100.00\end{array}$ & $\begin{array}{l}5.5257 \\
5.1853 \\
4.9187 \\
4.7217 \\
4.5764 \\
4.4679 \\
4.3846 \\
4.3201 \\
4.2678 \\
4.2259 \\
4.1960 \\
4.1610 \\
4.1370 \\
4.1155 \\
4.0973\end{array}$ & $\begin{array}{r}-0.0015 \\
0.0008 \\
0.0006 \\
0.0003 \\
0.0000 \\
0.0002 \\
0.0006 \\
0.0622 \\
0.0027 \\
0.9035 \\
0.0059 \\
0.0061 \\
0.0080 \\
0.0083 \\
0.0092\end{array}$ & $\begin{array}{l}0.0013 \\
0.0097 \\
0.0006 \\
0.0005 \\
0.0005 \\
0.0005 \\
0.0006 \\
0.0006 \\
0.0006 \\
0.0005 \\
0.0037 \\
0.0007 \\
0.0008 \\
0.0009 \\
0.0010\end{array}$ & $\begin{array}{l}32.211 \\
23.133 \\
24.635 \\
23.522 \\
24.793 \\
28.030 \\
30.122 \\
31.835 \\
34.054 \\
35.348 \\
37.224 \\
39.128 \\
42.431 \\
48.215 \\
51.297\end{array}$ \\
\hline
\end{tabular}

Table 6. Spherically symmetric average Love wave group velocity.

\begin{tabular}{|c|c|c|c|c|}
\hline $\begin{array}{l}\text { Period } \\
\text { (sec) }\end{array}$ & $\begin{array}{c}\mathrm{U}_{00} \\
(\mathrm{~km} / \mathrm{sec})\end{array}$ & $\begin{array}{c}\mathrm{U}_{00^{-U}}{ }_{\text {PREM }} \\
(\mathrm{km} / \mathrm{sec})\end{array}$ & $\begin{array}{c}\sigma\left(\mathrm{U}_{00}\right) \\
(\mathrm{kmo} / \mathrm{sec})\end{array}$ & $\begin{array}{c}\sigma_{b}^{\star} \\
\left(\sec ^{\star}\right)\end{array}$ \\
\hline $\begin{array}{l}160.00 \\
108.78 \\
118.34 \\
128.73 \\
140.04 \\
152.34 \\
165.72 \\
180.28 \\
196.11 \\
213.34 \\
232.08 \\
252.46 \\
274.63 \\
298.76 \\
325.00\end{array}$ & $\begin{array}{l}4.3870 \\
4.3866 \\
4.3849 \\
4.3851 \\
4.3854 \\
4.3453 \\
4.3355 \\
4.3852 \\
4.3955 \\
4.3874 \\
4.3837 \\
4.3917 \\
4.3968 \\
4.4848 \\
4.4173\end{array}$ & $\begin{array}{r}0.0071 \\
0.0040 \\
0.0009 \\
0.0001 \\
0.0304 \\
0.0009 \\
0.0019 \\
0.0031 \\
0.0045 \\
0.0959 \\
0.0056 \\
0.0052 \\
0.0331 \\
-0.0014 \\
-0.0388\end{array}$ & $\begin{array}{l}0.0022 \\
0.0019 \\
0.0018 \\
0.0017 \\
0.0016 \\
0.0015 \\
0.0015 \\
0.0015 \\
0.0015 \\
0.0016 \\
0.0017 \\
0.0019 \\
0.0023 \\
0.0033 \\
0.0041\end{array}$ & $\begin{array}{l}101.67 \\
69.254 \\
85.316 \\
80.836 \\
76.758 \\
73.542 \\
71.025 \\
70.567 \\
26.796 \\
71.749 \\
76.204 \\
61.913 \\
93.573 \\
113.73 \\
147.05\end{array}$ \\
\hline
\end{tabular}

Table 7. Spherically symmetric average Rayleigh wave group velocity.

\begin{tabular}{|c|c|c|c|c|}
\hline $\begin{array}{l}\text { Period } \\
\text { (sec) }\end{array}$ & $\begin{array}{c}\mathrm{U}_{00} \\
(\mathrm{~km} / \mathrm{sec})\end{array}$ & $\begin{array}{c}\mathrm{U}_{00}{ }^{-\mathrm{U}_{\text {PREM }}} \\
(\mathrm{km} / \mathrm{sec})\end{array}$ & $\begin{array}{c}\sigma\left(\mathrm{u}_{00}\right) \\
(\mathrm{km} / \mathrm{sec})\end{array}$ & $\begin{array}{c}\sigma_{b}^{k} \\
(s e c)\end{array}$ \\
\hline $\begin{array}{l}100.00 \\
108.78 \\
118.34 \\
128.73 \\
146.04 \\
152.34 \\
165.72 \\
160.28 \\
196.11 \\
213.34 \\
232.08 \\
252.46 \\
274.63 \\
298.76\end{array}$ & $\begin{array}{l}\text { 3.7861 } \\
3.7696 \\
3.7460 \\
3.7236 \\
3.6967 \\
3.6743 \\
3.6485 \\
3.6226 \\
3.5996 \\
3.5791 \\
3.5710 \\
\text { 3.5837 } \\
\text { 3.6334 } \\
3.7316\end{array}$ & $\begin{array}{l}0.0352 \\
0.0331 \\
0.0291 \\
0.0229 \\
0.0175 \\
0.0129 \\
0.0089 \\
0.0061 \\
0.0046 \\
0.6031 \\
0.0632 \\
0.0630 \\
0.0059 \\
0.0106\end{array}$ & $\begin{array}{l}0.0022 \\
0.0018 \\
0.0016 \\
0.0014 \\
0.0612 \\
0.0011 \\
0.0010 \\
0.0009 \\
0.0009 \\
0.0009 \\
0.0010 \\
0.0010 \\
0.0014 \\
0.0022\end{array}$ & $\begin{array}{l}110.86 \\
100.31 \\
93.969 \\
84.549 \\
78.842 \\
72.521 \\
65.016 \\
62.885 \\
62.897 \\
61.958 \\
65.887 \\
65.511 \\
78.548 \\
108.76\end{array}$ \\
\hline
\end{tabular}

the results. Adding $l=$ odd terms is less effective in improving the inversions than adding $l=$ even terms. This is expected from the form of (26), which shows that the even harmonics are more constrained by observations than are the odd harmonics. The best earthquakestation combination is obtained for an epicentral distance of $90^{\circ}$. Even for this case, the even harmonics are better constrained than the odd harmonics. This poor constraint on odd harmonics leads to large standard deviations of the solution coefficients of these harmonics. The increase of $L$ from 6 does not improve the inversions. This is expected from the smaller 


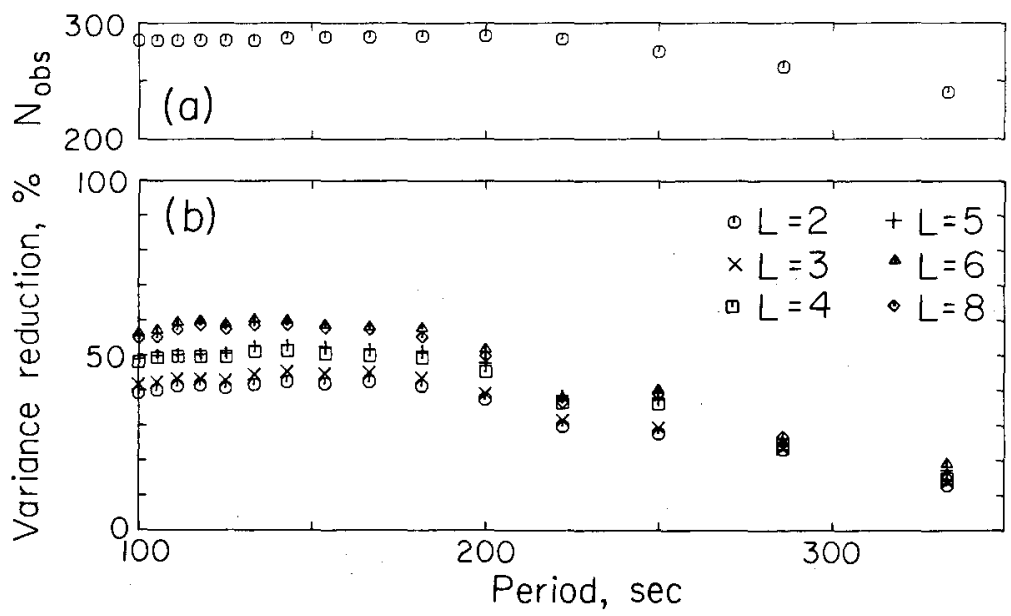

Figure 3. Results of spherical harmonic inversion of Love wave phase velocities. (a) Number of data. (b) Variance reduction (per cent). Symbol conventions are indicated in the figure.

contribution of the odd harmonics and the results, even harmonics inversions, of Paper I, where $L=8$ does not improve the inversions over $L=6$. The variance reduction in this paper is smaller than in Paper I for both Love and Rayleigh wave phase velocities. In the even harmonics inversions the maximum variance reduction is about 70 and 90 per cent for Love and Rayleigh waves, respectively. In Figs 3 and 4, the maximum variance reduction is about 60 and 70 per cent, respectively. This decrease in the variance reduction must be caused by inconsistencies of the phase velocities obtained by the single-station method.

In Figs 3-6 the variance reduction starts to decrease at a period of about $200 \mathrm{~s}$. Here we point out several possible sources of this decrease. One is the relative increase of the errors expected in the velocity measurements with respect to real lateral velocity variations. We expect smaller lateral variations at longer periods than at shorter periods. In the previous section we estimated errors associated with our velocity measurements. Our estimated values

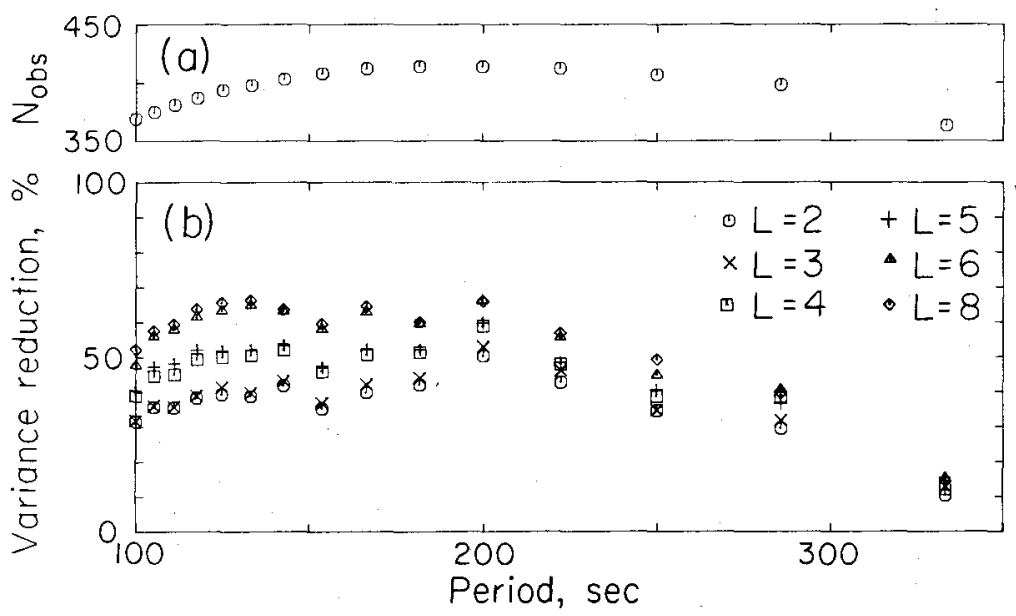

Figure 4. Results of spherical harmonic inversion of Rayleigh wave phase velocities. (a) Number of data. (b) Variance reduction (per cent). 


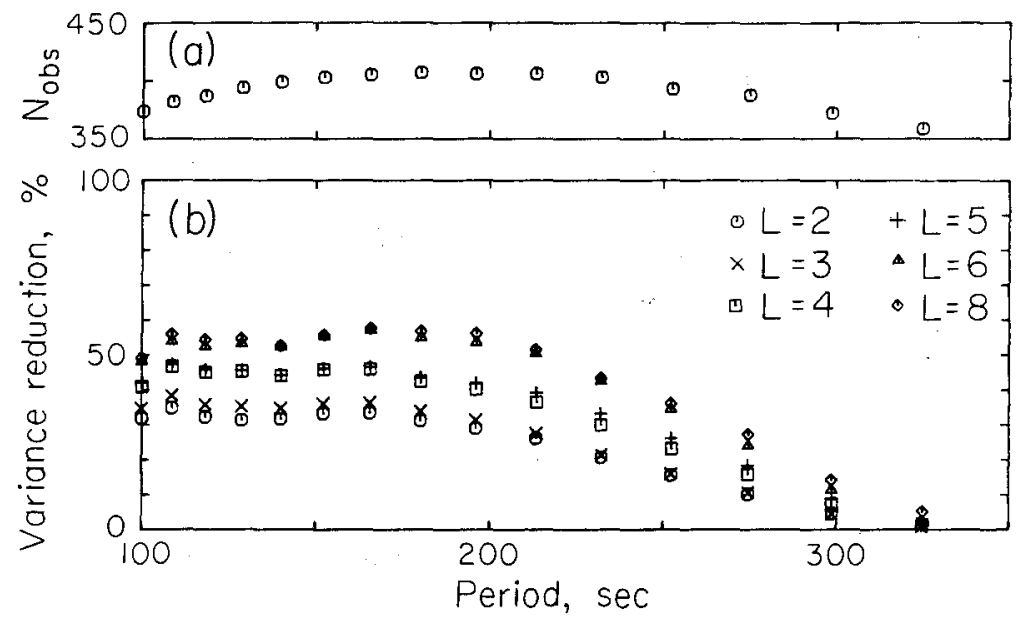

Figure 5. Results of spherical harmonic inversion of Love wave group velocities. (a) Number of data. (b) Variance reduction (per cent).

are independent of the period. Some of the errors, in particular source finiteness and source mechanism, might be frequency-dependent. Although the consistency between $P$-wave first motion and long-period (250 s) Rayleigh wave spectra (Nakanishi \& Kanamori 1984) suggests that the effect of the possible frequency-dependent source process is not strong (at least for the earthquakes used here) we cannot rule out this possibility. If the error in the source mechanism is constant, in terms of parts of cycle, the errors in phase or group delay increase linearly with increasing period. Another possibility comes from the zerothorder polar phase shift in equations (1)-(4), which has been used in the surface wave analyses since Brune et al.'s (1961) paper. The error in the zeroth-order approximation increases with the increase of wave periods and with the decrease of distance between
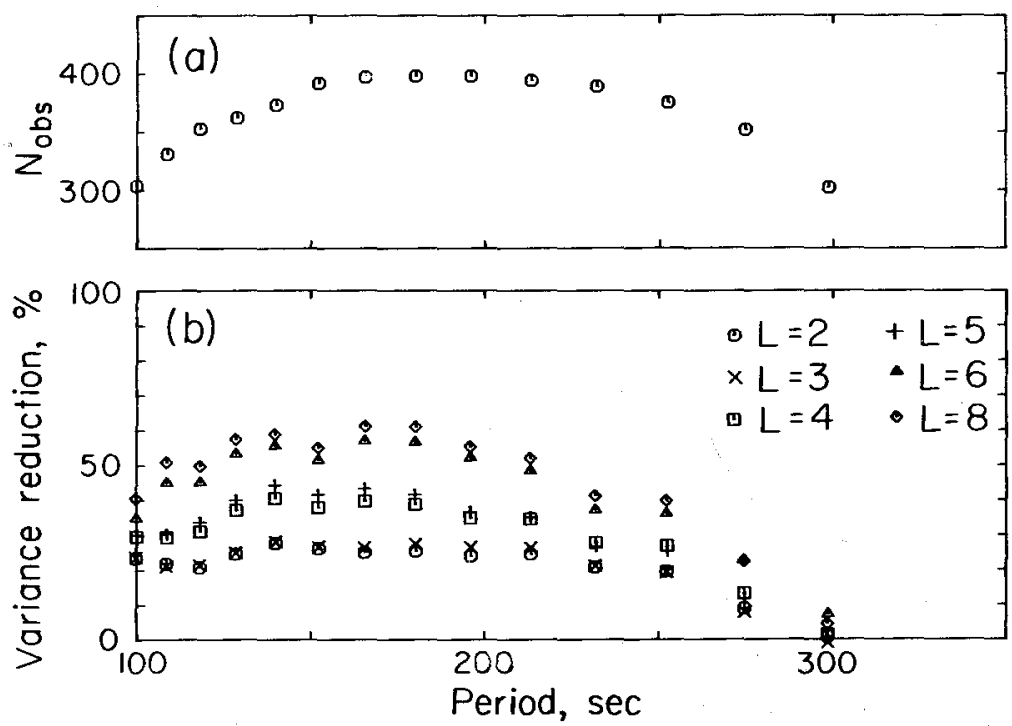

Figure 6. Results of spherical harmonic inversion of Rayleigh wave group velocities. (a) Number of data. (b) Variance reduction (per cent). 
Table 8. $A_{l m}$ and $B_{l m}$ for Love wave phase slowness.

PERIOD(SEC)

A10

A 11

B 11

A20

A2 1

B2 1

A22

B22

$\mathbf{A 3 0}$

A31

B3 1

A32

B92

A33

B33

A40

A4 1

B41 1

A42

B42

A43

B43

A44

B44

Ase

As 1

B5 1

A52

B52

A53

B53

A54

B54

A55

B55

A60

A61

B61

A62

B62

A63

B63

A64

B64

A65

B65

A66

B66

$\begin{array}{lllll}285.71 & 250.00 & 290.00 & 166.67 & 142.86\end{array}$

$125.00 \quad 111.11 \quad 100.00$

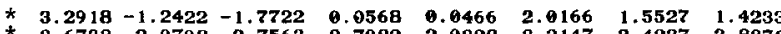
$\begin{array}{llllllll}3.6738 & 2.9798 & 2.7563 & 2.7982 & 2.9328 & 3.2147 & 3.4237 & 3.6376\end{array}$ $1.9656-7.9005-5.0436-2.7454-1.1320-0.4207-1.2454-1.8462$ $\begin{array}{lllllllll}\mathbf{4} .6885 & \mathbf{3 . 6 7 4 7} & \mathbf{3} .3256 & \mathbf{3} .3766 & \mathbf{3 . 5 3 9 9} & \mathbf{3 . 8 5 3 6} & \mathbf{4 . 1 0 4 2} & \mathbf{4} .6003\end{array}$

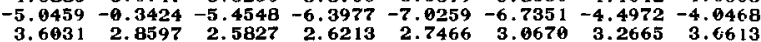

$\begin{array}{lllllllll}-0.7926 & 4.2630 & 1.2168 & -1.3867 & -2.8059 & -4.0670 & -0.8934 & 0.1228\end{array}$ $\begin{array}{llllllll}4.2546 & 3.4809 & 3.2299 & 3.2983 & 3.4632 & 3.7638 & 4.0086 & 4.4931\end{array}$ $0.6861 \quad 2.8059 \quad 0.0045-1.9889-1.9383-2.1173-1.3824 \quad 0.1114$ $\begin{array}{llllllll}1.9987 & 1.6192 & 1.4812 & 1.5188 & 1.5937 & 1.7383 & 1.8513 & 2.0751\end{array}$ $\begin{array}{llllllll}2.8223 & -0.0137 & \mathbf{3 . 8 1 6 5} & \mathbf{5 . 7 5 3 8} & \mathbf{7 . 3 7 2 9} & \mathbf{7 . 9 9 8 3} & \mathbf{6 . 6 7 3 7} & \mathbf{9 . 5 3 0 8}\end{array}$ $\begin{array}{llllllll}1.7624 & 1.4479 & 1.3427 & 1.3627 & 1.4280 & 1.5575 & 1.6588 & 1.6593\end{array}$ $\begin{array}{rrrrrrrr}-4.4574 & -7.6572 & -6.1488 & -5.9128 & -5.2586 & -5.8984 & -8.6920-16.7254 \\ 3.8103 & 2.9203 & 2.5950 & 2.6337 & 2.7629 & 3.0020 & 3.1972 & 3.5836\end{array}$ $\begin{array}{llllllll}\mathbf{3 . 8 4 9 9} & \mathbf{4 . 8 2 9 4} & \mathbf{2 . 5 4 4 6} & \mathbf{3 . 1 7 1 9} & \mathbf{3 . 6 1 5 5} & 1.6029 & \mathbf{2 . 0 6 5 6} & \mathbf{2 . 5 6 1 8}\end{array}$ $\begin{array}{llllllll}2.6355 & 1.5426 & 1.3289 & 1.3495 & 1.4141 & 1.5379 & 1.6379 & 1.8358\end{array}$

$-4.9618-5.1343-1.2689 \quad 3.0586 \quad 0.3739-2.8671-3.0919-3.4915$ $\begin{array}{llllllll}4.3462 & 3.5763 & 3.2511 & 3.3248 & 3.5160 & 3.8704 & 4.1221 & 4.6204\end{array}$ $0.6511-0.7155-1.5662-1.3618-1.6093-3.0603-2.7828-0.3127$ $\begin{array}{llllllll}\mathbf{4} .5828 & \mathbf{3} .4622 & \mathbf{3 . 2 0 2 5} & \mathbf{3 . 2 5 9 6} & \mathbf{3 . 4 1 5 5} & \mathbf{3 . 7 1 8 2} & \mathbf{3 . 9 5 9 9} & \mathbf{4 . 4 3 8 6}\end{array}$

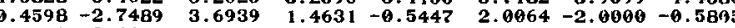
$\begin{array}{llllllll}4.5893 & 3.6693 & \mathbf{3 . 3 7 5 4} & \mathbf{3 . 4 2 6 4} & \mathbf{3 . 5 9 5 9} & \mathbf{3 . 9 8 3 1} & \mathbf{4 . 2 4 2 1} & \mathbf{4 . 7 5 4 9}\end{array}$ $-5.7777-2.4170-2.6291-5.8313-9.1982-6.1587-7.4751-6.4239$

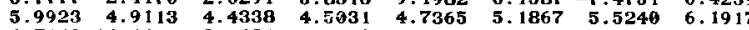
-6.7149-14.1491 -2.1621 $-2.3398-1.4466 \quad 0.8529 \quad 0.6088 \quad 0.8294$ $\begin{array}{rrrrrrrrr}5.5402 & 4.4923 & 4.6693 & 4.1293 & \mathbf{4 . 3 2 8 8} & \mathbf{4 . 7 4 2 5} & \mathbf{5 . 0 5 0 8} & \mathbf{5 . 6 6 1 4}\end{array}$ $\begin{array}{rlllllll}-3.485 \% & 0.8708 & 12.0245 & 11.5167 & 8.1427 & 9.2668 & 6.8385 & 8.1150\end{array}$ $\begin{array}{rrrrrrrrr}7.9949 & 6.5545 & 6.0066 & 6.0993 & 6.4031 & 5.9824 & 7.4364 & 8.3354\end{array}$ $\begin{array}{rrrrrrrr}6.3011 & 3.9484 & 9.0553 & 9.5407 & 13.9988 & 11.9646 & 9.6412 & 12.3828 \\ 6.0437 & 4.6503 & 4.1258 & 4.2093 & 4.4212 & 4.8023 & 5.1146 & 5.7328\end{array}$

$-3.1037-4.5387-4.1152-3.3482-2.5466-0.9590-2.6393-3.0439$ $\begin{array}{lllllllll}3.9046 & 3.0616 & 2.6794 & 2.7410 & 2.8729 & 3.1243 & 3.3274 & 3.7296\end{array}$ $\begin{array}{llllllll}-5.1438 & -5.4958 & -5.3661 & -6.7395 & -6.5482 & -5.4068 & -6.5172 & -7.1363\end{array}$ $\begin{array}{lllllllll}3.1196 & 2.3936 & 2.2243 & 2.3144 & 2.4491 & 2.6653 & 2.8386 & 3.1817\end{array}$ $\begin{array}{llllllll}-0.4820 & 0.4352 & -7.2012 & -4.8866 & -5.6024 & -7.3820 & -6,1005 & -5.6527\end{array}$ $\begin{array}{llllllll}\mathbf{3 . 3 4 7 5} & 2.6162 & 2.3899 & 2.4288 & 2.5480 & 2.7747 & 2.9551 & \mathbf{3 . 3 1 2 3}\end{array}$ $\begin{array}{llllllll}-0.1465 & 1.2340 & 0.2276 & 0.0274 & 0.1902 & -0.3220 & -1.4442 & -2.9623\end{array}$ $\begin{array}{llllllll}2.7846 & 2.1685 & 1.9785 & 2.0166 & 2.1120 & 2.3111 & 2.4614 & 2.7589\end{array}$ $\begin{array}{llllllll}-0.1035 & 0.2156 & -2.1241 & -1.5262 & -0.4378 & -0.6256 & -1.6037 & -2.6878\end{array}$ $\begin{array}{llllllll}2.1139 & 1.6695 & 1.4553 & 1.4777 & 1.5505 & 1.6872 & 1.7969 & 2.0142\end{array}$ $\begin{array}{llllllll}0.3603 & 1.2923 & 1.4736 & 2.9888 & 4.2576 & 5.6072 & 6.18 A 2 & 6.7991\end{array}$ $\begin{array}{lllllllll}1.9687 & 1.5793 & 1.4407 & 1.4622 & 1.5322 & 1.6706 & 1.7786 & 1.9936\end{array}$ $\begin{array}{lllllllll}-0.5894 & -2.5292 & 1.2574 & 0.6201 & 0.8416 & 0.8080 & 0.9176 & 0.6365\end{array}$ $\begin{array}{rrrrrrrr}1.9383 & 1.4209 & 1.2948 & 1.3144 & 1.3776 & 1.5071 & 1.6051 & 1.7992\end{array}$ $-1.3830 \quad 1.6184-0.9614-3.2936-3.4894-2.5707-1.6517-1.4689$

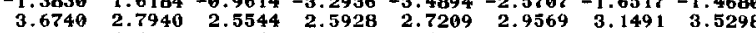
$-3.9945-6.6603-5.5386-4.0936-4.4480-3.8412-2.8791-3.3351$

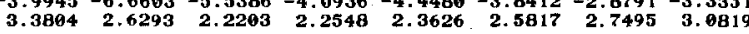

$\begin{array}{rllllllll}-1.5554 & 6.1079 & 9.0299 & 5.693 B & 3.4906 & 2.5730 & 2.1067 & 6.0536\end{array}$ $\begin{array}{lllllllll}5.8052 & 4.5783 & 4.1694 & 4.2916 & 4.5129 & 5.0879 & 5.4187 & 6.0737\end{array}$ $3.6360-6.6750-6.0420-8.2839-10.2702-7.1463-8.5814-10.7162$ $\begin{array}{llllllllll}6.3969 & 5.0116 & 4.5841 & 4.6578 & 4.8443 & 5.3049 & 5.6499 & 6.3328\end{array}$ $0681-2.3562-3.8778-6.6051-3.9575-3.1080-1.8960-3.8182$ $\begin{array}{llllllll}4.9453 & 4.0716 & 3.7738 & 3.8322 & 4.0342 & 4.4239 & 4.7116 & 5.2811\end{array}$ $\begin{array}{rlllllll}-0.6605 & -1.2655 & 3.0055 & 4.3181 & 2.6317 & 4.6893 & 6.7561 & 6.189\end{array}$ $5.91124 .7181 \quad 4.3179 \quad 4.38414 .6026 \quad 4.9992 \quad 3242 \quad 5.9679$ $\begin{array}{rrrrrrrr}5.9112 & 4.7181 & 4.3179 & 4.3841 & 4.6026 & 4.9992 & 5.3242 & 5.9679\end{array}$ $\begin{array}{llllllll}7.7836 & 2.0164 & -3.2217 & -6.5465 & -1.1820 & -0.6150 & -0.2566 & 1.8569\end{array}$ $\begin{array}{rrrrrrrrr}6.4839 & 5.1955 & 4.7890 & 4.8615 & 5.1166 & 5.5680 & 5.9300 & 6.6468\end{array}$ $\begin{array}{lllllllll}1.6465 & 9.9544 & \mathbf{6 . 9 4 6 6} & 7.6410 & 10.6401 & 6.8906 & 6.2037 & 5.7822\end{array}$ $\begin{array}{rllllllll}5.9350 & 4.8557 & 4.3525 & 4.4261 & 4.6645 & 5.1135 & 5.4459 & 6.1042\end{array}$ $\begin{array}{llllllll}15.2297 & 7.2898 & -3.1137 & -1.6450 & 4.6212 & 4.5279 & 2.6370 & -0.0515\end{array}$ $\begin{array}{lllllllll}0.5235 & 5.3103 & 4.8002 & 4.8730 & 5.1138 & 5.6002 & 5.9643 & 6.6853\end{array}$ $1.9893-1.2628-9.2318-8.8873-7.1678-10.1216-9.2953-16.0568$ $\begin{array}{rrrrrrrrr}7.7977 & 6.2611 & 5.6849 & 5.7779 & 6.0812 & 6.6117 & 7.0416 & \mathbf{7 . 6 9 2 8}\end{array}$ $\begin{array}{lllllllll}13.3779 & 9.4248 & 4.9276 & 1.3850 & 2.9962 & 7.2831 & 6.7161 & 7.4245\end{array}$ $\begin{array}{llllllll}6.3644 & 4.9996 & 4.4038 & 4.4778 & 4.6936 & 5.1274 & 5.4608 & 6.1209\end{array}$ $0.6145-6.6723-9.6981-7.8369-9.1457-10.6660-8.7158-11.9393$ $9.6133 \quad 7.62146 .75486 .8585 \quad 7.1879 \quad 7.8081 \quad 8.3158 \quad 9.3210$ $\begin{array}{crrrrrrr}-3.4778-13.6312 & -6.6428 & -6.8911 & -8.7879 & -4.7581 & -3.6729 & -5.6456 \\ 7.6126 & 5.8684 & 5.6847 & 5.1881 & 5.4598 & 5.9353 & 6.3212 & 7.0854\end{array}$

$\begin{array}{llllllll}-4.0086 & -1.0602 & 1.1666 & 0.5216 & -1.0871 & -0.9654 & 0.1539 & 0.7057\end{array}$ $\begin{array}{llllllll}2.8878 & 2.3138 & 2.1197 & 2.1537 & 2.2568 & 2.4784 & 2.6396 & 2.9587\end{array}$

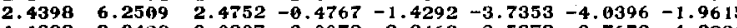
$\begin{array}{llllllll}4.1328 & 3.3438 & 3.0307 & 3.0972 & 3.2463 & 3.5372 & \mathbf{3 . 7 6 7 2} & \mathbf{4 . 2 2 2 6}\end{array}$ $\begin{array}{lllllllll}\mathbf{2} .3861 & 1.4926 & 2.7807 & 3.2815 & 5.5298 & \mathbf{7 . 4 3 0 2} & \mathbf{7 . 6 5 2 8} & \mathbf{5 . 9 8 B 3}\end{array}$ $\begin{array}{llllllll}\mathbf{2} .6933 & 2.2334 & 2.0810 & 2.1175 & 2.2240 & 2.4443 & 2.6032 & 2.9179\end{array}$ $\begin{array}{llllllll}-0.3635 & -2.2187 & 0.9795 & 1.8043 & 2.3429 & 2.7296 & 2.4030 & 1.205\end{array}$ $\begin{array}{lllllllll}\mathbf{3 . 5 5 7 2} & 2.7717 & \mathbf{2 . 4 9 5 2} & \mathbf{2 . 5 4 8 1} & \mathbf{2} .6714 & 2.9115 & \mathbf{3} .1008 & \mathbf{3 . 4 7 5 6}\end{array}$ $\begin{array}{llllllll}-2.6117 & -1.9994 & 2.8673 & 1.0209 & 2.5598 & 3.2748 & 2.1189 & 2.6652\end{array}$ $\begin{array}{llllllll}3.0531 & 2.3866 & 2.1572 & 2.1899 & 2.2965 & 2.4965 & 2.6599 & 2.9814\end{array}$ $\begin{array}{llllllll}-1.5221 & -2.7633 & 1.4355 & 3.0860 & 1.9628 & 2.6997 & 4.2341 & 5.4499\end{array}$ $\begin{array}{llllllll}2.4116 & 1.9996 & 1.8440 & 1.8748 & 1.9682 & 2.1476 & 2.2872 & 2.5637\end{array}$ $-4.7685-2.6535-2.6762-4.1182-3.4349-4.4906-5.2132-5.1187$ $\begin{array}{llllllll}2.4837 & 1.9016 & 1.6879 & 1.7142 & 1.7974 & 1.9580 & 2.0853 & 2.337\end{array}$ $-2.2170 \quad 0.6999-0.9060-0.3823-1.2077-0.93710 .8955 \quad 1.4382$ $\begin{array}{llllllll}2.7066 & 2.1552 & 1.9596 & 1.9919 & 2.0916 & 2.2763 & 2.4243 & 2.7174\end{array}$ $-2.2483-2.6772-4.8047-6.1230-7.3868-7.9220-7.6950-7.5935$ $\begin{array}{llllllll}2.1328 & 1.6921 & 1.5022 & 1.5253 & 1.6012 & 1.7525 & 1.8664 & 2.0920\end{array}$ $-2.2034-1.7097-3.6537-4.2802-5.5592-6.8234-7.7456-7.9100$ $\begin{array}{llllllll}2.0633 & 1.6294 & 1.4619 & 1.4844 & 1.5555 & 1.6898 & 1.7997 & 2.9173\end{array}$ $1.1265-1.7748-0.0464-0.0848 \quad 0.6333-0.2193-1.0823-2.3679$ $\begin{array}{llllllll}2.3204 & 1.8703 & 1.7041 & 1.7299 & 1.8136 & 1.9872 & 2.1164 & 2.3722\end{array}$

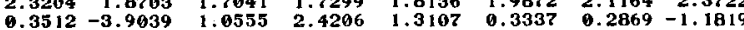
$\begin{array}{rrrrrrrrr}6.3512 & -3.9639 & 1.0555 & 2.4206 & 1.3107 & 0.3337 & 6.2869 & -1.1819 \\ \mathbf{3 . 1 8 1 3} & \mathbf{2 . 5 1 3 0} & 2.2183 & \mathbf{2} .2528 & \mathbf{2} .3638 & \mathbf{2 . 5 6 8 5} & \mathbf{2 . 7 3 5 5} & \mathbf{3 . 0 6 6 2}\end{array}$

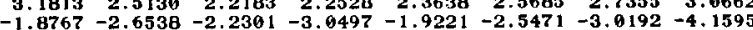

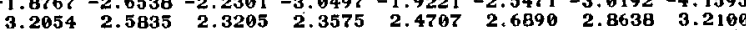
* The upper and lower values are $A_{l m}$ (or $B_{l m}$ ) and $\sigma A_{l m}$ (or $\sigma B_{l m}$ ) respectively.

$\star{ }^{\star} A_{l m}, \sigma A_{l m}, B_{l m}$ and $\sigma B_{l m}$ are $10^{-4} \mathrm{~s} \mathrm{~km}^{-1}$. 
Table 9. $A_{l m}$ and $B_{l m}$ for Ray leigh wave phase slowness.

$\begin{array}{lllllllll}\text { PERIOD(SEC) } & 285.71 & 250.00 & 200.00 & 166.67 & 142.86 & 125.00 & 111.11 & 100.00\end{array}$

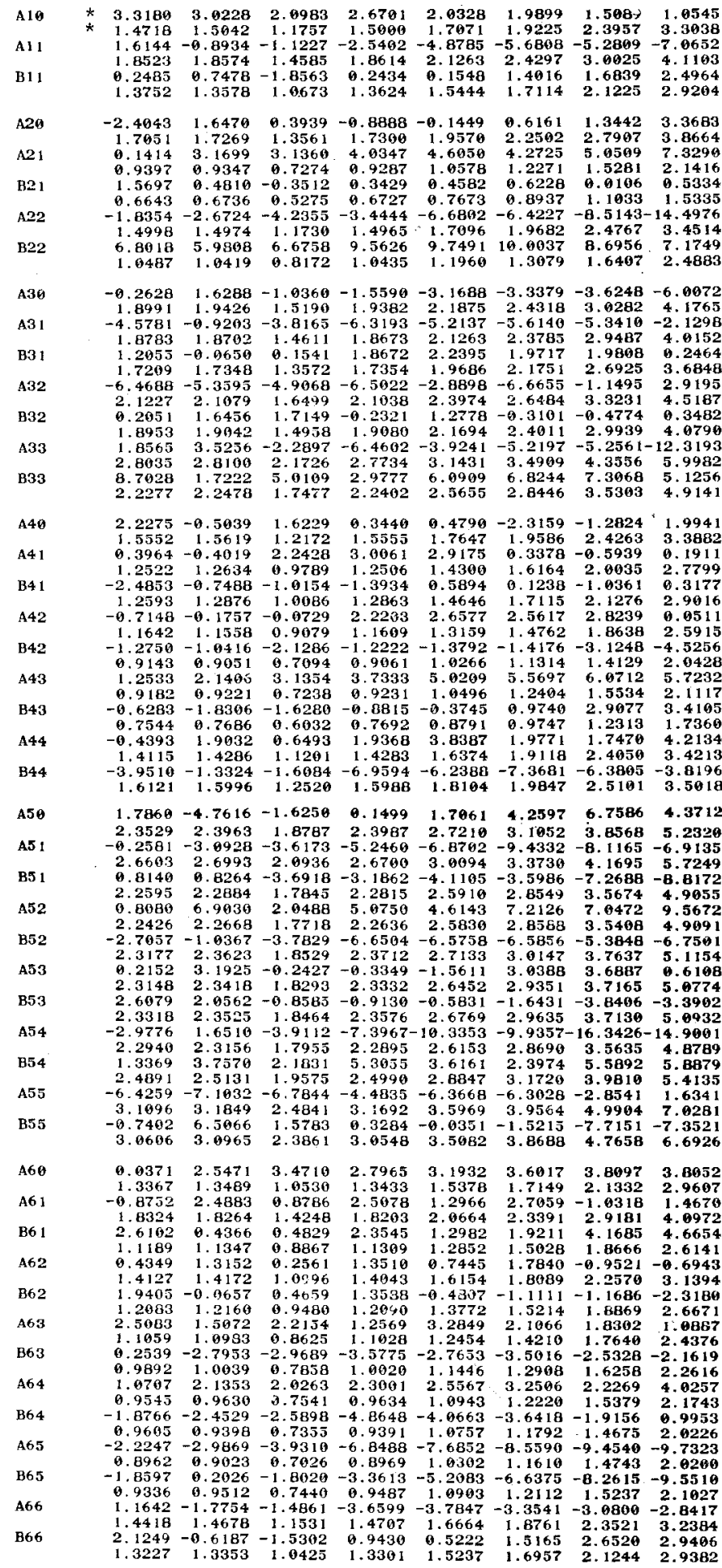

` The upper and lower values are $A_{I m}$ (or $B_{l m}$ ) and $\sigma A_{l m}$ (or $\sigma B_{l m}$ ), respectively.

$\star \star A_{l m}, \sigma A_{l m}, B_{l m}$ and $\sigma B_{l m}$ are $10^{-4} \mathrm{~s} \mathrm{~km}^{-1}$. 
Table 10. $A_{l m}$ and $B_{l m}$ for Love wave group slowness.

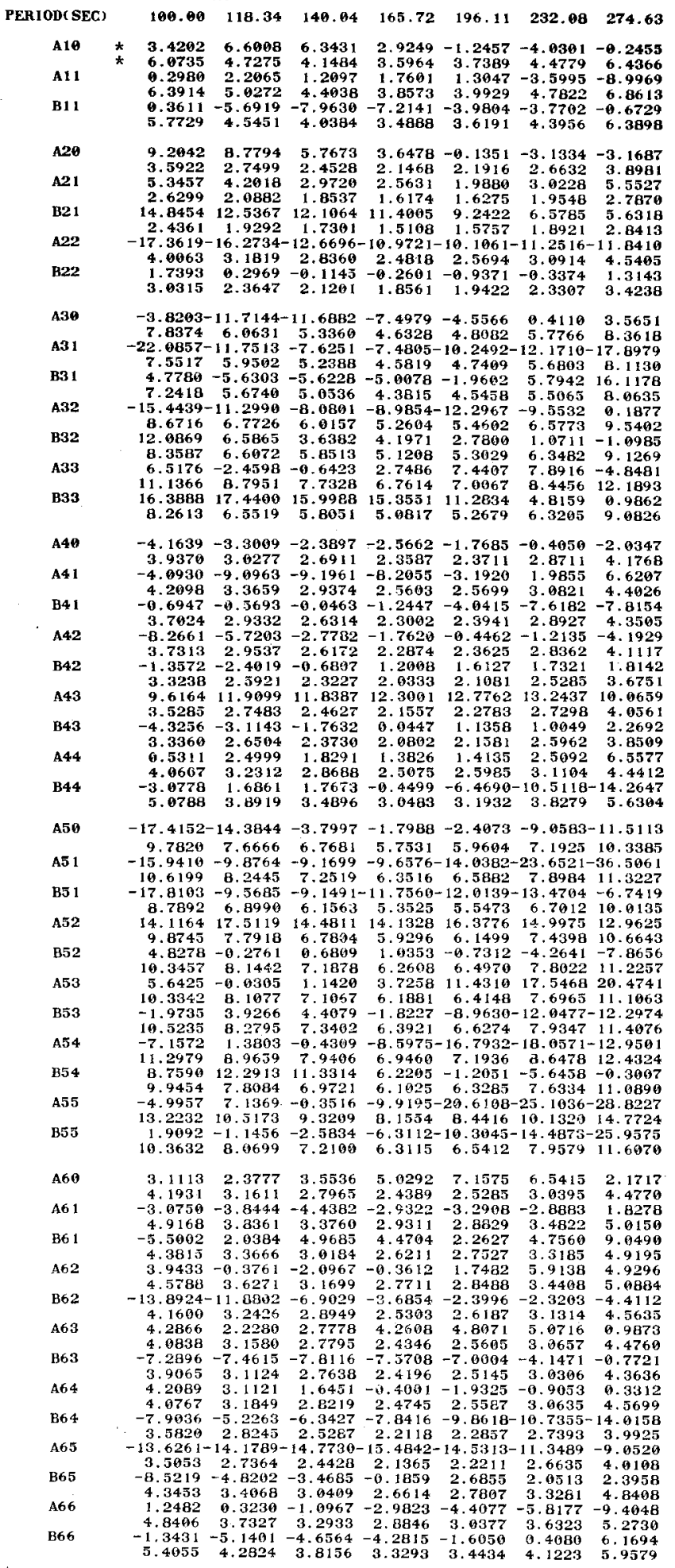

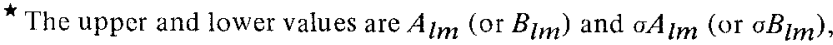
respectively.

${ }^{\star \star} A_{l m}, \sigma A_{l m}, B_{l m}$ and $\sigma B_{l m}$ are $10^{-4} \mathrm{~s} \mathrm{~km}^{-1}$. 
Table 11. $A_{l m}$ and $B_{l m}$ for Rayleigh wave group slowness.

$\begin{array}{llllllll}\text { PERIOD(SEC) } & 100.00 & 118.34 & 140.04 & 165.72 & 196.11 & 232.08 & 274.63\end{array}$

\begin{tabular}{|c|c|c|c|c|c|c|c|c|}
\hline A10 & & $\begin{array}{r}* .6911 \\
* \quad 8.4882\end{array}$ & $\begin{array}{l}3.3415 \\
6.1467\end{array}$ & $\begin{array}{l}3.3882 \\
4.4187\end{array}$ & $\begin{array}{l}2.0144 \\
3.5166\end{array}$ & $\begin{array}{l}1.3176 \\
\mathbf{3 . 6 0 1 5}\end{array}$ & $\begin{array}{r}-1.2825 \\
4.3473\end{array}$ & $\begin{array}{r}-7.3808 \\
6.1201\end{array}$ \\
\hline A.1 1 & & 16.9 & & 8.9595 & 11.3432 & -5.9017 & 2851 & -8.1270 \\
\hline B11 & & $\begin{array}{r}11.1527 \\
14.4336 \\
8.9812\end{array}$ & $\begin{array}{l}7.4549 \\
7.4421 \\
5.8568\end{array}$ & $\begin{array}{l}5.3482 \\
6.5309 \\
4.2390\end{array}$ & $\begin{array}{r}4.2178 \\
-0.7625 \\
3.2638 .\end{array}$ & $\begin{array}{r}4.3012 \\
-2.2329 \\
3.3467\end{array}$ & $\begin{array}{r}5.3674 \\
-0.9585 \\
4.0525\end{array}$ & $\begin{array}{l}7.3994 \\
7.9285 \\
5.5649\end{array}$ \\
\hline A20 & & $\begin{array}{r}-5.2696 \\
11.5479\end{array}$ & $\begin{array}{r}1.3390 \\
7.5303\end{array}$ & $\begin{array}{r}-1.7400 \\
5.0713\end{array}$ & $\begin{array}{r}-4.6145 \\
3.9616\end{array}$ & $\begin{array}{r}-8.8413 \\
4.0472\end{array}$ & $\begin{array}{r}-3.8354 \\
4.9132\end{array}$ & $\begin{array}{r}11.9286 \\
6.7672\end{array}$ \\
\hline A2 1 & & $\begin{array}{r}10.5281 \\
6.0487\end{array}$ & $\begin{array}{r}1.1459 \\
3.6896\end{array}$ & $\begin{array}{l}2.8602 \\
2.6678\end{array}$ & $\begin{array}{l}4.2667 \\
2.0899\end{array}$ & & $\begin{array}{l}8.5785 \\
2.6440\end{array}$ & $\begin{array}{l}4.4420 \\
3.7015\end{array}$ \\
\hline B2 1 & & $\begin{array}{r}17.0949 \\
4.6415\end{array}$ & $\begin{array}{l}6.3746 \\
2.9219\end{array}$ & $\begin{array}{l}2.9821 \\
1.9871\end{array}$ & & $\begin{array}{l}0.8358 \\
1.5610\end{array}$ & $\begin{array}{r}-1.354 B \\
1.9063\end{array}$ & $\begin{array}{r}-5.2350 \\
2.6739\end{array}$ \\
\hline A 22 & & $\begin{array}{r}-13.4796 \\
9.3671\end{array}$ & $\begin{array}{r}-7.1595 \\
6.4521\end{array}$ & $\begin{array}{r}-7.1548 \\
4.5571\end{array}$ & $\begin{array}{r}-2.8719 \\
3.5709\end{array}$ & $\begin{array}{l}2.0258 \\
3.6526\end{array}$ & $\begin{array}{r}-6.546- \\
4.4733\end{array}$ & $\begin{array}{r}-6.5597 \\
6.1655\end{array}$ \\
\hline $\mathrm{B22}$ & & $\begin{array}{r}19.0993 \\
6.8938\end{array}$ & $\begin{array}{r}10.3795 \\
4.6997\end{array}$ & $\begin{array}{r}11.7803 \\
3.1980\end{array}$ & $\begin{array}{r}12.6203 \\
2.4342\end{array}$ & $\begin{array}{r}16.8096 \\
2.4914\end{array}$ & $\begin{array}{r}15.7250 \\
3.0726\end{array}$ & $\begin{array}{l}8.9959 \\
4.3077\end{array}$ \\
\hline $\mathbf{A 3} 0$ & & $\begin{array}{r}-12.5 \\
11.5\end{array}$ & $\begin{array}{r}14.1 \\
7.9\end{array}$ & $\begin{array}{r}13.2534 \\
5.7578\end{array}$ & $\begin{array}{r}-7.7325 \\
4.5577\end{array}$ & & $\begin{array}{l}0.3956 \\
5.6320\end{array}$ & 4983 \\
\hline 3 & & $\begin{array}{r}5.3995 \\
11.7673\end{array}$ & $\begin{array}{r}-0.4398 \\
7.5874\end{array}$ & $\begin{array}{r}-7.4088 \\
5.5363\end{array}$ & $\begin{array}{r}-6.7813 \\
4.3675\end{array}$ & $\begin{array}{r}-4.3537 \\
4.4522\end{array}$ & $\begin{array}{r}-4.2315 \\
5.6057\end{array}$ & $\begin{array}{r}-4.5451 \\
7.8550\end{array}$ \\
\hline B31 & & $\begin{array}{r}-4.3686 \\
10.2689\end{array}$ & $\begin{array}{l}0.1810 \\
7.2564\end{array}$ & $\begin{array}{r}-2.0298 \\
5.2158\end{array}$ & $\begin{array}{l}2.7329 \\
4.1190\end{array}$ & $\begin{array}{l}4.6349 \\
4.1963\end{array}$ & $\begin{array}{l}3.7484 \\
5.1032\end{array}$ & $\begin{array}{r}-4.1041 \\
7.0549\end{array}$ \\
\hline 32 & & & 5.6374 & -4.0073 & -6.5 & -13.7267 & -5 & 038 \\
\hline 32 & & -25 & $\begin{array}{r}8 \\
-17\end{array}$ & $\begin{array}{l}6 . \\
-8 .\end{array}$ & 27 & 890 & 196 & $\begin{array}{l}97 \\
58\end{array}$ \\
\hline & & 12. & & & 4. & & & 17 \\
\hline A & & 8. & $\begin{array}{l}21.3 \\
11.7\end{array}$ & $\begin{array}{r}15.8304 \\
8.67+8\end{array}$ & $\begin{array}{l}4.5 \\
6.5\end{array}$ & $\begin{array}{r}-9 \\
6\end{array}$ & & $\begin{aligned}-11 \\
11\end{aligned}$ \\
\hline 33 & & 6.4 & $\begin{array}{r}19.2 \\
9.5\end{array}$ & $\begin{array}{r}13.4145 \\
6.9493\end{array}$ & $\begin{array}{r}12.2 \\
5.3\end{array}$ & $\begin{array}{l}7.1207 \\
5.4825\end{array}$ & $\begin{array}{l}7.9145 \\
6.7717\end{array}$ & $\begin{array}{r}-6.2016 \\
9.4954\end{array}$ \\
\hline & & $\begin{array}{r}-12.2281 \\
11.3826\end{array}$ & $\begin{array}{r}-6.0827 \\
6.6828\end{array}$ & & $\begin{array}{r}-6.5 \\
3.5\end{array}$ & $\begin{array}{r}-5.6 \\
3.8\end{array}$ & $\begin{array}{r}-1.5323 \\
4.5024\end{array}$ & \\
\hline & & $\begin{array}{r}-8.2079- \\
7.9540\end{array}$ & $\begin{array}{r}-18.6573 \\
4.9976\end{array}$ & $\begin{array}{r}-8.0734 \\
3.6515\end{array}$ & $\begin{array}{r}1.0 \\
2.8\end{array}$ & $\begin{array}{l}8.0662 \\
2.8696\end{array}$ & & $\begin{array}{r}-0.5874 \\
5.0548\end{array}$ \\
\hline B & & & $\begin{array}{l}6.2 \\
5.3\end{array}$ & $\begin{array}{r}-1 \\
3 .\end{array}$ & $\begin{array}{r}-5.8 \\
2.8\end{array}$ & -4 & & 12. \\
\hline A & & $\begin{array}{r}11.0848 \\
7.7773\end{array}$ & $\begin{array}{l}5.7474 \\
5.0832\end{array}$ & $\begin{array}{r}10.5 \\
3.6\end{array}$ & & & & -0 \\
\hline & & $\begin{array}{l}2.0661 \\
6.3674\end{array}$ & $\begin{array}{r}-0.8267 \\
3.8918\end{array}$ & $\begin{array}{r}-3.8085 \\
\text { 2.7600 }\end{array}$ & $\begin{array}{r}-4.7135 \\
2.1485\end{array}$ & $\begin{array}{r}-0.6835 \\
2.1905\end{array}$ & $\begin{array}{l}2.3630 \\
2.6966\end{array}$ & $\begin{array}{l}-1.8 \\
3 .\end{array}$ \\
\hline A45 & & & 19. & 16. & 10. & & & 11. \\
\hline & & & & & & & & \\
\hline & & $\begin{array}{r}-5.1155 \\
4.8572\end{array}$ & $\begin{array}{r}-1.5746 \\
3.3355\end{array}$ & $\begin{array}{r}1.0650 \\
2.4060\end{array}$ & $\begin{array}{l}9.7096 \\
1.8045\end{array}$ & $\begin{array}{l}898 \\
391\end{array}$ & & $\begin{array}{l}0.6366 \\
3.0817\end{array}$ \\
\hline & & $\begin{array}{r}10.2184 \\
0.5804\end{array}$ & $\begin{array}{l}0.8957 \\
6.0408\end{array}$ & $\begin{array}{r}1.1985 \\
4.4591\end{array}$ & $\begin{array}{r}-2.6891 \\
3.4567\end{array}$ & $\begin{array}{r}-4.5054 \\
3.5171\end{array}$ & $\begin{array}{l}76 \\
85\end{array}$ & $\begin{array}{l}0.5971 \\
5.9890\end{array}$ \\
\hline & & $\begin{array}{r}-26 . \\
10 .\end{array}$ & $\begin{array}{r}12.6 \\
6.8\end{array}$ & $\begin{array}{r}-19.7142- \\
4.7516\end{array}$ & $\begin{array}{r}-20.1386 \\
3.6661\end{array}$ & $\begin{array}{r}-21.1650 \\
3.7593\end{array}$ & $\begin{array}{r}-8.9270 \\
4.6419\end{array}$ & $\begin{array}{r}12.0884 \\
6.3720\end{array}$ \\
\hline
\end{tabular}

$\begin{array}{llll}12.6918 & 2.9787 & -0.2800 & -9.912 i\end{array}$ $\begin{array}{rlrr}-26.3369-11.3503-18.6765-22.6045 & 5.7158 & 6.9961 & 9.6976\end{array}$ $\begin{array}{lllllll}15.6867 & 11.0636 & \text { B. } 1887 & 6.5395 & 6.6681 & 8.1630 & 11.7289\end{array}$ $-6.0890-12.8326-4.7622-4.3152-4.4208-8.1413-12.7545$ $\begin{array}{llllllll}13.9022 & 9.6005 & 6.8762 & 5.3636 & 5.4528 & 6.6070 & 9.3804\end{array}$ $\begin{array}{lllllll}10.6038 & 11.6256 & \text { B.6821 } & \mathbf{5 . 0 9 9 3} & \mathbf{7 . 2 1 9 6} & 1.3885 & \mathbf{- 0 . 2 6 0 7}\end{array}$ $\begin{array}{llllllll}13.1368 & 9.1950 & 6.5966 & 5.2466 & 5.3591 & 6.6414 & 9.2098\end{array}$ $6.7686-4.0371-1.5676-10.3606-16.4853-12.2792$ 2.2920

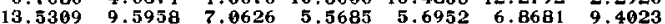
$\begin{array}{rlllllll}9.9505 & 2.5198 & 8.4314 & 8.1814 & 9.4339 & 2.5705 & -8.0941\end{array}$ $\begin{array}{rrrrrrr}\mathbf{9} .0728 & 9.9399 & \mathbf{7 . 3 2 8 8} & \mathbf{5 . 6 6 5 2} & \mathbf{5 . 7 8 8 5} & \mathbf{7 . 0 2 7 5} & \mathbf{9 . 8 5 1 7}\end{array}$ $9.8070 \quad 13.1452 \quad 3.7060-0.5335-3.7011 \quad 1.1504-1.4602$ $\begin{array}{lllllll}13.5074 & 9.7833 & 7.1502 & 5.6040 & 5.7158 & 6.9783 & 9.7293\end{array}$ $-25.5946-21.7701-18.7876-16.6228-10.5695-7.3753-10.9658$ $13.6694 \quad 9.37416 .8660 \quad 5.34315 .4579 \quad 6.7100 \quad 9.2362$ $\begin{array}{rrrrrrr}13.6694 & 9.3741 & 6.8660 & 5.3431 & 5.4579 & 6.7100 & 9.2362 \\ -5.7086 & .7249 & 3.5799 & 4.2490 & -0.9394 & -1.0768 & 7.7826\end{array}$ $\begin{array}{rrrrrrr}-5.7086 & 0.7249 & 3.5799 & 4.2490 & -0.9394 & -1.0768 & 7.7826 \\ 14.4017 & 10.2428 & 7.4581 & 5.8199 & 5.9047 & 7.1999 & 10.1397\end{array}$

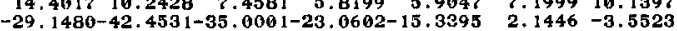

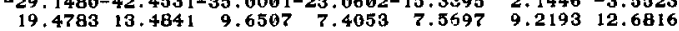

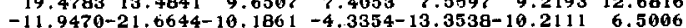

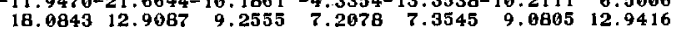

$\begin{array}{lllllllll}-2.2085 & 12.7659 & \text { B.3326 } & 4.4928 & 5.3932 & 19.1537 & 13.9177\end{array}$ $\begin{array}{rrrrrrr}-2.2085 & 12.7659 & 8.3326 & 4.4928 & 5.3932 & 19.1537 & 13.9177 \\ 9.2507 & \mathbf{5 . 8 3 1 8} & \mathbf{3 . 9 5 3 4} & 3.9276 & \mathbf{3 . 0 9 7 0} & \mathbf{3 . 8 1 3 7} & \mathbf{5 . 3 0 2 6}\end{array}$ $\begin{array}{rrrrrrrr}9.2507 & \mathbf{5} .8318 & \mathbf{3} .9534 & 3.6276 & \mathbf{3 . 0 9 7 0} & \mathbf{3 . 8 1 3 7} & \mathbf{5} .3026 \\ \mathbf{5} .9882 & -2.0403 & \mathbf{2} .8103 & 0.9516 & \mathbf{4} .1645 & \mathbf{6 . 7 0 7 2} & \mathbf{5 . 3 3 1 1} \\ 10.8813 & \mathbf{7 . 2 2 3 7} & \mathbf{5 . 3 6 3 0} & \mathbf{4} .1703 & \mathbf{4} .2406 & \mathbf{5 . 2 5 5 0} & \mathbf{7 . 2 9 4 9}\end{array}$ $\begin{array}{rrrrrrrr}16.4663 & 7.3337 & 3.4836 & 1.6997 & 6.3038 & 3.9779 & 0.4359 \\ 7.6267 & 4.7193 & \mathbf{3 . 2 2 7 2} & 2.5112 & 2.5442 & 3.0727 & 4.2666\end{array}$ $\begin{array}{rrrrrrr}7.6267 & 4.7193 & 3.2272 & 2.5112 & 2.5442 & 3.0727 & 4.2606 \\ 14.2381 & 5.5527 & 5.9314 & 5.6124 & 4.3295 & -3.8568-11.607\end{array}$ $\begin{array}{llllll}14.2381 & 5.5527 & 5.9314 & 5.6124 & 4.3295 & -3.8568-11.6072\end{array}$

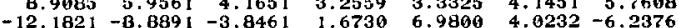
$\begin{array}{rrrrrrr}-12.1821 & -8.8891 & \mathbf{- 3 . 8 4 6 1} & 1.6730 & 6.9800 & 4.0232 & -6.2376 \\ 7.5931 & 5.1054 & 3.6180 & 2.7810 & 2.8370 & 3.4871 & 4.7797\end{array}$ $\begin{array}{rrrrrrr}7.5931 & 5.1054 & 3.6180 & 2.7810 & 2.8370 & 3.4871 & 4.7797\end{array}$ $\begin{array}{lllllll}-8.8958 & 3.8607 & 2.6641 & 3.0567 & 0.5418 & -0.4760 & -0.4228\end{array}$

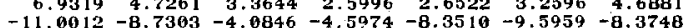

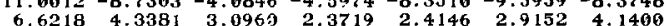
$\begin{array}{rrrrrrr}6.6218 & 4.3381 & 3.0963 & 2.3719 & 2.4146 & 2.9152 & 4.1400 \\ -3.1989 & 3.7471 & 1.9483 & 1.3910 & 1.0287 & 2.4353 & 8.7329\end{array}$ $\begin{array}{rllllll}5.9637 & 4.1442 & 3.0235 & 2.3523 & 2.3983 & 2.4353 & 0.7329\end{array}$

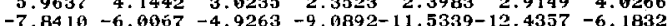
$-7.8410-6.0057-4.9263-9.0892-11.5339-12.4357-6.1832$

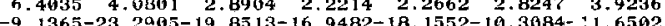
$-9.1365-23.2905-19.8513-16.9482-18.1552-10.3084-1.6502$ . 6380 . $4.4583-3.1604-9.5983-10.5029-6.2374-6.2991-13.5391$ $\begin{array}{lllllll}6.2193 & 4.0377 & 2.9762 & 2.2072 & 2.2510 & 2.7506 & 3.8673\end{array}$ $\begin{array}{lllllll}23.7293 & -6.7895 & -4.4174 & -4.6221 & -9.3313 & -6.6366 & 4.7192\end{array}$ $\begin{array}{rrrrrrr}9.1191 & 6.0944 & 4.5151 & 3.4602 & 3.5246 & 4.2864 & \mathbf{6 . 2 1 5 0} \\ 3.1171 & -7.4723 & \mathbf{2 . 1 0 4 0} & 2.8301 & 1.3955 & -1.6487 & -\mathbf{9 . 2 4 6 5}\end{array}$

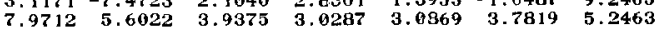

${ }^{\star}$ The upper and lower values are $A_{l m}$ (or $B_{l m}$ ) and $\sigma A_{l m}$ (or $\sigma B_{l m}$ ), respectively.

${ }^{\star \star} A_{l m}, \sigma A_{l m}, B_{l m}$ and $\sigma B_{l m}$ are $10^{-4} \mathrm{~s} \mathrm{~km}^{-1}$. 
station and poles. Wielandt (1980) studied this effect upon the apparent Rayleigh wave phase velocities. The effect depends on the source mechanism. To estimate the effect we assume here a strike-slip on a vertical fault. For this type of fault the effect is maximized. For an epicentral distance of $45^{\circ}$, the error expressed as a phase delay is $1.4,2.4,3.6$ and $5.2 \mathrm{~s}$ for a period of $200,250,300$ and $350 \mathrm{~s}$, respectively. At an epicentral distance of $30^{\circ}$, it is $2.4,4.1,6.3$ and $9.0 \mathrm{~s}$.

Spherically average phase velocities obtained in the inversions are presented in Tables 4 and 5. Deviations from PREM (Dziewonski \& Anderson 1981) are also given. These average phase velocities are very similar to those obtained in Paper I. The difference is at most $0.007 \mathrm{~km} \mathrm{~s}^{-1}$ at $333 \mathrm{~s}$ and averages $0.002 \mathrm{~km} \mathrm{~s}^{-1}$ for Love waves. For Rayleigh waves these are $0.0028 \mathrm{~km} \mathrm{~s}^{-1}(222 \mathrm{~s})$ and $0.0015 \mathrm{~km} \mathrm{~s}^{-1}$, respectively. The average differences are equivalent to differences in phase delay of 3.2 and $2.6 \mathrm{~s}$ for Love and Rayleigh waves. In our measurements of phase velocities by the single-station method, we corrected for source mechanism, source finiteness and instrumental response. In these corrections the second and third have finite non-directional parts. The source mechanism should not contribute to the differences if the azimuthal average was complete for each earthquake. If we attribute all of the differences in the phase velocities between Paper I and the present paper to errors in determinations of source process times by Nakanishi \& Kanamori (1984), the overall errors in the source process times are estimated to be about $6 \mathrm{~s}$.

We expect a similar size of uncertainty in spherical average group velocities presented in Tables 6 and 7 , because the finite source process affects the group velocity measurement in the same way as the phase velocity measurement (see 10 and 18).

Spherical harmonic coefficients of phase and group slownesses and their standard deviations are listed in Tables $8-11$. We notice here that the results of this paper preserve one of the main features of the spherical harmonic coefficients obtained in the even harmonics inversion of Paper I. As Tables 8 and 9 show, the sectoral component $(\mathrm{lm}=22)$ dominates the $l=2$ harmonics of phase velocities of Love and Rayleigh waves. This large amplitude sectoral component is found for phase velocities in Paper I. For Love waves, the next largest component is a tesseral harmonic $B_{21}$. This is also consistent with the result of Paper I. The group velocities have similar features for $l=2$ harmonics (Tables 10 and 11). The odd harmonics are less constrained by the observations than the even harmonics (29 and 30). This is evident in the results. The old harmonics scatter more than the even harmonics, and the former have less coherency among different periods than the latter. The odd harmonics have larger standard deviations than the even harmonics. This result suggests that a straightforward application of the usual sum formula (23) will lead to an unstable estimation of the variation of surface wave velocity.

\section{Lateral variations of surface wave velocities}

Global distribution of surface wave velocities is inferred by using the spherical harmonic solutions presented in the previous section. A problem is how to treat the poorly constrained odd harmonics in synthesizing the velocity distribution. To overcome this problem we apply the filter formulated in the previous section following the method of Whaler \& Gubbins (1981). We use the spherical harmonic coefficients for $L=6$.

\subsection{AVERAGING FUNCTION}

To construct the filter, we have to find an appropriate trade-off parameter $\lambda$ of (35) for each period by considering the variance of the estimate. However, as Whaler \& Gubbins point 


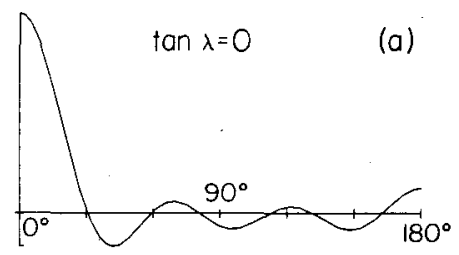

Love
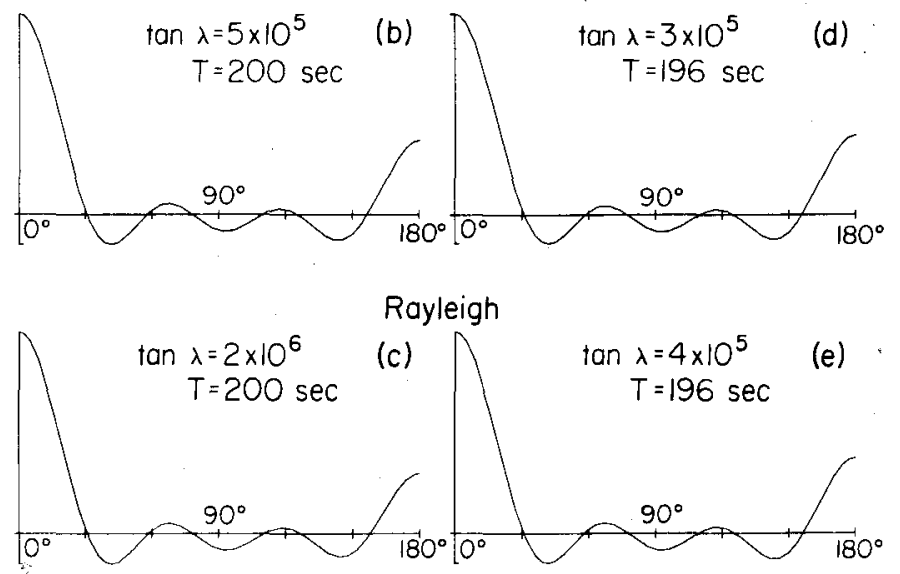

Figure 7. Averaging functions, plotted as a function of angular distance from the point of estimation. All are for $L=6$. (a) $\tan \lambda=0$. (b) Love wave phase velocity at $200 \mathrm{~s}, \tan \lambda=5 \times 10^{5}$. (c) Rayleigh wave phase velocity at $200 \mathrm{~s}, \tan \lambda=2 \times 10^{6}$. (d) Love wave group velocity at $196 \mathrm{~s}, \tan \lambda=3 \times 10^{5}$. (e) Rayleigh wave group velocity at $196 \mathrm{~s}, \tan \lambda=4 \times 10^{5}$.

out, there is no well-founded criterion to determine an optimum $\lambda$, because no numerical value is assigned to the spread $\alpha$ of (36). To facilitate examination of the effect of $\lambda$ on the variance of the estimate, we tentatively assume $\sigma_{l m}$ to be independent of $m$ and calculate an average $\sigma_{l}$ of $\sigma_{l m}$ by (40). In this case the variance $\epsilon^{2}$ is independent of the position on the Earth's surface, as (41) shows. Tables 8-11 suggest that this is a good approximation. Of course, as (41) shows, $\epsilon^{2}$ decreases with increasing $\tan \lambda$.

Fig. 7 presents averaging functions calculated by using (42). The averaging function of Fig. $7(a)$ is for $\tan \lambda=0$ or a noise-free case. It is an oscillatory function with six nodes. The number of nodes increases with increasing $L$. This oscillatory nature of the averaging function results from the abrupt truncation at $l=L$. From the form of the averaging function of Fig. 7(a), we know that even if the coefficients are free of noise we can learn only an average of velocity distribution weighted over a wide area of the Earth's surface, and that this averaging function has significant oscillations and is not well localized. For $L=6$, the first node is located at $\Delta \sim 30^{\circ}$. We have to remember this lack of localization when interpreting synthesized velocity distribution. In geomagnetic data, analysed by Whaler \& Gubbins, errors in the spherical harmonic coefficients increase rapidly with increasing $l$ when the coefficients are downward continued to the mantle-core boundary. In this case the averaging function they proposed corresponds to tapering in Fourier analysis. In our case, the standard deviations of the coefficients do not increase rapidly with increasing $l$ in the range $l=1-6$, but oscillate between even and odd $l$. The averaging function constructed in the following is a multiple-notch filter. Fig. $7(b-e)$ shows examples of the averaging functions calculated from (42) for finite $\tan \lambda$. For these particular $\tan \lambda$, the variance of the estimate calculated from (41) is about one-half as large as that of $\tan \lambda=0$ 
in the period range from about 150 to $250 \mathrm{~s}$. Tables $8-11$ show that the standard deviations generally have wide troughs in their values in this period range. A feature we have to notice in Fig. $7(\mathrm{~b}-\mathrm{e})$ is a peak at the antipode caused by a heavy damping of the old harmonics. In spite of this unwelcome antipodal ambiguity, we prefer the averaging functions of Fig. $7(b-e)$ to that of Fig. $7(a)(\tan \lambda=0)$, because this filtering process with finite $\tan \lambda$ stabilizes the synthesized geographical distribution of the surface wave velocity and we can suppress unacceptably large variations in the velocity distribution.

Next we examine the effect of the trade-off parameter $\lambda$ on the velocity estimate ( 31 and 32) for the case where $\sigma_{l m}$ is dependent on $m$. After examining many cases, we found that finite $\tan \lambda$ does not significantly change the overall pattern of velocity distribution, but reduces the amplitude of velocity variations. Fig. $8(a, b)$ is an example that shows the effect of finite $\tan \lambda$. Here $\tan \lambda$ is chosen to be $10^{6}$, and Love wave phase velocity at $200 \mathrm{~s}$ is considered. Comparing the results for $\tan \lambda=0$ (Fig. 8a) and $\tan \lambda=10^{6}$ (Fig. 8b), we see that the general pattern of the lateral variations of the phase velocity does not change. However, the antipodal ambiguity is increased in the figure for $\tan \lambda=10^{6}$, and about 20 per cent of power of the velocity variation at a point on the surface comes from its antipode when using $\tan \lambda=10^{6}$ for the Love wave phase velocity at $200 \mathrm{~s}$. Fig. 8(c) is an averaging function calculated from (33) by using $\tan \lambda=5 \times 10^{5}$, which is localized at a point in the south-western end of the Arabian peninsula $\left(15^{\circ} \mathrm{N}, 45^{\circ} \mathrm{E}\right)$. A peak is seen at its antipode in the south-eastern Pacific. The averaging function is dependent on the angular distance and the azimuth between $\Omega_{0}$ and $\Omega$. After examining many cases of $\tan \lambda$, we decided to use $\tan \lambda=5 \times 10^{5}, 2 \times 10^{6}, 3 \times 10^{5}$ and $4 \times 10^{5}$ for the Love wave phase velocity, Rayleigh wave phase velocity, Love wave group velocity and Rayleigh wave group velocity, respectively, in the following synthesis of velocity distribution. The averaging functions for these $\tan \lambda$ are presented in Fig. $7(\mathrm{~b}-\mathrm{e})$, assuming $\sigma_{l m}$ to be independent of $m$. The velocity distribution will be synthesized at periods of $100,153,200$ and $250 \mathrm{~s}$ for phase velocities, at periods of 100,152, 196 and $252 \mathrm{~s}$ for Love wave group velocities, and at periods of $118,152,196$ and $252 \mathrm{~s}$ for Rayleigh wave group velocities. The following describes the resulting geographical velocity distribution for each of the four types of surface wave velocities.

\subsection{LOVE WAVE PHASE VELOCITY}

Contour maps of Love wave phase velocity are presented at four periods in Fig. 9. Considering the incompleteness of the averaging function in localizing the lateral heterogeneity, it is not straightforward to interpret the velocity distribution in terms of lateral heterogeneity of the Earth's mantle. Nevertheless, we can say that the overall pattern of the Love wave phase velocity variations shows a general correlation with surface tectonics.

There are large velocity variations between young regions along the oceanic ridges and old regions within ocean basins. In Fig. 9, low-velocity regions are located in the south-eastern Pacific, the central Atlantic, the central Indian Ocean, and the marginal seas behind the western margin of the Pacific. On the other hand, a high-velocity region is located in the north-western Pacific. Love wave phase velocities are low along the Mid-Atlantic Ridge, especially near the triple junctions in the north and south Atlantic.

High-velocity regions in continents generally coincide with Precambrian shields and Phanerozoic platforms (north-western Eurasia, western and southern parts of Africa, western Australia, eastern parts of North and South America, and Antarctica). The Indian shield is too small to be detected uniquely from the inversions of long-period surface wave velocities if we consider the broad peak of the averaging functions presented in Figs 7 and 8 and the 
diameter of the shield of about $20^{\circ}$. The contour maps show a high-velocity region off the south coast of the Indian continent. It is difficult to say whether this high velocity is really located in the northern Indian Ocean or is a result of interference between the low velocity of south Eurasia (e.g. the Tibetan region), possible high velocity of the Indian continent, and the high velocity of western Australia. Stark \& Forsyth (1983) have found a fast region just south of India, as did Nakanishi \& Anderson (1982). Tectonically active regions, such as the
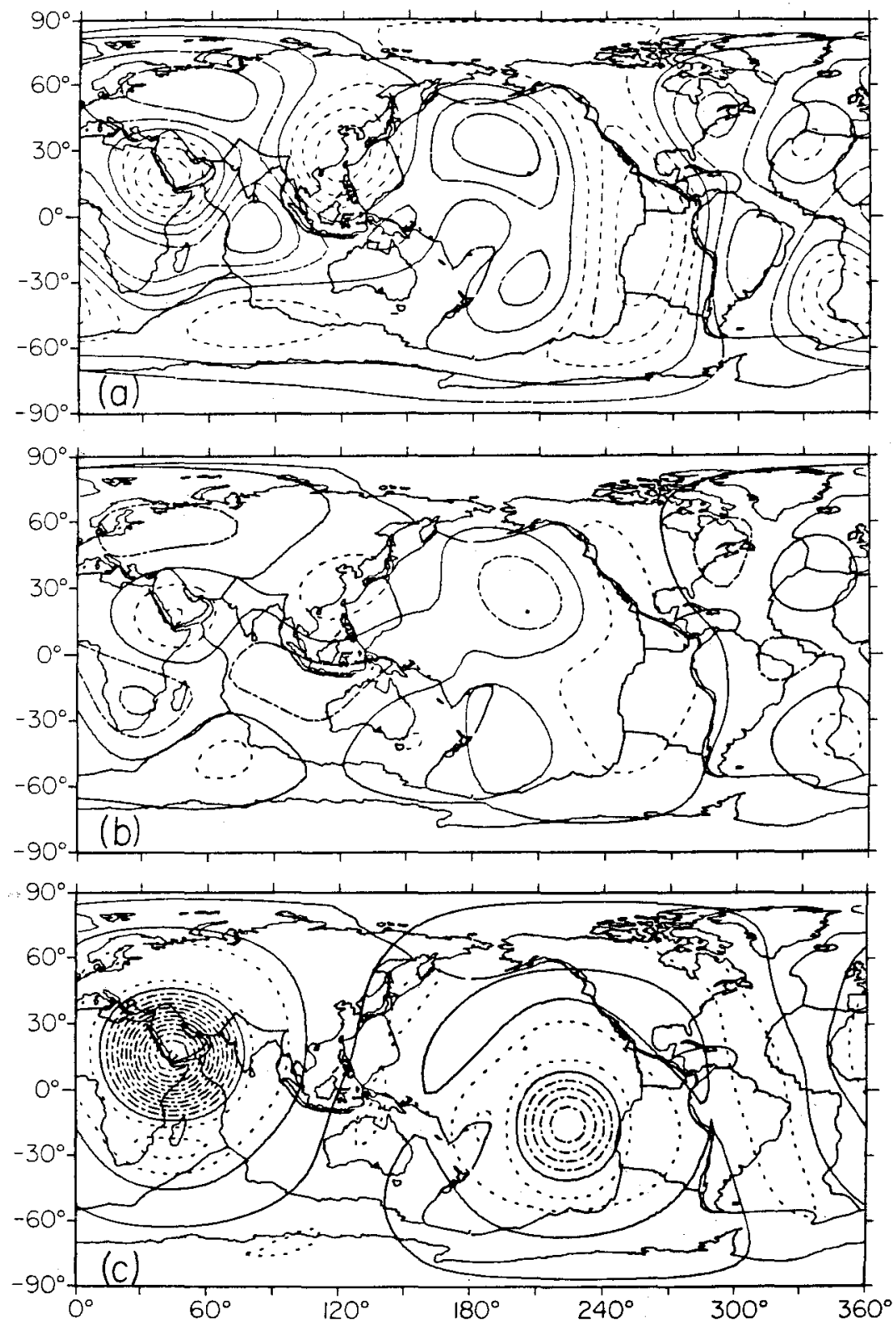

Figure 8. An example of the filtering. All are Love wave phase velocity at $200 \mathrm{~s}$ and for $L=6$. (a) $\tan \lambda=0$, (b) $\tan \lambda=10^{6}$. In (a) and (b) the contour interval is $0.05 \mathrm{~km} \mathrm{~s}^{-1}$. The solid, chain, and dashed lines indicate spherical average, higher, and lower velocities, respectively. (c) is an averaging function located at $\left(15^{\circ} \mathrm{N}, 45^{\circ} \mathrm{E}\right)$ for $\tan \lambda=5 \times 10^{5}$. The contour interval is 0.2 . 

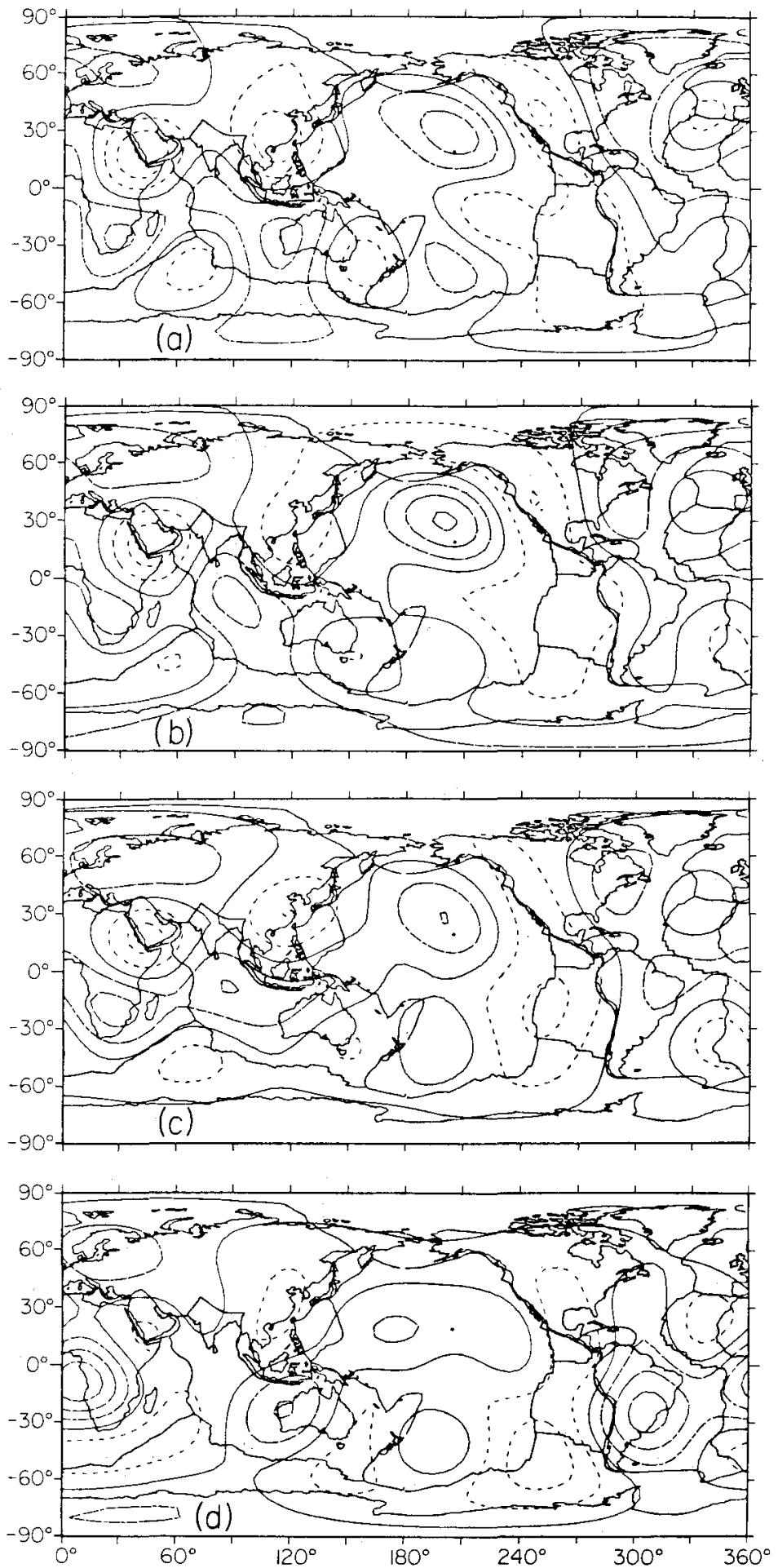

Figure 9. Contour maps of Love wave phase velocities. $L=6$ and $\tan \lambda=5 \times 10^{5}$ for all maps. The solid, chain, and dashed lines indicate the spherical average, higher, and lower velocities, respectively. The contour interval is $0.05 \mathrm{~km} \mathrm{~s}^{-1}$. (a) $100 \mathrm{~s}$, (b) $153.8 \mathrm{~s}$, (c) $200 \mathrm{~s}$, (d) $250 \mathrm{~s}$. 
Middle East centred on the Red Sea, eastern and southern Eurasia, eastern Australia, and western North America, and island arcs, such as the southern Alaskan margin, the Aleutian, Kurile, Japanese, Izu-Bonin, Mariana, Ryukyu, Philippine, Fiji, Tonga, Kermadec, and New Zealand arcs, exhibit low velocities. The Indonesian and New Guinean regions, complicated in tectonic setting, show relatively high velocities. These are narrow areas sandwiched between the high velocities of the western Pacific and western Australia. Other island arcs, such as the Mediterranean, Caribbean, and Sandwich regions, are probably too small to be detected even if these regions are characterized by low velocities.

\subsection{RAYLEIGH WAVE PHASE VELOCITY}

Fig. 10 shows regional variations of Rayleigh wave phase velocity. We have to be careful in interpreting these maps because, in contrast to the Love wave results, the variance reductions associated with the inversion of Rayleigh wave phase velocities, measured by the singlestation method (this paper), are much smaller than those obtained in the even harmonics inversions of great circle Rayleigh wave phase velocities (Paper I). The Rayleigh wave phase velocity data have the smallest pre-inversion variances. We made similar error estimates for Love wave and Rayleigh wave phase velocity measurements. The decrease in variance reduction might be a reflection of an internal inconsistency in the single-station method data set caused, probably, by errors in source parameters. An examination of the excitation functions used in this study $\left(P_{L}^{(1)}, Q_{L}^{(1)}, S_{R}^{(1)}, P_{R}^{(1)}\right.$ and $\left.Q_{R}^{(1)}\right)$ reveals that the shape of the Love wave excitation function is much more insensitive to the source depth than that of the Rayleigh wave excitation function in the period range concerned (100-300 s). In other words, an error in the source depth has a greater effect on the Rayleigh wave initial phase than on that of Love waves. On the other hand, Love waves are less sensitive to errors in source parameters than Rayleigh waves when studying lateral heterogeneity of the upper mantle. Furthermore, Love waves are more affected by heterogeneity of the upper mantle than are Rayleigh waves.

In spite of the expected larger uncertainties in observed Rayleigh wave phase velocities, the contour maps of Fig. 10 exhibit a significant correlation with surface tectonics. Here we mention only the differences from the Love wave phase velocities.

One difference is evident in the island arcs along the north-western margins of the Pacific Ocean, such as the Aleutian, Kurile, Japanese, Izu-Bonin-Mariana, Ryuku, and Philippine regions. In Fig. 10 the results for periods of 153 and $200 \mathrm{~s}$ show high velocities for the regions mentioned above. Exceptions are the Ryukyu and the Philippine regions for a period of $100 \mathrm{~s}$ and the Aleutian region for a period of $250 \mathrm{~s}$. In the contour map for $250 \mathrm{~s}$ a high-velocity region is localized near the Izu-Bonin-Mariana trenches, which are between the Philippine Sea and the western margin of the north-western Pacific. The general pattern is similar to that of the map for the same period synthesized from $l=2$, 4 and 6 harmonics obtained from the even harmonics inversion of great circle Rayleigh wave data (fig. 15b of Paper I). Fig. 10(d) contains both even and odd harmonics. The averaging function for Rayleigh wave phase velocity at $250 \mathrm{~s}$ has an antipodal peak of a similar size to that of Fig. 7(c) (200 s). Thus, $70 \sim 80$ per cent of the power of the high velocity in Fig. 10(d) comes from the Izu-Bonin-Mariana regions, and $20 \sim 30$ per cent from the antipodal regions.

For Rayleigh waves the Atlantic ocean is generally high velocity. Except for the northern part, the low velocity of the Mid-Atlantic Ridge is not resolved in Fig. 10. The figures exhibit higher than average velocity for the entire period range of the figures. Comparing average velocities of similar age ocean, say $25-100 \mathrm{Myr}$, we find that the Rayleigh wave 

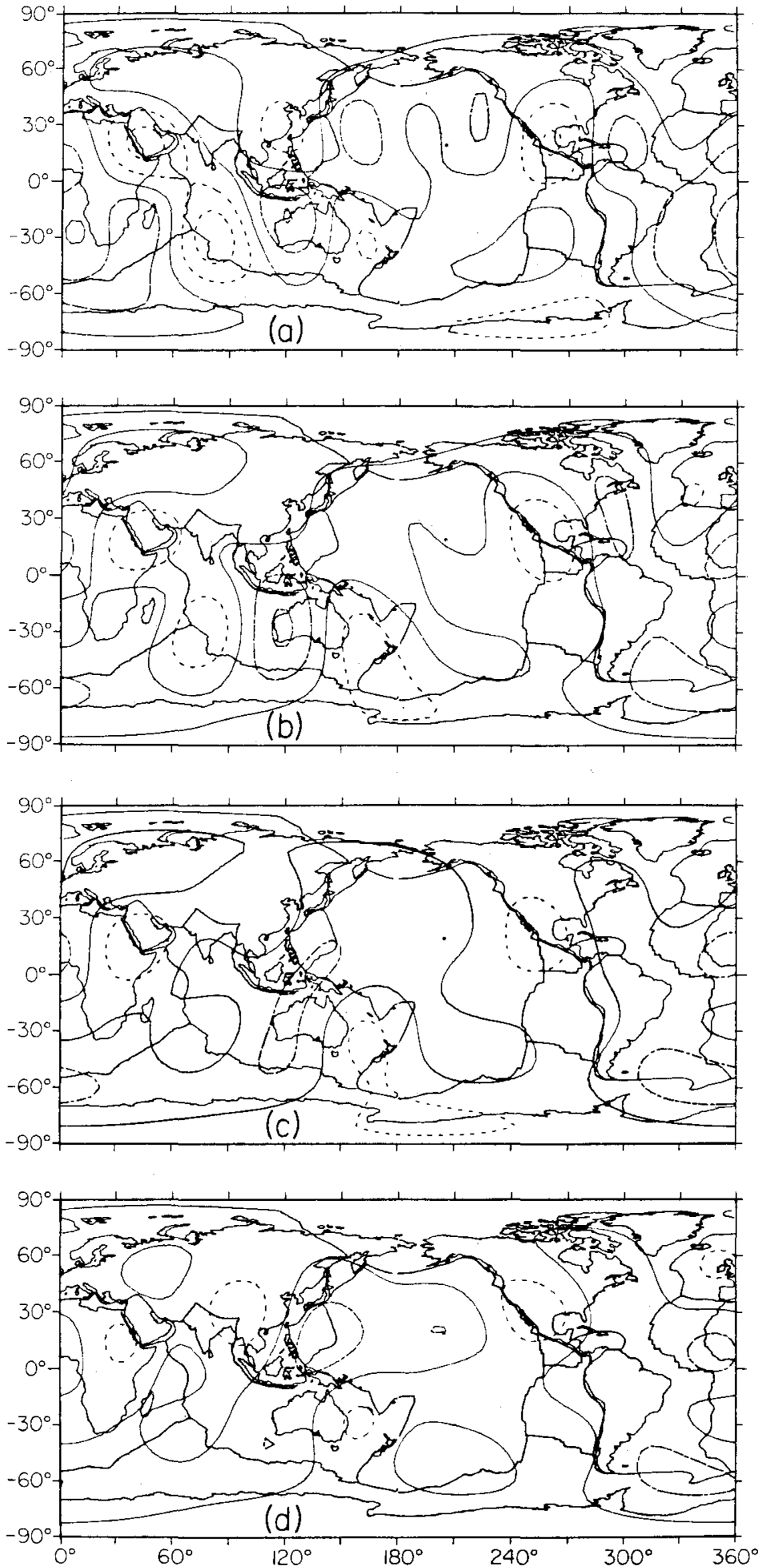

Figure 10. Contour maps for Rayleigh wave phase velocities. $L=6$ and $\tan \lambda=2 \times 10^{6}$ for all maps. Conventions the same as in Fig. 9. (a) $100 \mathrm{~s}$, (b) $153.8 \mathrm{~s}$, (c) $200 \mathrm{~s}$, (d) $250 \mathrm{~s}$. 
phase velocities in the Atlantic, especially in the central and southern parts, are faster than those in the corresponding age regions of the Pacific. This difference is not apparent in the Love wave phase velocities, Fig. 9. The southern part of the Atlantic Ocean has higher Rayleigh wave phase velocities than the northern part. Differences in seismic structure between the Atlantic and the Pacific, and between the northern and the southern Atlantic, have been reported by Christensen, Kimball \& Mauk (1980) for short-period (20-100s) Rayleigh wave group velocities. If these differences are real, they affect results of the conventional regionalization approach, which assumes identical properties for regions of the same age.

Studies by Masters et al. (1982) and our Paper I reveal that lateral variations of eigenperiods of spheroidal modes and great circle phase velocities of long-period Rayleigh waves are dominated by $l=2$ terms which have two high-velocity peaks centred near the Mariana trench and the central Atlantic Ocean off the Brazilian coast. Comparing the results of $L=2$ even harmonics inversions of great-circle Rayleigh wave phase velocities with $l=2$ spherical harmonic expansion of regionalized phase velocities obtained by using Okal's (1977) model from the identical Rayleigh wave phase velocity data set (our Paper I) suggests that the high-velocity peak in the central Atlantic is caused by the antipodal ambiguity in the spherical harmonic representation using only the even $(l=2)$ terms. Kawakatsu (1983) also suggests that the large $(l=2)$ terms. Kawakatsu (1983) also suggests that the large $l=2$ pattern comes from the configuration of seafloor age, ocean basin, and continents, and shows that regionalized phase velocities derived from Okal's model have a very similar $l=2$ pattern to that presented by Masters et al. (1982). Okal's model, however, assumes oceanic regions of the same seafloor age to have an identical dispersion character. As mentioned above, the study by Christensen et al. (1980) and the present study suggest a breakdown of this assumption.

The wavelengths of the fundamental spheroidal modes analysed by Masters et al. (1982) and the long-period Rayleigh waves analysed in our Paper I are more than $1300 \mathrm{~km}$. The narrowest part of the central Atlantic is about $4900 \mathrm{~km}$. The central Atlantic is bordered by tectonically stable regions, eastern South America and western Africa. When we analyse the intrinsic lateral heterogeneity in the Atlantic in terms of spherical harmonics, we should expect a strong interference from these two regions. Thus, it would be difficult to detect any intrinsic lateral heterogeneity of the deeper part of the upper mantle in the Atlantic Ocean by using only long-period fundamental modes.

\subsection{LOVE WAVE GROUP VELOCITY}

As mentioned in a previous section, Love wave group velocity is insensitive to source depth and source mechanism. Comparing Figs 11 and 9, we find that the patterns are very similar except for a period of about $250 \mathrm{~s}$. Almost all the correlations between the surface wave velocities and surface tectonics mentioned for Love wave phase velocities are also apparent in Fig. 11.

A significant difference between the phase and group velocities of Love waves exists in Antarctica. The phase velocities are relatively high, but the group velocities are lower than the spherical average.

\subsection{RAYLEIGH WAVE GROUP VELOCITY}

Fig. 12 shows the geographical distribution of Rayleigh wave group velocities. A strong correlation with surface tectonics is evident. Exceptions are the high velocities near the 

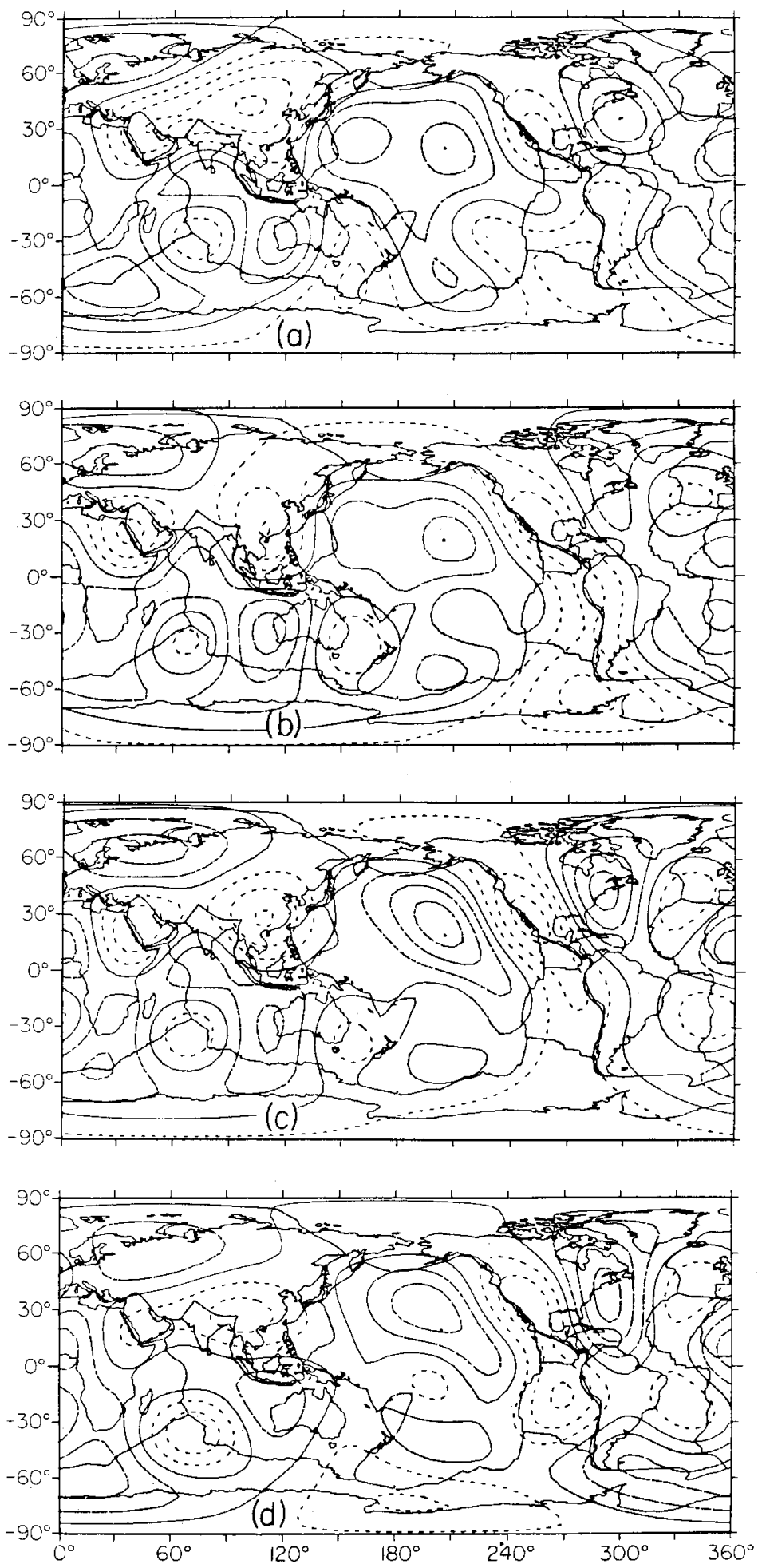

Figure 11. Contour maps for Love wave group vclocities. $L=6$ and $\tan \lambda=3 \times 10^{5}$ for all maps. Conventions the same as in Fig. 9. (a) $100 \mathrm{~s}$, (b) $152.3 \mathrm{~s}$, (c) $196.1 \mathrm{~s}$, (d) $252.4 \mathrm{~s}$. 

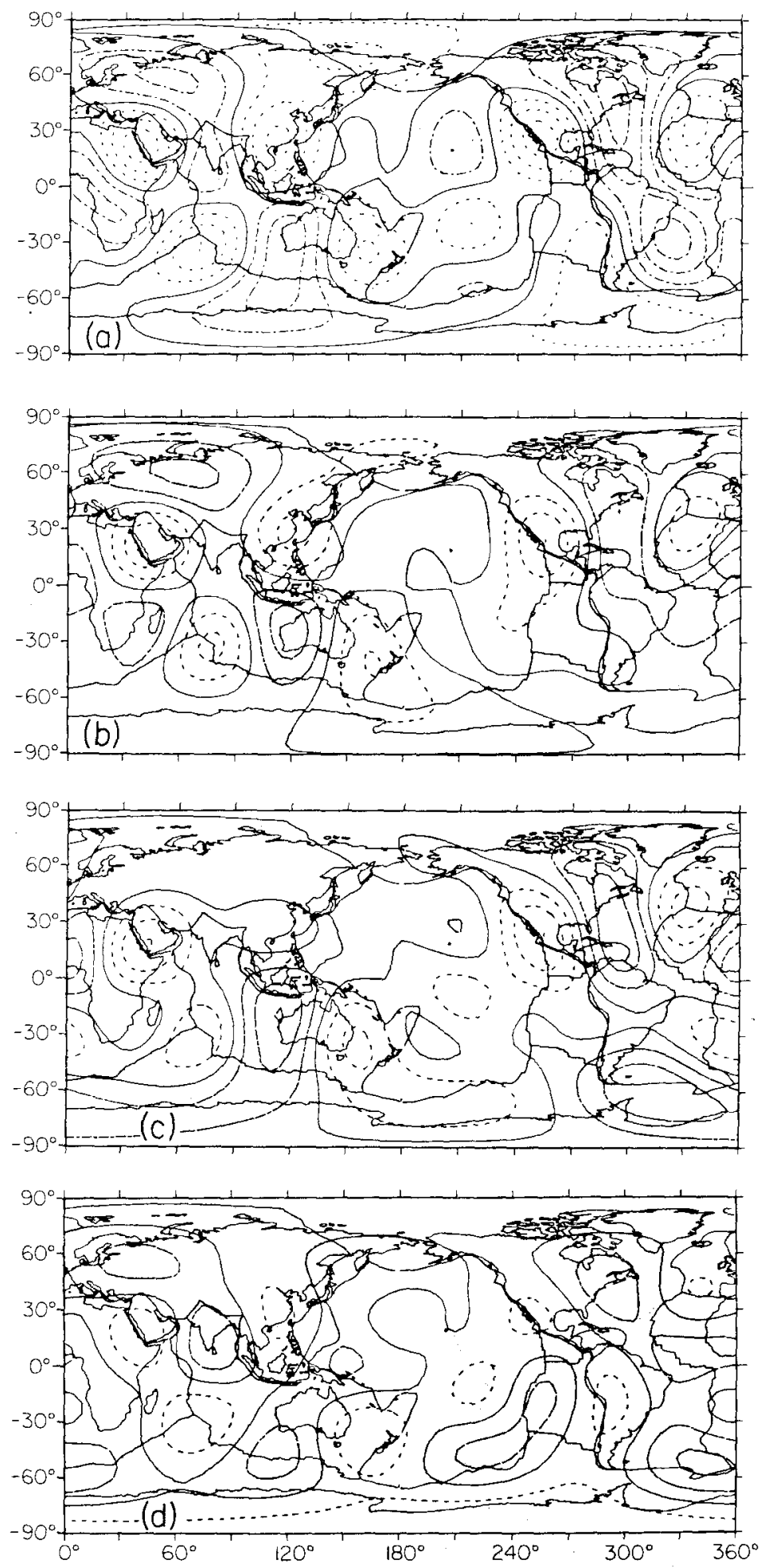

Figure 12. Contour maps for Rayleigh wave group velocities. $L=6$ and $\tan \lambda=4 \times 10^{5}$ for all maps. Conventions the same as in Fig. 9. (a) $118.3 \mathrm{~s}$, (b) $152.3 \mathrm{~s}$, (c) $196.1 \mathrm{~s}$, (d) $252.4 \mathrm{~s}$. 
SE Pacific Rise at $252 \mathrm{~s}$. These features might result from an instability due to the cubic polynomials fitted to the observed Rayleigh wave group velocities. The latter also show higher velocity in the southern Atlantic than in the Pacific and the northern Atlantic. At 196 and $252 \mathrm{~s}$ the island arcs along the western margins of the Pacific exhibit high velocities.

\subsection{REMARKS}

Regionalization models based on plate tectonics that have been applied to interpretations of great circle observations of fundamental-mode surface wave velocities (Wu 1972; Okal 1977; Nakanishi 1979; Lévêque 1980; Jordan 1981; Silver \& Jordan 1981; Dziewonski \& Steim 1982; Souriau \& Souriau 1983) may be considered to be a good approximation to the actual lateral heterogeneity of the upper mantle, at least for periods between 100 and $250 \mathrm{~s}$. Older tectonic regionalizations (Toksöz \& Anderson 1966; Kanamori 1970; Dziewonski 1970) are inappropriate for oceanic regions.

In spite of the general agreement between the regionalization approach and the spherical harmonic approach of the present paper, there are some discrepancies. As mentioned above, we have evidence for a breakdown of the relation between seafloor age and dispersion when comparing the Atlantic and the Pacific. This may be due, at least in part, to the broad lateral averaging kernels and the difference in spreading rates between the Atlantic and the Pacific.

The islands arcs along the north-western margins of the Pacific exhibit an interesting property. Rayleigh wave phase velocities are high, while Love waves are slow. Rayleigh waves sample to greater depth than Love waves. This suggests that we are sampling the fast material that has subducted beneath the island ares. Anisotropy may also be involved. This point will be analysed in terms of lateral heterogeneity and anisotropy in a later publication (Nataf, Nakanishi \& Anderson 1984).

Our group velocity results, especially Rayleigh waves, appear to be more unstable than the phase velocity results. This may be expected, partly from the nature of the group velocity kernels, and partly from the velocity measurements themselves.

\section{Comparison with other geophysical data}

In Paper I we studied correlations of $l=2$ harmonics of phase velocities of Love and Rayleigh waves with $l=2$ terms of heat flow and geoid and noted that even complete correlation of the even harmonics of two variables does not necessarily indicate coincidence of their sources. We pursue this discussion in the following.

Figs 13 and 14 present the heat flow and geoid distributions used in the discussion. The heat flow data is taken from Chapman \& Pollack (1975), who obtained a spherical harmonic representation from observed heat flow and a tectonic predictor. Fig. 13(a) is synthesized by using the coefficients up to degree and order 12 presented in their table 3 (observed and predicted), and is identical to their fig. 7. To facilitate comparison with the surface wave data, heat flow distributions synthesized by using $l=1-6$ and $l=2$ are presented in Fig. 13(b, c). Fig. 14(a, b) shows the non-hydrostatic geoid obtained from $l=1-6$ and $l=2$ of GEM8 (Wagner et al. 1977) corrected for the hydrostatic figure of the Earth by Nakiboglu (1982). As Figs 13(c) and 14(b) show, the $l=2$ heat flow map correlates better with the $l=2$ surface wave phase velocities (figs 12 and 14 of Paper I) than does the $l=2$ geoid.

To study the correlation between the surface wave velocities and the heat flow or the 

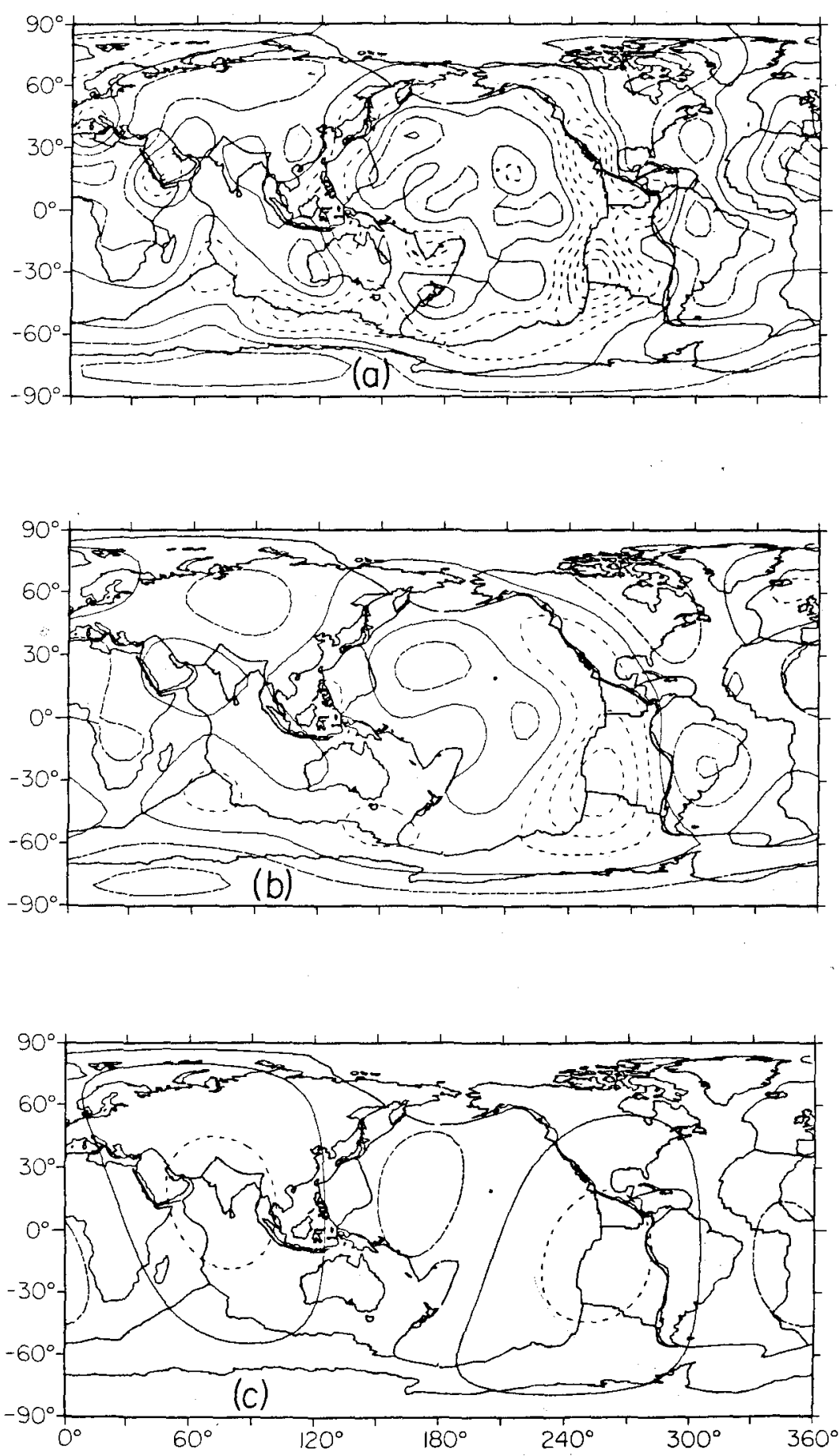

Figure 13. Contour maps for heat flow synthesized from table 3 (observed and predicted) of Chapman \& Pollack (1975). The contour interval is $10 \mathrm{~mW} \mathrm{~m}^{-2}$ in (a) and (b), and $5 \mathrm{~mW} \mathrm{~m}^{-2}$ in (c). The solid, chain, and dashed lines represent the spherical average, lower, and higher heat flow, respectively. (a) $L=12$, (b) $L=6$, (c) $l=2-2$. 
geoid, we compute the degree cross-correlation coefficients

$$
r_{l}=\frac{\sum_{m=-l}^{m=l} X_{l m} Z_{l m}}{\left(\sum_{m=-l}^{m=l} X_{l m}^{2}\right)^{1 / 2}\left(\sum_{m=-l}^{m=l} Z_{l m}^{2}\right)^{1 / 2}},
$$

where $X_{l m}$ are coefficients for surface waves, $Z_{l m}$ are for heat flow or geoid, and $r_{l}$ is calculated for $l=1-6$. For the surface waves we use

$X_{l m}=\frac{s_{l m}}{1+(4 \pi \tan \lambda) \sigma_{l m}^{2}}$,

where $s_{l m}$ and $\sigma_{l m}$ are obtained from the least-squares solutions of (25). We adopt the same $\tan \lambda$ as used in Figs $9-12$. In Figs 15 and 16 we present the degree correlation coefficients for four surface wave data sets. It is apparent that the heat flow has a higher overall correlation $(l=1-6)$ with our surface wave data than does the geoid.
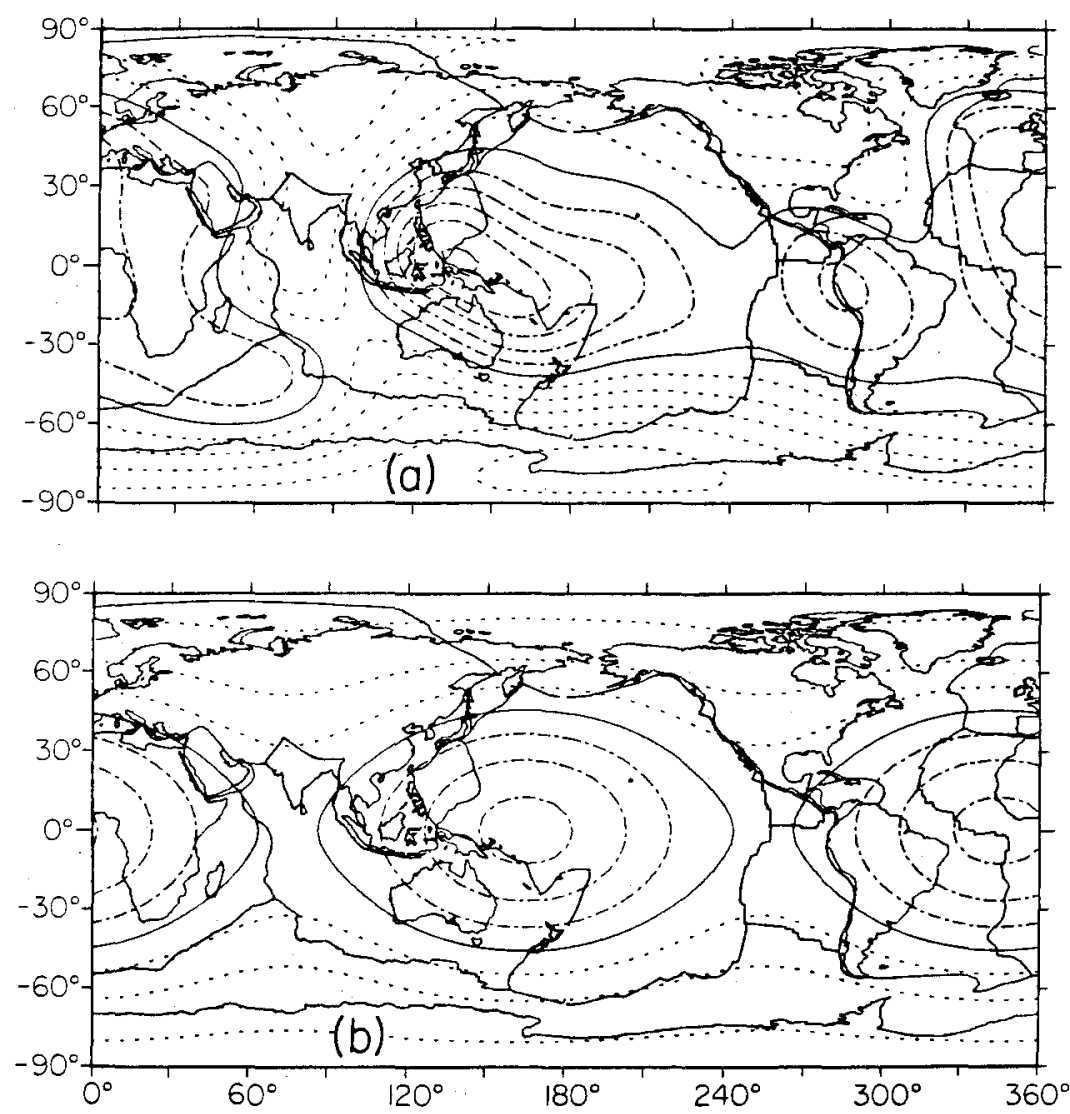

Figure 14. Contour maps for the non-hydrostatic geoid synthesized from the results of Wagner et al. (1977) (GEM 8) and Nakiboglu (1982). The contour interval is $20 \mathrm{~m}$ for both (a) and (b). The solid, chain, and dashed lines indicate the spherical average, higher, and lower geoid, respectively. (a) $l=2-6$, (b) $l=2-2$. 


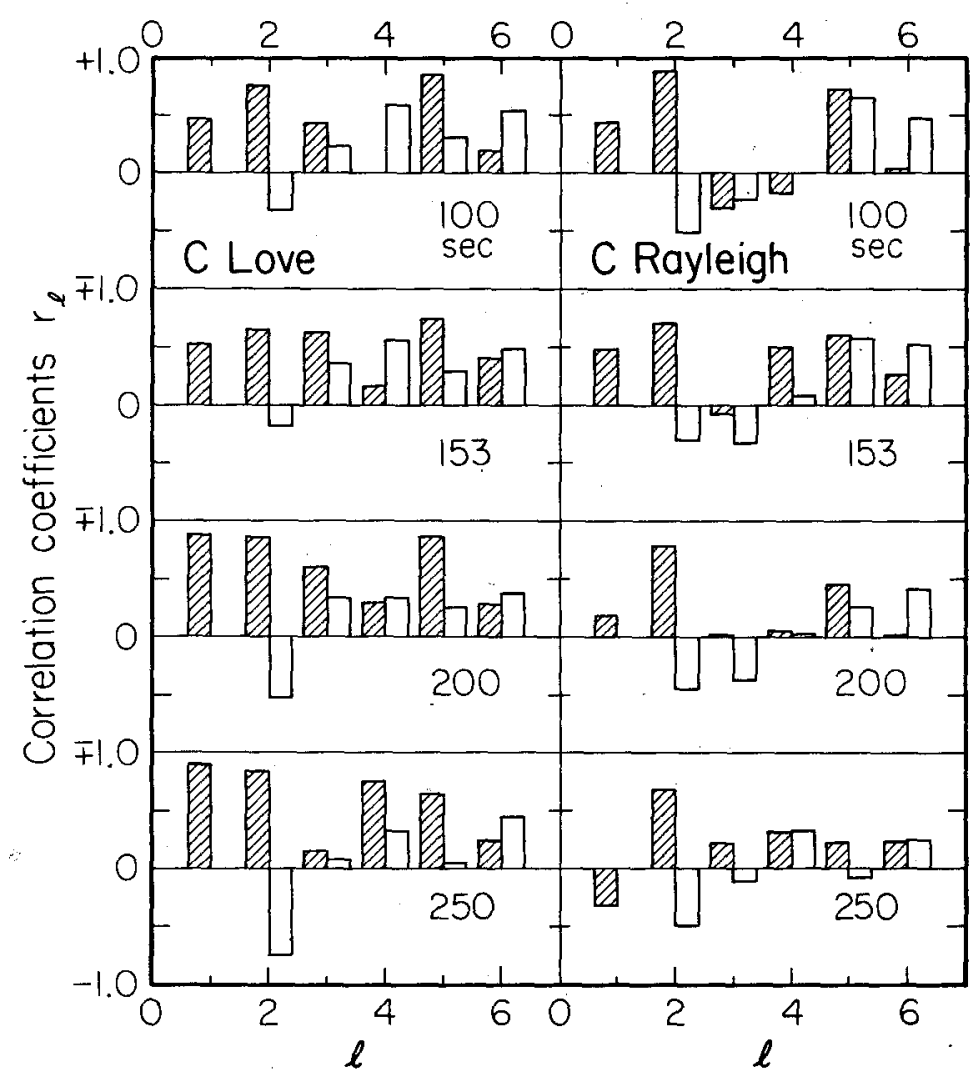

Figure 15. Degree correlations of surface wave phase slownesses with heat flow and the geoid. Shaded symbols mean correlations with heat flow. Open symbols indicate correlations with the geoid.

The heat flow and the geoid exhibit some differences in the degree correlations. The heat flow shows positive correlations with surface wave slownesses for $l=1-6$. The coefficients peak at $l=2$ and 5 . On the other hand, the geoid has negative correlations at lower degrees $(l=2$ and 3$)$ and positive correlations at higher degrees $(l=4-6)$. For $l=2$ the heat flow correlates with the slownesses better than the geoid does. For $l=4-6$ the figures show a similar size of correlations for both the heat flow and the geoid. This suggests a correlation between them at $l=4-6$.

Fig. 17 presents the contour maps for the heat flow and the geoid synthesized by using $l=4-6$ spherical harmonics. Although there are a few exceptions, we can see an obvious correspondence between high heat flow and high geoid, and vice versa. Exceptions are high heat flow and low geoid in the East Pacific Rise and the central and southern Mid-Atlantic Ridge, and low heat flow and high geoid in western South America. In Fig. 17(b) it should be noted that oceanic ridges are not evident in the geoid. Islands arcs, in general, show up as geoid highs.

Chapman \& Pollack (1975) used predictors based on tectonic setting and age to supplement heat flow data, which is relatively sparse. They did not use seismic data for the prediction. The high correlations between surface wave velocities and heat flow $(l=1-6)$ partly reflect the correlation between tectonic setting (age) and surface wave velocity. The latter correlations are well known from analyses of short-period $(<100 \mathrm{~s})$ surface waves 


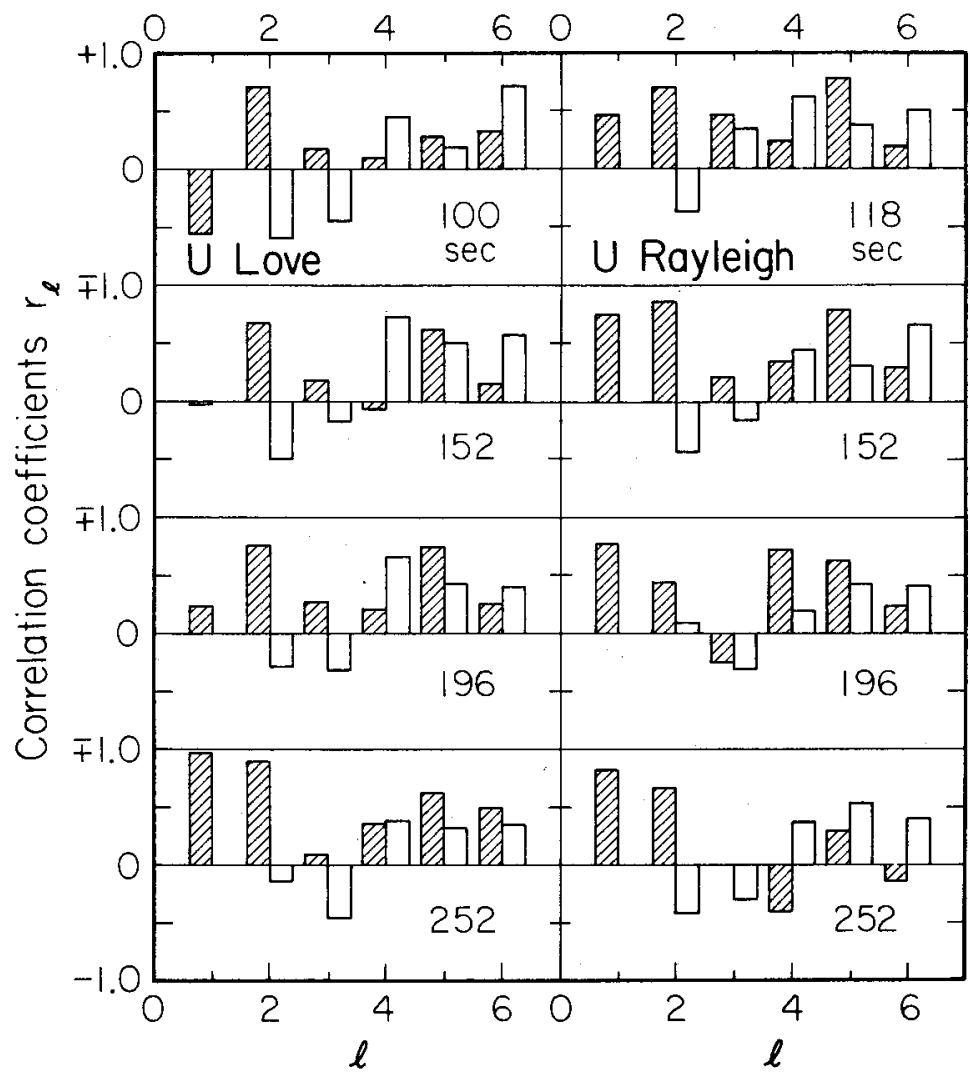

Figure 16. Degree correlations of surface wave group slownesses with heat flow and the geoid. Conventions the same as in Fig. 15.

(Kausel, Leeds \& Knopoff 1974; Leeds, Knopoff \& Kausel 1974; Yoshii 1975). The correlation with long-period $(\geqslant 100 \mathrm{~s})$ surface waves has been discussed already in this paper.

The non-hydrostatic geoid is derived without assuming surface tectonics. As Fig. 17(b) shows, the $l=4-6$ geoid has a strong correlation with global tectonic features, especially in the Circum-Pacific subduction region. Examining the tectonic regionalization model of Okal (1977), we find that its $T$ region (trench and marginal sea) and $M$ region (mountainous) correspond to the geoid highs in the figure. The other published tectonic models (Wu 1972; Lévêque 1980; Jordan 1981; Dziewonski \& Steim 1982) show less correlation with the $l=4-6$ geoid than does Okal's model. The correlation between surface wave slownesses and the geoid at $l=4-6$ presented in Figs 15 and 16 suggests that the geoid-tectonics correspondence may be one of the reasons for the efficiency of Okal's regionalization model demonstrated by Souriau \& Souriau (1983) and Nakanishi \& Anderson (1984).

In Paper I we demonstrated that there is a significant difference in the $l=2$ terms between surface wave phase velocity and the geoid. The surface wave phase velocity is dominated by the sectoral component $(l m=22)$. This appears to be primarily due to the north-south-trending East Pacific Rise. The geoid has the largest amplitude in the zonal $(l m=20)$ component. The geoid, however, also has significant power in the sectoral component. The $l=2$ sectoral and zonal harmonics of the Rayleigh wave phase velocity have a weak correlation with the corresponding harmonics of the geoid. The $l=2$ sectoral 

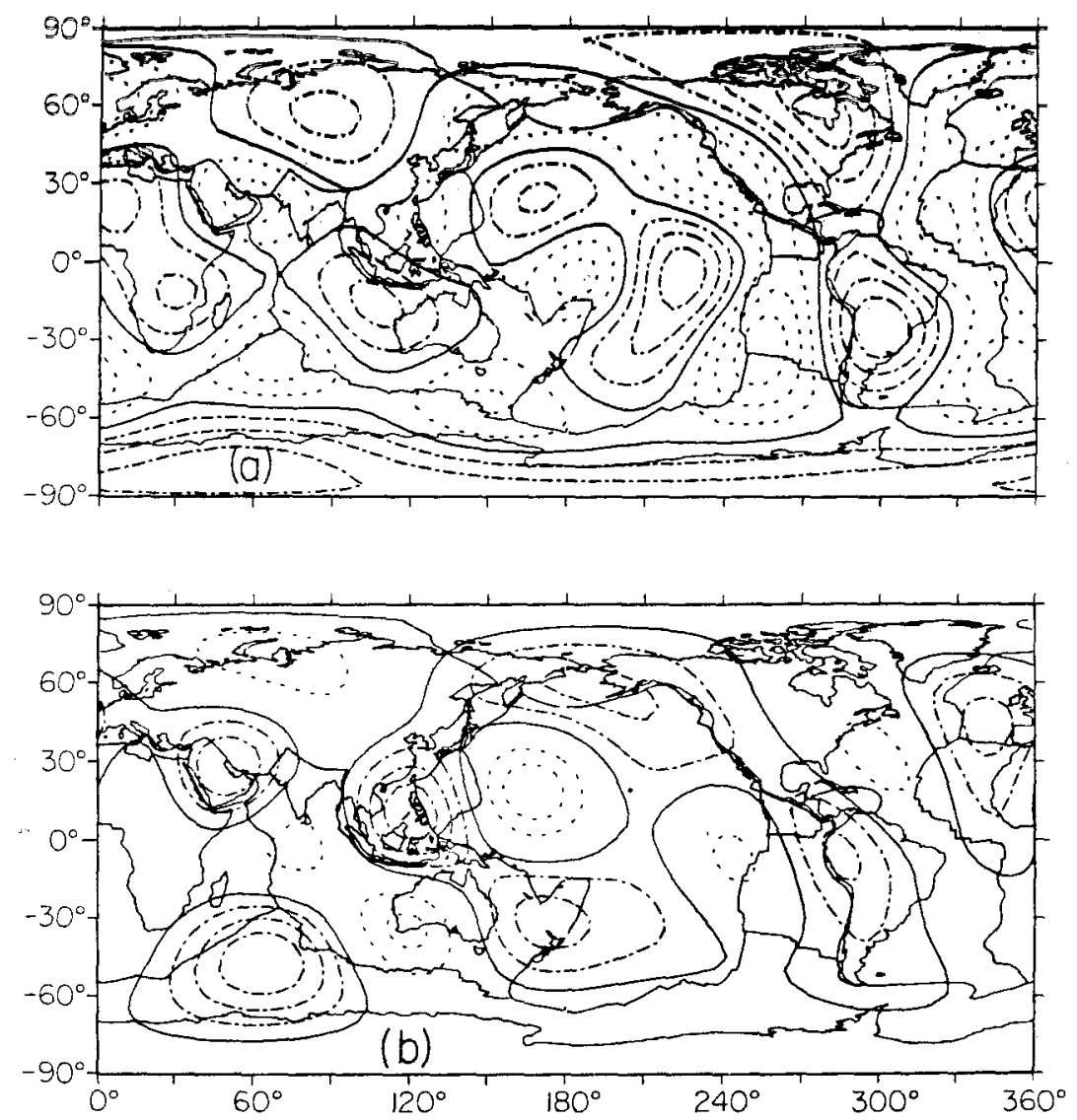

Figure 17. Contour maps for heat flow and the non-hydrostatic geoid synthesized by using $l=4-6$ harmonics. (a) Heat flow. The contour interval is $5 \mathrm{~mW} \mathrm{~m}^{-2}$. The solid, chain, and dashed lines represent the spherical average, lower, and higher heat flow, respectively. (b) Geoid. The contour interval is $10 \mathrm{~m}$. The solid, chain, and dashed lines represent the spherical average, higher, and lower geoid respectively.

harmonics of the Love wave phase velocity also show a correlation with those of the geoid. The correlation coefficients shown in Figs 15 and 16 are consistent with those of our previous observations.

The lateral variations of seismic wave velocities, heat flow, and the geoid may be caused by variations of many sources, such as composition, mineralogy, depths of discontinuities, temperature, and so on. Since the contribution from each source has different power and interfers, the correlation analysis should be made by segregating their harmonics by degree, as is done in this paper. The importance of the degree correlation analysis is demonstrated by comparing contour maps of the geoid composed of $l=1-6$ (Fig. 14a) and $l=4-6$ (Fig. 17b) harmonics. In the former map it is difficult to see an obvious correlation between the geoid and tectonic features. In the latter map, however, the correlation is evident. If we examined only the overall correlation $(l=1-6)$, we could not find the correlation between surface wave velocity and the geoid at higher degrees $(l=4-6)$. For this type of study the spherical harmonic approach has an advantage over another method of surface wave analysis, such as gridding technique. 


\section{Conclusions}

From our measurements and inversions of surface wave velocities the following conclusions are derived.

(1) Applying the single-station method to long-period surface waves recorded on digital networks we can reach an accuracy level comparable to great circle velocity measurements. The spherically averaged phase velocities obtained from the two methods agree within about $0.002 \mathrm{~km} \mathrm{~s}^{-1}$. The differences are probably due to uncertainties in source duration.

(2) Even harmonics derived from the single-station method agree well with those derived from the great circle method.

(3) The odd harmonics are less constrained by the data than are the even harmonics. However, by using a filter that suppresses the poorly determined harmonics at the expense of increasing the antipodal ambiguity we find that the overall patterns of velocity distributions are essentially unchanged by the filtering.

(4) Considering the variance reductions attained in the inversions, the maximum order and degree of 6 is adequate to fit the data of this study.

(5) Velocity patterns in the resulting contour maps, especially those of Love waves, exhibit a good correlation with surface geology. The correlation is weaker for Rayleigh waves. This may be caused partly by the sensitivity of Rayleigh wave velocities measured by the single-station method to errors in assumed source depths and source mechanisms. The difference may also be real, since Rayleigh waves sample much deeper than Love waves. Numerical experiments suggest that Love waves in the period range (100-300 s) and the depth range $(<50 \mathrm{~km})$ of our study are not as sensitive to these source uncertainties.

(6) Large velocity variations exist within the oceans and continents themselves. Young oceans, including ridges, and tectonically active regions of continents are slower than spherically averaged values. Old oceans and tectonically stable regions of continents have higher velocities. Thus, a simple regionalization model which contains a single oceanic region is inappropriate even for long-period surface waves. The subduction regions along the western margins of the Pacific are characterized by high Rayleigh wave phase velocities and low Love wave phase velocities. This suggests the existence of the fast material beneath the subduction zones.

(7) Surface wave slownesses correlate positively with the heat flow map proposed by Chapman \& Pollack (1975) for degrees from 1 to 6 . The correlation peaks at $l=2$ and 5 . The correlation of surface wave data with the non-hydrostatic geoid (GEM8) is negative for $l=2$ and 3 , and positive for $l=4-6$.

\section{Acknowledgments}

The authors wish to thank Henri-Claude Nataf, Hiroo Kanamori, and Bradford Hager for suggestions. Jeffrey Given, Fumiko Tajima, and Jeanne Sauber helped us retrieve the seismograms from the GDSN day tapes at an early stage of this study. The IDA data used in this study were made available to us by courtesy of the IDA project team at the Institute of Geophysics and Planetary Physics, University of California, San Diego. This research was supported by National Aeronautics and Space Administration grant No. NSG-7610 and National Science Foundation grant No. EAR811-5236. Contribution No. 3902, Division of Geological and Planetary Sciences, California Institute of Technology. 


\section{References}

Agnew, D., Berger, J., Buland, R., Farrell, W. \& Gilbert, F., 1976. International deployment of accelerometers: a network for very long period seismology, Eos, Trans. Am. geophys, Un., 57, 180-188.

Aki, K., 1966. Generation and propagation of $G$ waves from the Nigata earthquake of June 16, 1964. Part I: a statistical analysis, Bull. Earthq. Res. Inst. Tokyo Univ., 44, 23-72.

Backus, G. E., 1964. Geographical interpretation of measurements of average phase velocities of surfacewaves over great circular and great semi-circular paths, Bull. seism. Soc. Am., 54, 571-610.

Ben-Menahem, A., 1961. Radiation of seismic surface waves from finite moving sources, Bull. seism. Soc. Am., 51, 401-435.

Ben-Menahem, A. \& Harkrider, D. G., 1964. Radiation patterns of seismic surface waves from buried dipolar point sources in a flat stratified Earth, J. geophys. Res., 69, 2605-2620.

Ben-Menahem, A., Rosenman, M. \& Harkrider, D. G., 1970. Fast evaluation of source parameters from isolated surface-wave signals. Part I - Universal tables, Bull. seism. Soc. Am., 60, 1337-1387.

Bomford, B. G., 1962. Geodesy, 2nd edn, Clarendon Press, Oxford.

Boore, D. M., 1969. Effect of higher mode contamination on measured Love wave phase velocities, $J$. geophys. Res., 74, 6612-6616.

Brune, J. N., Nafe, J. E. \& Alsop, L. E., 1961. The polar phase shift of surface waves on a sphere, Bull. seism. Soc. Am., 51, 247-257.

Brune, J. N., Nafe, J. E. \& Oliver, J. E., 1960. A simplified method for the analysis and synthesis of dispersed wave trains, J. geophys. Res., 65, 287-304.

Chapman, D. S. \& Pollack, H. N., 1975. Global heat flow: a new look, Earth planet. Sci. Lett, 28, 23-32.

Christensen, D. H., Kimball, J. K. \& Mauk, F. J., 1980. Rayleigh wave group velocity dispersion in the north and south Atlantic oceans, Bull. seism. Soc. Am., 70, 1787-1809.

Dahlen, F. A., 1975. The correction of great circular surface wave phase velocity measurements for the rotation and ellipticity of the Earth, J. geophys. Res., 80, 4895-4903.

Dahlen, F. A., 1976. Reply (to Dziewonski and Sailor), J. geophys. Res., 81, 4951-4956.

Dziewonski, A. M., 1970. On regional differences in dispersion of mantle Rayleigh waves, Geophys. J. R. astr. Soc., 22, 289-325.

Dziewonski, A. M. \& Anderson, D. L., 1981. Preliminary reference Earth model, Phys. Earth planet. Int., 25, 297-356.

Dziewonski, A. M. \& Sailor, R. V., 1976. Comments on "The correction of great circular surface wave phase velocity measurements from the rotation and ellipticity of the Earth" by F. A. Dahlen, J. geophys. Res., 81, 4947-4950.

Dziewonski, A. M. \& Steim, J. M., 1982. Dispersion and attenuation of mantle waves through waveform inversion, Geophys. J. R. astr. Soc., 70, 503-527.

Engdahl, E. R., Peterson, J. \& Orsini, N. A., 1982. Global digital networks - current status and future directions, Bull. seism. Soc. Am., 72, S242-S259.

Frez, J. \& Schwab, F., 1976. Structural dependence of the apparent initial phase of Rayleigh waves, Geophys. J. R. astr. Soc., 44, 311-331.

Furumoto, M. \& Nakanishi, I., 1983. Source times and scaling relations of large earthquakes, J. geophys. Res., 88, 2191-2198.

Herrin, E. \& Taggart, J., 1962. Regional variations in $P_{n}$ velocity and their effect on the location of epicenters, Bull. seism. Soc. Am., 52, 1037-1046.

Herrin, E. \& Taggart, J., 1968. Source bias in epicenter determinations, Bull. seism. Soc. Am., 58, 1791-1796.

James, D. E., 1971. Anomalous Love wave phase velocities, J. geophys. Res., 76, 2077-2083.

Jordan, T. H., 1981. Global tectonic regionalization for seismological data analysis, Bull. seism. Soc. Am., $71,1131-1141$.

Kanamori, H., 1970. Velocity and $Q$ of mantle waves, Phys. Earth planet. Int., 2, 259-275.

Kanamori, H. \& Given, J. W., 1981. Use of long-period surface waves for rapid determination of earthquake-source parameters, Phys. Earth planet. Int., 27, 8-31.

Kanamori, H. \& Given, J. W., 1982. Use of long-period surface waves for rapid determination of earthquake source parameters, 2. Preliminary determination of source mechanisms of large earthquakes $(M \geqslant 6.5)$ in 1980, Phys. Earth planet. Int., 30, 260-268.

Kanamori, H. \& Stewart, G. S., 1976. Mode of the strain release along the Gibbs fracture zone, Mid-Atlantic Ridge, Phys. Earth planet. Int., 11, 312-332.

Kausel, E. G., Leeds, A. R. \& Knopoff, L., 1974. Variations of Rayleigh wave phase velocities across the Pacific Ocean, Science, 186, 139-141. 
Kawakatsu, H., 1983. Can 'pure-bath' models explain free oscillation data?, Geophys. Res. Lett., 10, $186-189$.

Knopoff, L., 1972. Observation and inversion of surface-wave dispersion, Tectonophys., 13, 497-519.

Knopoff, L. \& Schwab, F. A., 1968. Apparent initial phase of a source of Rayleigh waves, J. geophys. Res., 73, 755-760.

Landisman, M., Dziewonski, A. \& Satô, Y., 1969. Recent improvements in the analysis of surface wave observations, Geophys. J. R. astr. Soc., 17, 369-403.

Leeds, A. R., Knopoff, L. \& Kausel, E. G., 1974. Variations of upper mantle structure under the Pacific Ocean, Science, 186, 141-143.

Lêvêque, J. J., 1980. Regional upper mantle $S$-velocity models from phase velocities of great-circle Rayleigh waves, Geophys. J. R. astr. Soc., 63, 23-43.

Maruyama, T., 1967. On the geodesic once round the geoellipsoid (in Japanese), Zisin, 20, 50-53.

Masters, G., Jordan, T. H., Silver, P. G. \& Gilbert, F., 1982. Aspherical earth structure from fundamental spheroidal-mode data, Nature, 298, 609-613.

Nakanishi, I., 1979. Phase velocity and $Q$ of mantle Rayleigh waves, Geophys. J. R. astr. Soc., 58, 35-59.

Nakanishi, I. \& Anderson, D. L., 1982. World-wide distribution of group velocity of mantle Rayleigh waves as determined by spherical harmonic inversion, Bull. seism. Soc. Am., 72, 1185-1194.

Nakanishi, I. \& Anderson, D. L., 1983. Measurements of mantle wave velocities and inversion for lateral heterogeneity and anisotropy. Part I: analysis of great circle phase velocities, J. geophys. Res., 88, $10267-10283$.

Nakanishi, I. \& Kanamori, H., 1982. Effects of lateral heterogeneity and source process time on the linear moment tensor inversion of long-period Rayleigh waves, Bull. seism. Soc. Am., 72, 2063-2080.

Nakanishi, I. \& Kanamori, H., 1984. Source mechanisms of twenty-six large shallow earthquakes $\left(M_{\mathrm{S}} \gtrsim 6.5\right)$ during 1980 from $P$-wave first motion and long-period Rayleigh wave data, Bull. seism. Soc. Am. in press.

Nakiboglu, S. M., 1982. Hydrostatic theory of the Earth and its mechanical implications, Phys. Earth planet. Int., 28, 302-311.

Nataf, H.-C., Nakanishi, I. \& Anderson, D. L., 1984. Anisotropy and shear-velocity heterogeneities in the uppermantle, Geophys. Res. Lett., 11, 109-112.

Okal, E. A., 1977. The effect of intrinsic oceanic upper-mantle heterogeneity on regionalization of longperiod Rayleigh-wave phase velocities, Geophys. J. R. astr. Soc., 49, 357-370.

Satô, Y., 1958. Attenuation, dispersion, and the wave guide of the G wave, Bull. seism. Soc. Am., 48, $231-251$.

Schlue, J. W., 1975. Anisotropy of the upper mantle of the Pacific Basin, PhD thesis, University of California at Los Angeles.

Silver, P. G. \& Jordan, T. H., 1981. Fundamental spheroidal mode observations of aspherical heterogeneity, Geophys. J. R. astr. Soc., 64, 605-634.

Souriau, A. \& Souriau, M., 1983. Test of tectonic models by great circle Rayleigh waves, Geophys. J. R. astr. Soc., 73, 533-551.

Stark, M. \& Forsyth, D. W., 1983. The geoid, small-scale convection, and differential travel time anomalies of shear waves in the central Indian Ocean, J. geophys. Res., 88, 2273-2288.

Thatcher, W. \& Brune, J. N., 1969. Higher mode interference and observed anomalous apparent Love wave phase velocities, J. geophys. Res., 74, 6603-6611.

Toksöz, M. N. \& Anderson, D. L., 1966. Phase velocities of long-period surface waves and structure of the upper mantle, 1. Great-circle Love and Ray leigh wave data, J. geophys. Res., 71, 1649-1658.

Wagner, C. A., Lerch, F. J., Brownd, J. E. \& Richardson, J. A., 1977. Improvement in the geopotential derived from satellite and surface data (GEM 7 and 8), J. geophys. Res., 82, 901-914.

Weidner, D. J., 1974. Rayleigh wave phase velocities in the Atlantic Ocean, Geophys. J. R. astr. Soc., 36, 105-139.

Whaler, K. A. \& Gubbins, D., 1981. Spherical harmonic analysis of the geomagnetic field: an example of a linear inverse problem, Geophys. J. R. astr. Soc., 65, 645-693.

Wielandt, E., 1980. First-order asymptotic theory of the polar phase shift of Rayleigh waves, Pure appl. Geophys., 118, 1214-1227.

Wu, F. T., 1972. Mantle Rayleigh wave dispersion and tectonic provinces, J. geophys. Res., 77, 64456453.

Yoshii, T., 1975. Regionality of group velocities of Rayleigh waves in the Pacific and thickening of the plate, Earth planet. Sci. Lett., 25, 305-312.

Zharkov, B. N. \& Lyubimov, V. M., 1970. The theory of spheroidal vibrations for a spherically asymmetric model of the Earth, Izv., Phys. Solid Earth, No. 10,613-618. 


\section{Appendix}

Figs A1-A6 show the computed group delay $d \phi_{\mathrm{s}} / d \omega$ as a function of period and azimuth for Love and Rayleigh waves generated from events 4, 21 and 26.

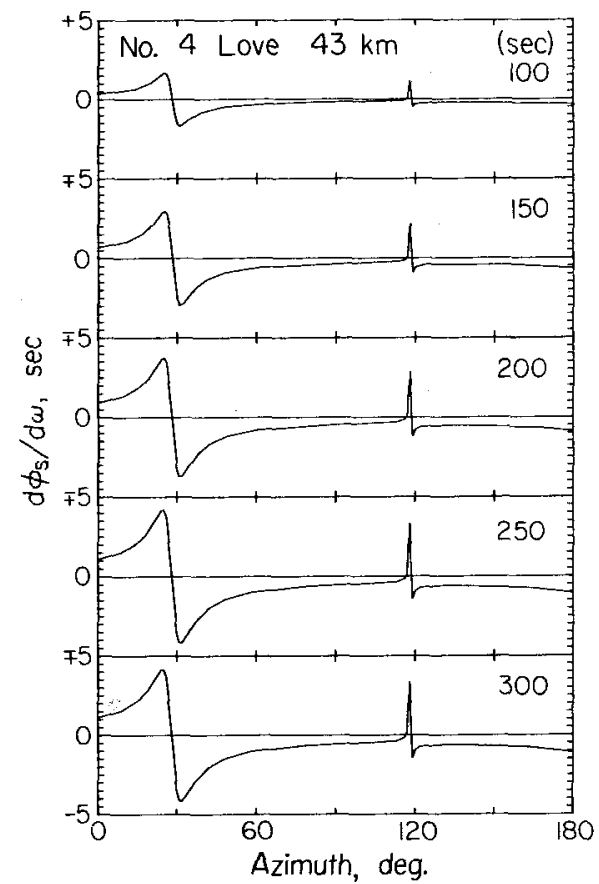

Figure A1. Love waves for event $4(d=43 \mathrm{~km})$.

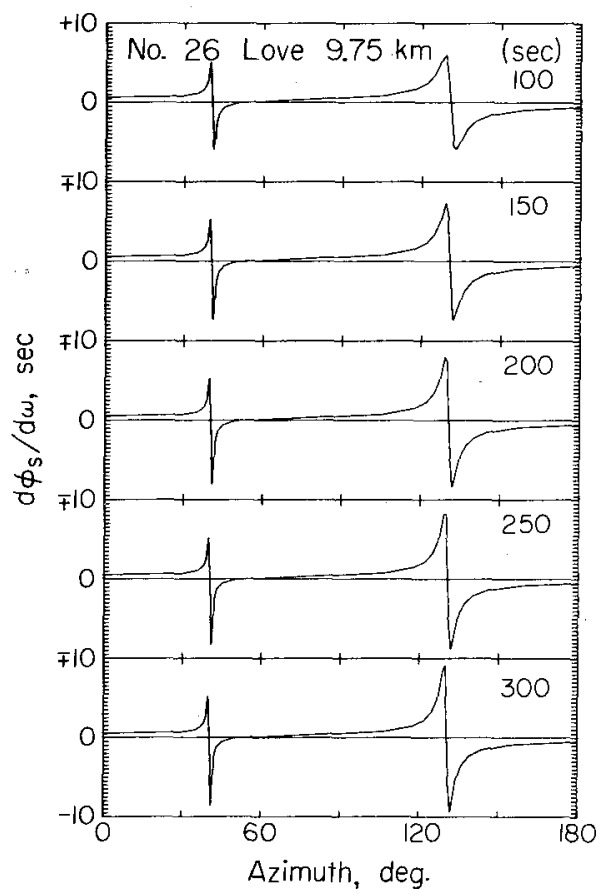

Figure A3. Love waves for event $26(d=9.75 \mathrm{~km})$.

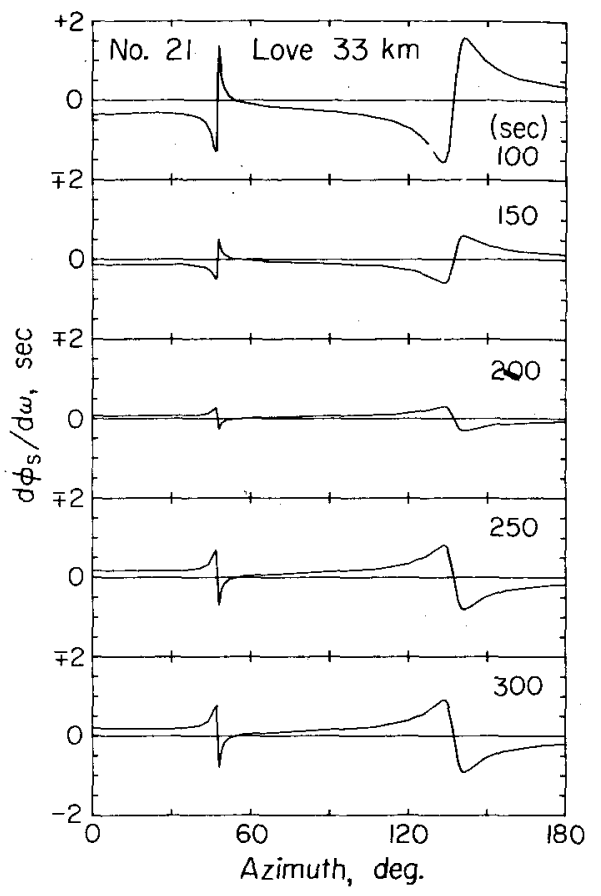

Figure A2. Love waves for event $21(d=33 \mathrm{~km})$.

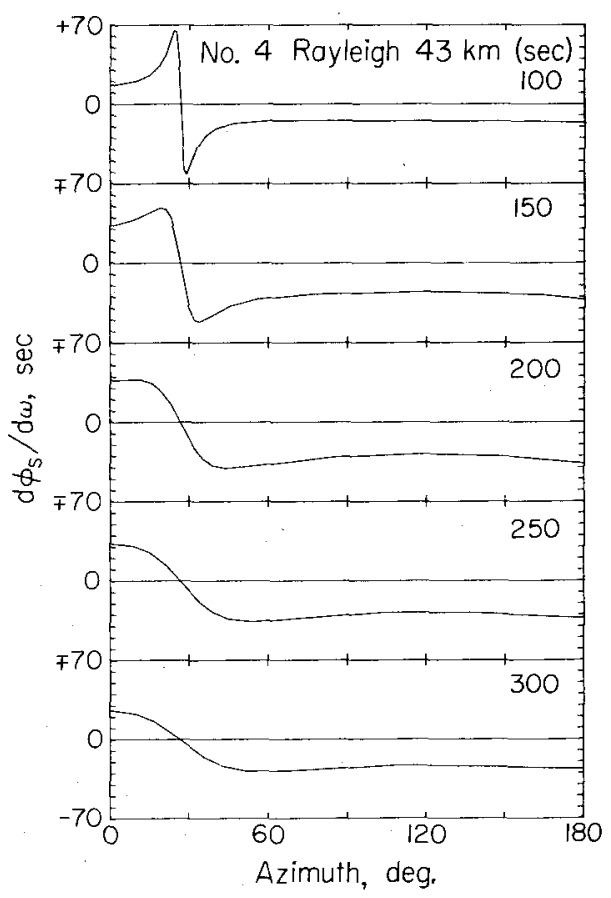

Figure A4. Rayleigh waves for event 4. 


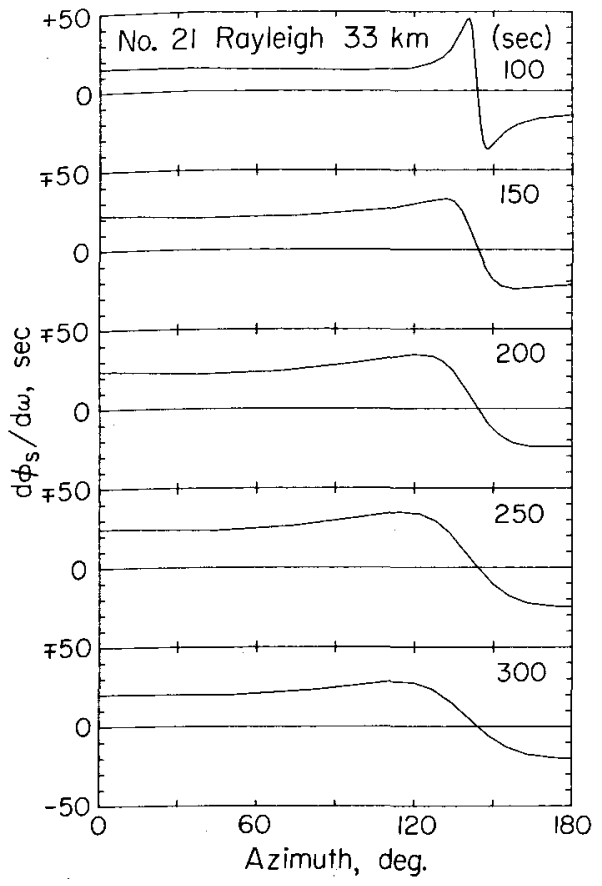

Figure A5. Rayleigh waves for event 21.

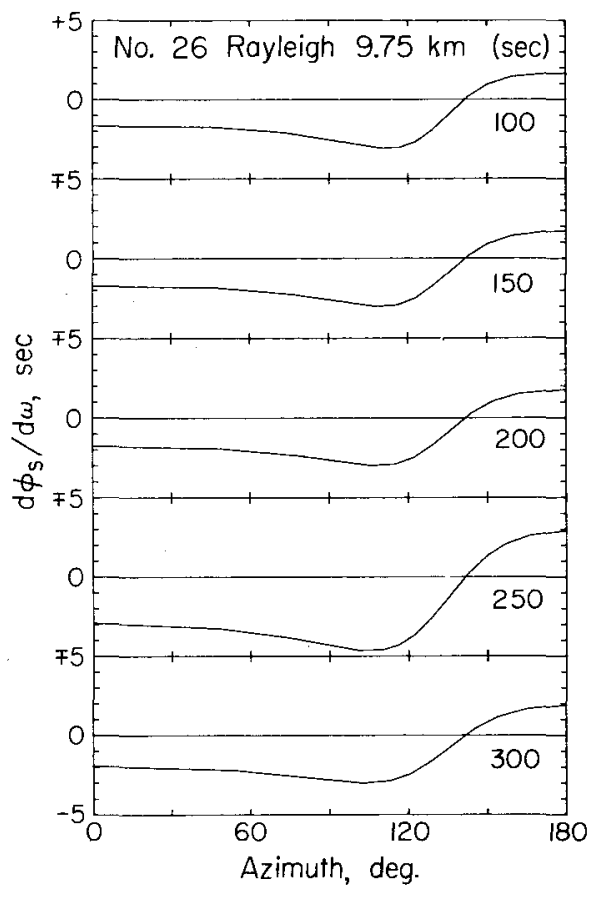

Figure A6. Rayleigh waves for event 26. 